\title{
Hybrid Lead-Acid/Lithium-Ion Energy Storage System with Power-Mix Control for Light Electric Vehicles
}

\author{
by
}

Steven Chung

A thesis submitted in conformity with the requirements for the degree of Master of Applied Science Graduate Department of Electrical and Computer Engineering University of Toronto

(C) Copyright 2016 by Steven Chung 


\begin{abstract}
Hybrid Lead-Acid/Lithium-Ion Energy Storage System with Power-Mix Control for Light Electric Vehicles

Steven Chung

Master of Applied Science

Graduate Department of Electrical and Computer Engineering

University of Toronto

2016
\end{abstract}

The performance versus cost tradeoffs of a fully electric, hybrid energy storage system (HESS), using lithium-ion (LI) and lead-acid (PbA) batteries, are explored in this work for a light electric vehicle (LEV). While LI batteries typically have higher energy density, lower internal resistance and longer lifetime than PbA batteries, the module cost of LI batteries are typically three to five times the cost of $\mathrm{PbA}$ batteries. The objective is to design a HESS configuration that 1) is cost-competitive with a $\mathrm{PbA}$ single energy storage system (SESS) and 2) maintains most of the performance benefits of a lithium SESS by minimizing the Peukert effect and increasing the usable energy of the lead-acid battery. A modular HESS architecture with a bi-directional dc-dc converter and controller is proposed, and a power-mix algorithm with active inter-chemistry battery state-of-charge (SOC) balancing is presented, simulated, and verified experimentally. A novel DLL and PLL based off-time control scheme is also demonstrated for quasi-fixed frequency (QFF) operation and inductor ripple current interleaving. The cost and performance of the HESS are assessed side-by-side with PbA and LI single energy storage system (SESS) configurations of comparable total energy, using expected vehicle range as the performance metric. The experimental HESS has a total projected cost midway between the SESS PbA cost and the SESS Li cost, while providing $17 \%$ range and $23 \%$ efficiency increase over the SESS PbA vehicle. 


\section{Acknowledgements}

I want to express my gratitude to Professor Olivier Trescases for his mentorship, support and guidance. His intellect, attention to detail, and commitment to excellence has been an inspiration over the past two years, and will continue to guide me in future endeavors in my career and life.

My work would not have been possible without the efforts of Roger Gerson, Larry Hilligoss, Jennifer Rafiner-Jarboe and everyone else at Brammo, Inc. as well as John Adams of Polaris Industries. Thank you all for your contributions, big or small, to the project.

To my colleagues and friends, Shahab Poshtkouhi, Shuze Zhao, Victor (Yue) Wen, Ryan Fernandes, David Li, Ahmed Diab-Marzouk, Miad Fard, Miad Nasr, and Zhe Gong: thank you for the motivation and spirited discussions, and most of all, thank you for the camaraderie in this short time. It has been a privilege to work and learn besides you all.

I also want to thank Nikita Gusev, Yueqi Chen, Zheyu Wu, Armina Khakpour, and Carl Lamoureux for your contributions to my projects. I hope you have learned as much from me as I have from you.

I want to thank Professor Josh Taylor and Bharath Vellaboyana for their time and willingness to discuss Dynamic Programming and its potential application to this work.

A sincere thanks to my good friend, Mauricio Carrasco, and my family and friends here in Canada and abroad for their unabated support in these challenging years as a masters student. Finally, I want to thank my best friend, Beverly Tu, for her continued understanding and patience over the years. You all have made me better, and for that, I am grateful. 


\section{Contents}

1 Introduction $\quad 1$

1.1 Energy Storage in Electric Vehicles . . . . . . . . . . . . . . . 3

1.1.1 Battery Terminology . . . . . . . . . . . . . . 3

1.1.2 Battery Chemistry Comparison . . . . . . . . . . . 4

1.1.3 Cost Comparisons . . . . . . . . . . . . . . . . 6

1.2 Single Energy Storage System Vehicle Comparison . . . . . . . . . . . . . 9

1.2.1 SESS Performance . . . . . . . . . . . . . . 9

1.2 .2 SESS Cost . . . . . . . . . . . . . . . 10

1.3 Thesis Objectives and Organization . . . . . . . . . . . . . 10

2 Hybrid Energy Storage Architectures for EVs 18

2.1 Hybrid Battery Topologies . . . . . . . . . . . . . . . . . . 19

2.1.1 Battery Selection ................. 21

2.2 Configuration Comparisons . . . . . . . . . . . . . . . . . . . . 22

2.3 Intelligent Hybrid Battery Manager . . . . . . . . . . . . . . . . . 24

2.4 Chapter Summary and Conclusions . . . . . . . . . . . . . 25

3 Drive-cycle Testing and Battery Modeling 28

3.1 Drive-cycle Testing . . . . . . . . . . . . . . . . . . 28

3.1 .1 Test Vehicle and Methodology . . . . . . . . . . . . . . 29

3.1 .2 Payload Variation . . . . . . . . . . . . . . . . . . 30

3.1 .3 Speed Variation . . . . . . . . . . . . . . . . . . . 31

3.2 Battery Testing and Modeling . . . . . . . . . . . . . . . 32

3.2.1 Lithium-Ion Battery Model . . . . . . . . . . . . . . 32

3.2 .2 Lead-Acid Model . . . . . . . . . . . . . . . . 37

3.3 Chapter Summary and Conclusions . . . . . . . . . . . . . . . 41 
4 Converter Design $\quad 44$

4.1 Converter Sizing . . . . . . . . . . . . . . . . . . 44

4.2 Peak Current-mode Control . . . . . . . . . . . . . . . . . 45

4.2.1 Digital Off-time Control . . . . . . . . . . . . . . . 46

4.2.2 Component Selection and Loss Analysis . . . . . . . . . . . . . . 48

4.3 Switching Frequency Control using DLL and PLL . . . . . . . . . . . . . 49

4.3.1 Quasi-Fixed Frequency Operation with a DLL . . . . . . . . . 51

4.3.2 Multi-phase Synchronization using PLLs . . . . . . . . . . . . . . 51

4.4 Delta Converter Topology . . . . . . . . . . . . . . . . . . 52

4.5 Chapter Summary and Conclusions . . . . . . . . . . . . . . . . 54

5 Power-Mix Algorithm and Simulation Results $\quad 57$

5.1 Power and Energy Mix . . . . . . . . . . . . . . . . 58

5.1 .1 The SOC Path . . . . . . . . . . . . . . . . . 59

5.1.2 The Perturb and Observe Method . . . . . . . . . . . . 60

5.2 Controller Tuning . . . . . . . . . . . . . . . . . . . . . . . 61

5.2.1 Continuous Drive-Cycle . . . . . . . . . . . . . . 62

5.2.2 Start-stop Drive-Cycle . . . . . . . . . . . . . 63

5.3 Simulated ESS Comparisons . . . . . . . . . . . . . . . 66

5.3.1 Effect of Payload . . . . . . . . . . . . . . . 67

5.3.2 Effect of Depth-of-Discharge . . . . . . . . . . . . . . 67

5.3.3 Effect of Speed . . . . . . . . . . . . . . . . . 69

5.4 Chapter Summary and Conclusions . . . . . . . . . . . . . . . . 69

6 Experimental Results $\quad 73$

6.1 DC-DC Converter Experimental Results . . . . . . . . . . . . . 73

6.1.1 Measured Efficiency . . . . . . . . . . . . . . 73

6.1.2 Off-time and Frequency Control . . . . . . . . . . . . . 76

6.2 Experimental Drive-cycles . . . . . . . . . . . . . . . . 78

6.2.1 Measured ESS Comparisons . . . . . . . . . . . . . . . . . 79

6.2.2 Start-stop Drive-cycle Measurements . . . . . . . . . . . . . . . . 80

6.3 Chapter Summary and Conclusions . . . . . . . . . . . . . . 82

7 Conclusions $\quad 84$

7.1 Thesis Summary and Contributions . . . . . . . . . . . . . . 84

7.2 Future Work . . . . . . . . . . . . . . . . . . 85 


\section{List of Tables}

1.1 Comparison of Battery Chemistries $[21] \ldots \ldots \ldots \ldots \ldots$

1.2 Polaris Ranger EV specifications. . . . . . . . . . . . . . . 9

1.3 SESS PbA, SESS LI Parameters and Normalized Range Measurements . 10

2.1 LI and $\mathrm{PbA}$ Module Specifications . . . . . . . . . . . . . . . . 21

2.2 Possible HESS Configurations . . . . . . . . . . . . . . . . . . . . . 23

2.3 ESS Parameters and Normalized Range Measurements . . . . . . . . . 23

3.1 LI Circuit Model Parameters . . . . . . . . . . . . . . . . . . . . . . 34

$3.2 \mathrm{PbA}$ Circuit Model Parameters . . . . . . . . . . . . . . 38

4.1 dc-dc Converter Specifications. . . . . . . . . . . . . . . . . . . 45

4.2 Dc-dc converter components $[8,9] \ldots \ldots \ldots \ldots$

4.3 Converter Losses . . . . . . . . . . . . . . . . . . . . . . . . . . 49

$5.1 I_{a d j}$ Coefficients of the Perturb and Observe Algorithm . . . . . . . 64

5.2 Comparison of Simulated ESS Configuration . . . . . . . . . . 67 


\section{List of Figures}

1.1 The growth of BEV and HEV sales from 2011 to 2015, in thousands [1]. . 2

1.2 Daily trips among commuters in Canada. [6] . . . . . . . . . . . . . 2

1.3 Specific energy versus energy density of various battery chemistries [21]. . 5

1.4 Tradeoffs between various lithium-based battery technologies [22]. . . . . 5

1.5 Projected EV battery cost $[4] \ldots \ldots$. . . . . . . . . . . . . 7

1.6 A cost breakdown of the EV lithium battery pack [23]. . . . . . . . . . 8

1.7 The Polaris Ranger EV. . . . . . . . . . . . . . . . . . . . 8

1.8 Projected HESS (a) range versus cost, (b) ESS efficiency versus cost, and (c) mass versus volume, compared to SESS vehicles. . . . . . . . . . . . . 11

1.9 Proposed HESS vehicle architecture with four modular IHBMs. . . . . . 12

2.1 A (a) power-split hybrid architecture [3] and (b) parallel fuel cell and battery hybrid vehicle architecture [4]. . . . . . . . . . . . 18

2.2 Seven possible configurations for a HESS containing two energy storage elements. Each configuration offers different trade-off of cost, dc-dc converter ratings and system performance. . . . . . . . . . . . 20

2.3 Two variants of the architecture in Fig. 2.2(c), with PbA modules and a dc-dc converter in parallel to (a) the inverter bus, variant-1, and (b) to each LI module, variant-2 . . . . . . . . . . . . . . . . . . . . . 22

2.4 Proposed modular IHBM with dc-dc converter and controller. . . . . . . 24

3.1 The bed of the Ranger EV test vehicle with $226 \mathrm{~kg}$ of bricks. . . . . . . . 29

3.2 The measured drive-cycle data of the modified Polaris Ranger EV . . . . . 30

3.3 A simplified block diagram of the Ranger EV electrical system and data collection buses. . . . . . . . . . . . . . . . . . . 31

3.4 Measured vehicle bus power during an acceleration event on flat, straight pavement with (a) varying vehicle payloads and (b) varying maximum speeds. . . . . . . . . . . . . . . . . . . 
3.5 The distribution of power demand of the various drive conditions over 5 minute durations. . . . . . . . . . . . . . . . . . 33

3.6 Lithium battery module circuit model. . . . . . . . . . . . . . . . . 34

3.7 Measured and simulated lithium battery (a) voltage and (b) SOC during a pulsed load current of 65 A. . . . . . . . . . . . . . . . .

3.8 Measured and simulated lithium battery (a) current, (b) voltage and (c) SOC during varying current pulses. . . . . . . . . . . . . . 36

3.9 Measured and simulated lithium battery (a) voltage and (b) estimated SOC for the equivalent current of a $15 \mathrm{MPH}$ drive-cycle on flat asphalt. . 37

3.10 Lead-acid battery module (a) equivalent circuit model and (b) SOC-OCV linear relationship. . . . . . . . . . . . . . . . . . 38

3.11 Lead-acid battery capacity versus discharge current due to the Peukert

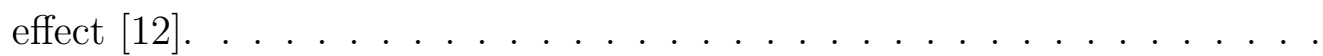

3.12 Measured and simulated lead-acid battery (a) voltage, (b) capacity, and (c) estimated SOC for the equivalent current of a $15 \mathrm{MPH}$ drive-cycle on flat asphalt. . . . . . . . . . . . . . . . . . . . 40

4.1 A non-inverting buck-boost converter. . . . . . . . . . . . . . . . . . 44

4.2 The circuit diagram of (a) traditional PCMC, (b) PCMC with slope compensation, and (b) PCMC with off-time control. . . . . . . . . . . 46

4.3 Steady-state operation of (a) traditional PCMC with $D>0.5$, (b) the SC method, and (c) the OTG method, and a transient reference current step using (d) traditional PCMC, (e) the SC method, and (f) the OTG. . . . 47

4.4 A breakdown of losses of a single sub-converter at $90 \mathrm{~W} \ldots \ldots . . . .49$

4.5 Ideal interleaving between three sub-converters. . . . . . . . . . . 50

4.6 A closed-loop block diagram of (a) a phase-locked loop (PLL), and (b) a delay-locked loop (DLL) . . . . . . . . . . . . . . . . . 51

4.7 An IHBM dc-dc with a peak current mode control loop and DLL/PLL-fed

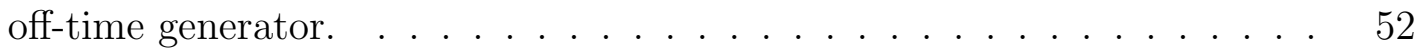

4.8 An (a) NIBB with added delta-converter connection, and (b) four series batteries with the balancing cells. . . . . . . . . . . . . . 53

4.9 Simulations of the balancing cells on four unbalanced capacitors. . . . . . 54

5.1 From left to right, the ideal path, the over-utilization path, and the underutilization path. . . . . . . . . . . . . . . . 58

5.2 Simulated HESS range versus constant current for near constant $15 \mathrm{MPH}$ drive-cycles and varying vehicle payloads. . . . . . . . . . . 
5.3 Block diagram of err $_{S O C}$ computation and perturb-and-observe algorithm. 60

5.4 A simplified block diagram of the MATLAB/Simulink simulation. . . . . 62

5.5 $I_{P b A}$ over a simulated drive-cycle as the battery SOCs follow their target trajectories. . . . . . . . . . . . . . . 63

5.6 A (a) start-stop emulated drive-cycle and (b) power demand. . . . . . . . 64

5.7 Simulated start-stop drive-cycle with varying $a_{2}$ and $T_{k} \ldots \ldots$. . . . . 65

5.8 Estimated range versus $I_{P b A, a v g}$ with varying $a_{2}$ and $T_{k}$ for the start-stop drive-cycle. . . . . . . . . . . . . . . . 65

5.9 The relative SOC path of the batteries for (a) a continuous drive-cycle, and (b) start-stop drive-cycle. . . . . . . . . . . . . . . . . 66

5.10 Simulated vehicle (a) range and (b) efficiency versus cost of measured SESS and simulated ESS vehicles, normalized to the no-load SESS PbA. 68

5.11 Lead-acid battery expected life cycles versus DOD [16] . . . . . . . . . . 68

5.12 The effect of HESS DOD on simulated range and cost. . . . . . . . . . 69

5.13 The effect of slower speed and total pack energy on simulated range and cost. . . . . . . . . . . . . . . . . . . . .

6.1 A (a) NIBB power stage PCB, (b) three sub-converters plugged into a common controller board, and (c) the lithium and lead-acid batteries used for experimental verification. . . . . . . . . . . . . . .

6.2 Measured (a) converter efficiency for a single and multi-phase dc-dc operation, and (b) phase shedding of the digital current reference commands.

6.3 A thermal image of the dc-dc converter shows that the inductor windings are the highest source of loss. . . . . . . . . . . . . . . . 76

6.4 A (a) single sub-converter operating with PCMC off-time control, and (b) the staggered start-up process of the three sub-converters. . . . . . . . . 77

6.5 Measured DLL and PLL frequency loop performance showing (a) switching period locking, and (b) interleaved phase locking. . . . . . . . . . . . . 77

6.6 Measured steady state inductor current interleaving with (a) two active sub-converters and (b) three active sub-converters, and measured transient (c) 7 to $20 \mathrm{~A}$ step-up response and (d) 20 to $7 \mathrm{~A}$ step-down response for three active sub-converters. . . . . . . . . . . . . . . . 78

6.7 Experimental bench setup. . . . . . . . . . . . . . . . 79

6.8 The measured normalized (a) range, and (b) efficiency of a near constant $15 \mathrm{MPH}$ drive-cycle. . . . . . . . . . . . . . . . . . 80 
6.9 The measured relative SOC path of the batteries for (a) a continuous drive-cycle, and (b) start-stop drive-cycle. . . . . . . . . . . 80

6.10 The measured start-stop drive-cycle (a) $I_{P b A}$, and (b) $S O C_{L I}$ and $S O C_{P b A}$, with uneven initial SOCs. . . . . . . . . . . . . . . 81

6.11 The measured $V_{L I}$ for a start-stop drive-cycle. . . . . . . . . . . . 82 


\section{Chapter 1}

\section{Introduction}

An increasing recognition of climate change science, the growing uncertainty about the stability of global oil supplies, shifts in public perception towards sustainable transportation, and stricter government regulations towards higher fuel efficiency standards have all fueled the growth and development of the EV market for the past two decades. Cost and range anxiety remain the two primary challenges for the mass adoption of electrified transportation.

The global sales of battery powered electric vehicles, (BEVs), hybrid electric vehicles, (HEVs), and plug-in hybrid electric vehicles, (PHEVs), have increased dramatically since 2011, as shown in Fig. 1.1 [1]. Even with this annual growth, EVs remain a niche market for the upper-middle class, environmentally-minded consumer, as EV sales are dwarfed by sales of the dominant internal combustion engine (ICE) automobile. A state of the art lithium-ion (LI) battery pack has a specific energy of $0.27 \mathrm{kWh} / \mathrm{kg}$ and sells for $\$ 400 / \mathrm{kWh}[2]$. Gasoline has a specific energy of $12.20 \mathrm{kWh} / \mathrm{kg}$ and sells for less than a dollar per kWh [3]. It is commonly understood that the battery powered EV (BEV) will not be truly cost-competitive with ICEs until its battery costs falls below $\$ 150 / \mathrm{kWh}[2,4]$.

Range anxiety can be attributed to three primary factors, 1) low range of existing EVs compared to ICE automobiles, 2) a lack of EV charging infrastructure to mirror the ubiquitous gas stations, and 3) the slow, hours long charging time, compared to a three minute top-up of gasoline. According to statistics from the 2009 National Household Travel Survey and a Canadian Plug-in Electric Vehicle study, the average daily commute in the United States and Canada is less than 40 miles, and that more than $80 \%$ of the driving population drives less than 70 miles daily, as shown in Fig. $1.2[5,6]$. The market leading Nissan Leaf, a low cost BEV, uses a $24 \mathrm{kWh}$ battery pack that provides a range of 80 miles, which is sufficient range for more than $80 \%$ of the driving population in the United States and Canada. Still, the low market penetration of the Nissan Leaf and its 
competitors suggests that most consumers, when given a choice, ultimately decides on the proven ICE automobile.

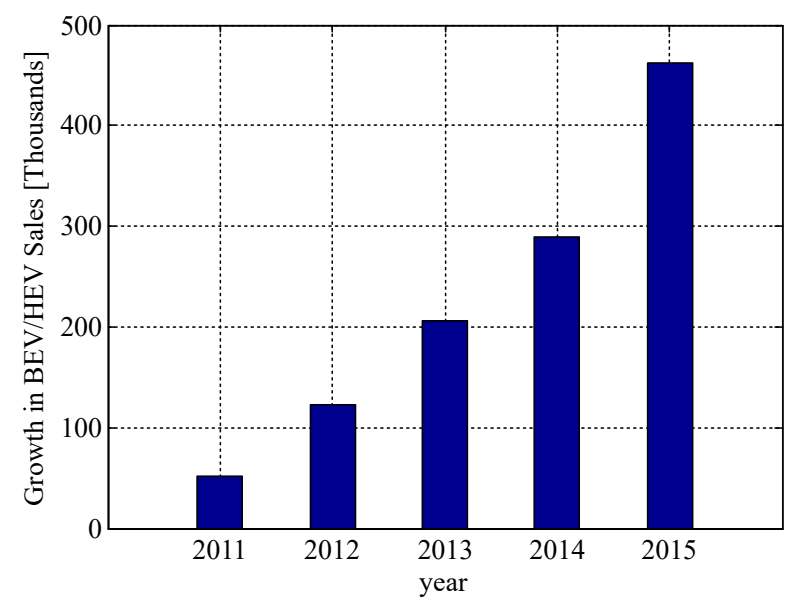

Figure 1.1: The growth of BEV and HEV sales from 2011 to 2015, in thousands [1].

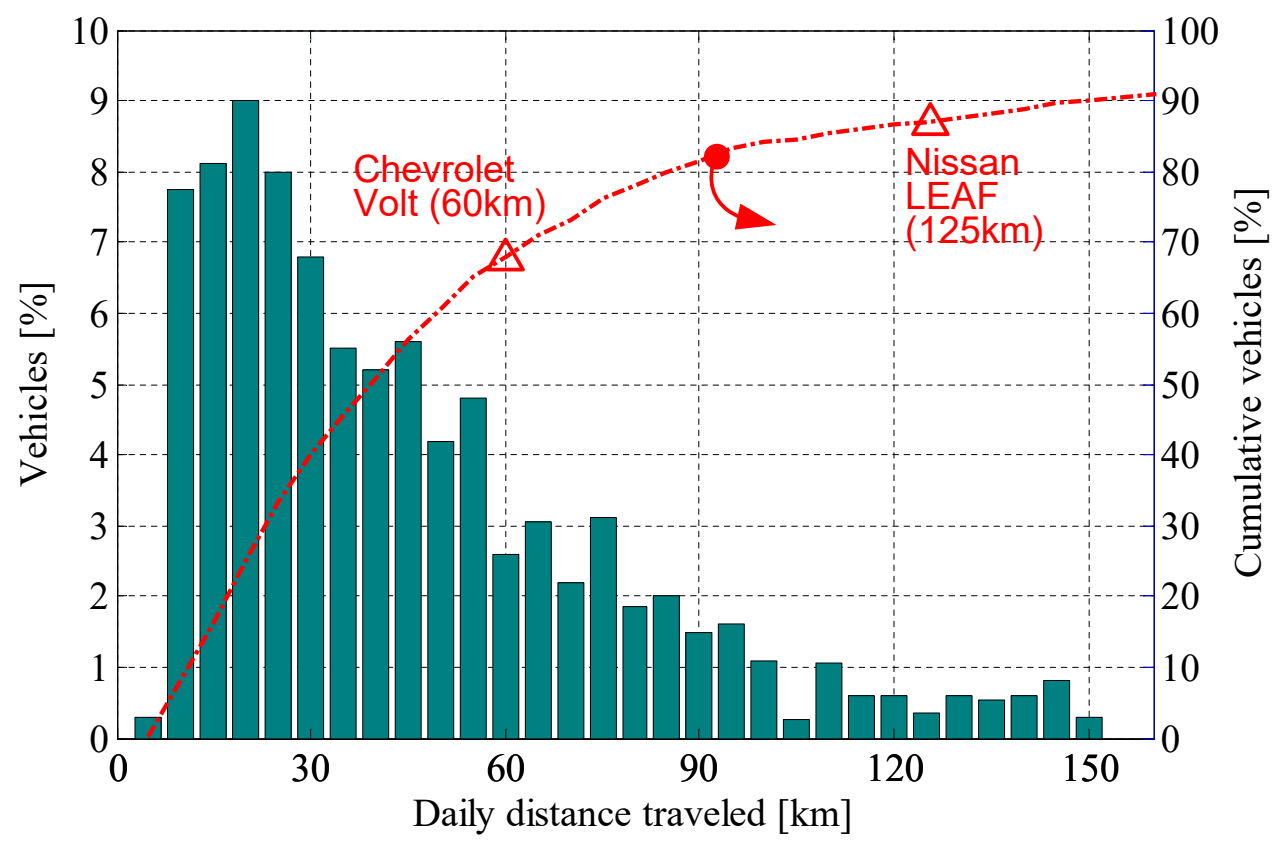

Figure 1.2: Daily trips among commuters in Canada. [6]

As a compromise between cost, range anxiety, and fuel efficiency, many automotive manufacturers have embraced alternative energy storage systems such as HEVs, fuel cell electric vehicles, (FCEV), and hydrogen power vehicles. Combining different forms of energy storage provides unique tradeoffs of cost, performance, mass, volume and fuel efficiency that can strike a competitive balance for certain applications. The aim of this work is to use a combination of lithium-ion (LI) batteries and lead-acid ( $\mathrm{PbA}$ ) batteries 
in a hybrid energy storage system, (HESS), to power a low-cost, high-performance light electric vehicle (LEV).

\subsection{Energy Storage in Electric Vehicles}

The available EV battery chemistries are explored and compared, and the cost versus performance tradeoffs are analyzed for the hybrid $\mathrm{PbA}$ and LI battery combination.

\subsubsection{Battery Terminology}

Before weighing the trade-offs of the various chemistries, discussing battery optimization, and investigating battery modeling, it is important to define battery-specific terminology as they are used in this document.

- Capacity - Defined in units of Ampere-hours (Ah), battery capacity refers to the amount of charge that can be drawn from a fully charged battery. A battery's usable capacity is highly dependent upon discharge current, effects of aging and life-cycles, and temperature [7-11]. Because of such environmental and usage effects, battery manufacturers typically list a battery's nominal rated capacity as a function of discharge rate and temperature.

- State-of-Charge (SOC) - Defined in terms of a percentage, a battery's SOC represents the remaining battery charge with respect to its nominal capacity. A fully charged battery has 100\% SOC, while a fully depleted battery has 0\% SOC. Although no method exists to directly measure a battery's SOC, many SOC estimation techniques exist that rely on accurate battery voltage and current measurement $[8,10,12-14]$.

- Depth-of-Discharge (DOD) - The complement of SOC, the DOD represents the amount of charge discharged from the battery with respect to the nominal capacity. DOD is also defined in terms of percentage.

- Life-cycles and Aging - A battery's lifetime is described in both absolute age, in years, and usage, in life-cycles. Over time and over repeated discharge cycles, a battery's capacity drops from its nominal value due to depletion of active chemicals, degradation of anode and cathode materials, adverse long term temperature effects, usage, average DOD, and idleness $[15,16]$. This phenomenon is often referred to as capacity fade. A battery reaches end-of-life (EOL) when its usable capacity reaches $80 \%$ of the manufacturer's nominal rated capacity. 
- Internal resistance - The battery's internal resistance represents the Thevenin equivalent resistance of the battery as a power source. The internal resistance varies with SOC, age, temperature, and other disturbances, and acts to restrict the battery terminal voltage [7].

- Open circuit voltage (OCV) - The OCV represents the voltage of the battery in an unloaded condition. In many battery chemistries, the OCV is a reliable and accurate measure of battery SOC, though the OCV can only be measured on the battery terminals when the battery has been at rest for an extended period of time due to the voltage hysteresis effect $[7,8,14,17]$.

- C-rate - This term describes charge and discharge currents of a battery relative to its maximum capacity. A battery, discharged at a $1 \mathrm{C}$ rate, would discharge from $100 \%$ SOC to $0 \% \mathrm{SOC}$ in one hour. A $2 \mathrm{C}$ rate represents double the $1 \mathrm{C}$ current, and a $0.5 \mathrm{C}$ rate represents half the $1 \mathrm{C}$ current.

- Specific energy - A measurement of energy over mass, Wh/kg. EVs using batteries that have higher specific energy are lighter, and tend to be able to provide more range.

- Energy density - A measurement of energy over volume, Wh/L. High energy density of $\mathrm{EV}$ batteries is desirable due to limited volume in a vehicle.

- Series Battery Balancing - Due to tolerances and environmental differences, series battery voltages tend to drift over time. As a result, the total battery pack can provide as much capacity as its weakest battery in the series string. Battery balancing is a technique to mitigate these effects by 1) passively discharging the strongest cells to equalize the charge, or 2) actively by redistributing charge from the strongest cells/modules to the weakest cells/modules [18-20]. Passive balancing is typically used in commercial battery packs due to the high cost of active balancing techniques.

\subsubsection{Battery Chemistry Comparison}

Each battery chemistry has different voltage, capacity, specific energy, energy density, lifetime, and cost. The energy density and specific energy of popular chemistries are shown in Fig. 1.3, and comparisons between the different chemistries are detailed in Table $1.1[21]$. A battery's specific energy and energy density are of particular importance to 


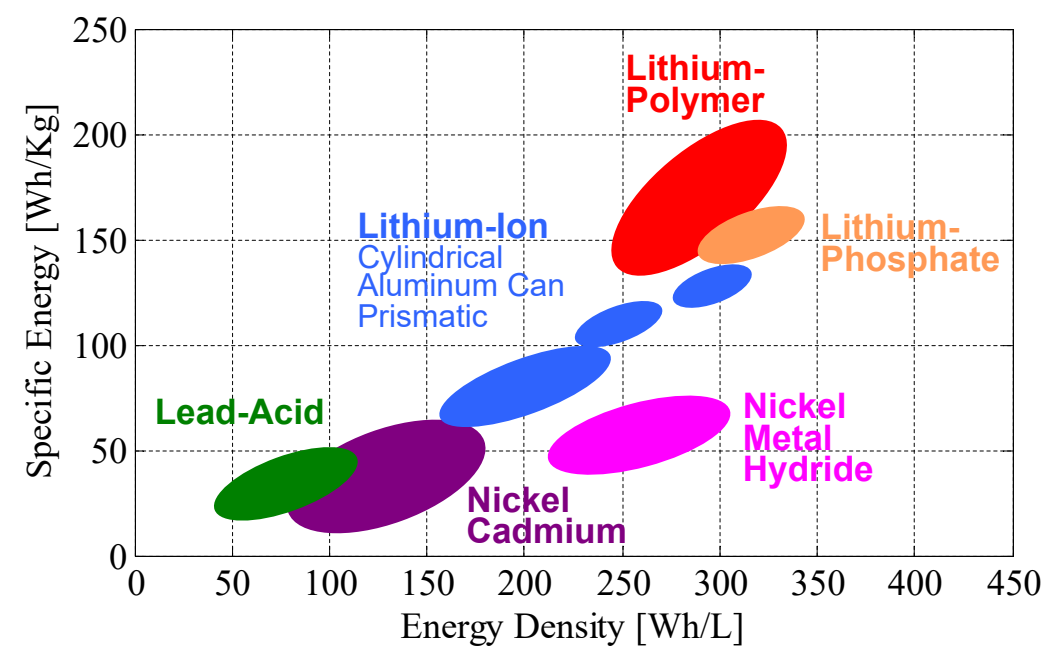

Figure 1.3: Specific energy versus energy density of various battery chemistries [21].

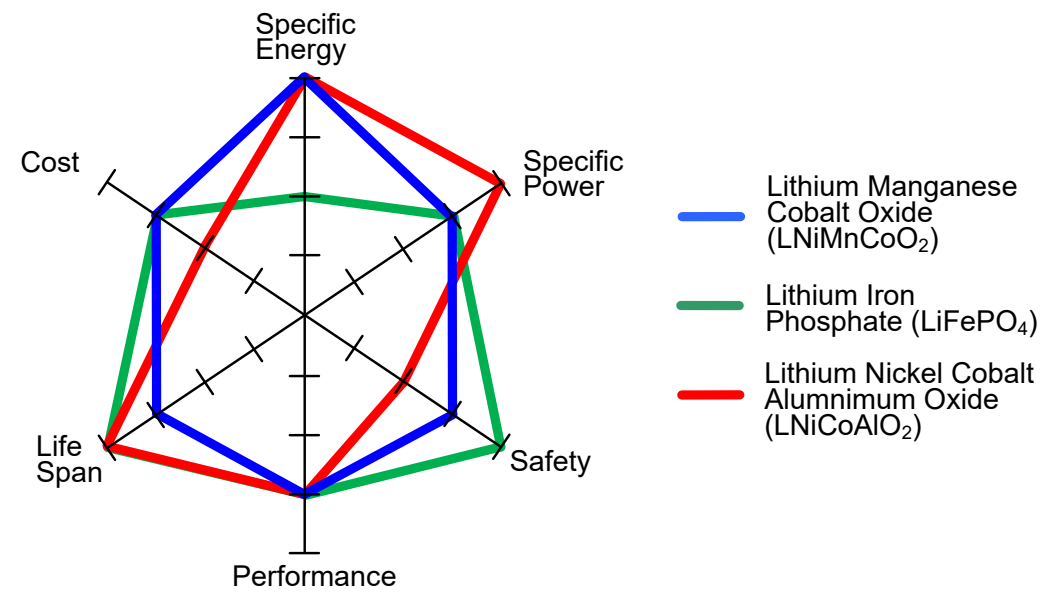

Figure 1.4: Tradeoffs between various lithium-based battery technologies [22].

BEVs. Minimizing the mass and the volume of the battery improves many other aspects of the vehicle, such as range, mechanical chassis constraints, and overall system costs.

\subsubsection{Lithium Batteries}

Lithium based technologies are among the highest in specific energy and cycle life, and are used extensively in high performance EV applications because of their lower mass. Differences in electrolyte material and cell construction can be made to improve mass and volume of cells, but such improvements are often accompanied by lower cycle life count, increased thermal instability, and increased cost, as shown in Fig. 1.4 [22]. LI batteries have low tolerance for over-voltage conditions and temperature effects, and often require a battery management system (BMS) for safe and reliable operation [22-24]. Prominent 
commercial BEVs such as the Nissan Leaf, Tesla Model S, and Chevrolet Volt use lithiumion batteries.

\subsubsection{Nickel Based Batteries}

Nickel Cadmium (NiCd) and nickel metal hydride (NiMH) batteries suffer from a memory effect that leads to capacity fade if not charged and discharged within manufacturer's specifications [21, 24]. NiMH batteries were used in many earlier Toyota Prius HEV models, and has favorable specific energy and energy density compared to the $\mathrm{PbA}$ and $\mathrm{NiCd}$ batteries. NiMH batteries have high power densities compared to $\mathrm{PbA}, \mathrm{NiCd}$ and even LI batteries, but suffer from relatively low cycle life and exhibit higher self-discharge than the alternatives.

\subsubsection{Lead-Acid Batteries}

The lead-acid battery has the lowest specific energy and energy density of the battery chemistries. Additionally, higher discharge currents diminish the usable capacity of a PbA battery, a phenomenon known as the Peukert effect $[8,9,13]$. The oldest rechargeable battery chemistry, the $\mathrm{PbA}$ is still used extensively as starter batteries in ICEs, and maintains prominence in light electric vehicle (LEV), marine and stationary storage applications. The longevity of the lead-acid battery means it is a developed technology with global suppliers and supply chains [11, 21, 24]. Because the overhead of additional protection and monitoring electronics is often unnecessary, the PbA battery is inexpensive, and easy to design into larger systems. This availability, ruggedness, and simplicity make the PbA an attractive energy source for low cost, electrified transportation.

\subsubsection{Cost Comparisons}

The cost per kWh of both NiMH and LI cells have fallen over the years due to technological improvements, advancements in manufacturing processes, and economies-ofscale $[4,21,25]$. In 2013 , the average $\mathrm{NiMH}$ cell cost roughly $\$ 700 / \mathrm{kWh}$, while a LI cell cost roughly $\$ 1000 / \mathrm{kWh}$. The price of the LI cell is projected to fall below the cost of NiMH batteries by 2016 , and continue falling further to between $\$ 300 / \mathrm{kWh}$ to $\$ 500 / \mathrm{kWh}$ by 2020, as shown in Fig. 1.1.3 [2, 4]. Cost per kWh figures vary widely between battery manufacturers because the OEM battery module cost is subjective to market forces, learning rates, and economies-of-scale.

With the aforementioned cost improvements in LI and NiMH chemistry technology, the lead-acid battery, up front, remains the most cost competitive of the various battery 
Table 1.1: Comparison of Battery Chemistries [21]

\begin{tabular}{lcccccc}
\hline Parameter & PbA & NiCd & NiMH & LI & LI-Po & Unit \\
\hline \hline Specific Energy & $30-50$ & $45-80$ & $60-120$ & $110-160$ & $100-130$ & Wh $/ \mathrm{kg}$ \\
Power Density & 180 & 150 & $250-1000$ & $110-160$ & 1800 & $\mathrm{~W} / \mathrm{kg}$ \\
Cycle Life & $300-1000$ & 1500 & $300-500$ & $500-2000$ & $300-500$ & Cycles \\
Charge Time & $8-16$ & 1 & $2-4$ & $2-4$ & $2-4$ & hours \\
Overcharge Tolerance & high & moderate & low & very low & low & \\
Self-discharge/month & $5 \%$ & $20 \%$ & $30 \%$ & $10 \%$ & $10 \%$ & SOC \\
Cell Voltage & 2 & 1.25 & 1.25 & 3.7 & 3.7 & $\mathrm{~V}$ \\
Peak discharge rate & $5 \mathrm{C}$ & $20 \mathrm{C}$ & $5 \mathrm{C}$ & $3 \mathrm{C}$ & $3 \mathrm{C}$ & $\mathrm{C}-$ rate \\
Ideal discharge rate & $<0.2 \mathrm{C}$ & $1 \mathrm{C}$ & $<0.5 \mathrm{C}$ & $<1 \mathrm{C}$ & $<1 \mathrm{C}$ & $\mathrm{C}-\mathrm{rate}$ \\
Operating Temp. & $-20-60$ & $-40-60$ & $-20-60$ & $-20-60$ & $0-60$ & ' C \\
Cost per kWh & 160 & 280 & $500-600$ & $400-1000$ & $400-1000$ & $\$ / \mathrm{kWh}$ \\
\hline
\end{tabular}

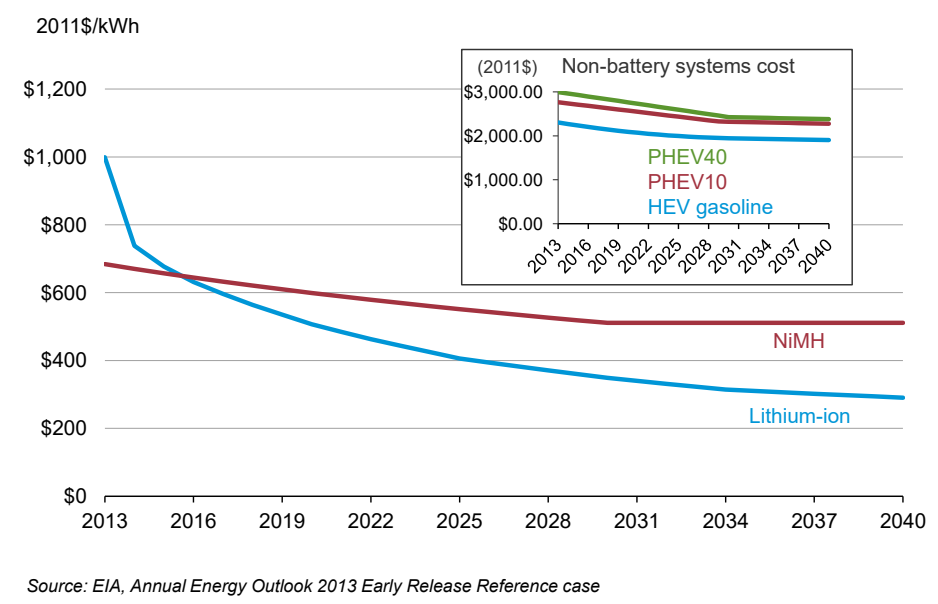

Figure 1.5: Projected EV battery cost [4].

chemistries with a price per $\mathrm{kWh}$ of $\approx 160 \$ / \mathrm{kWh}$. Additionally, the reported lithium pack costs from the various studies may or may not include the cost of the overhead engineering, battery management and protection system, or thermal management systems. These auxiliary systems add cost, complexity, and mass to the LI and NiMH modules that diminish their advantages in specific energy and energy density, as depicted in Fig. $1.6[23]$.

When analyzing costs, it is important to specify between vehicle costs, battery module costs, or recurring battery replacement costs. The recurring replacement cost hinges 


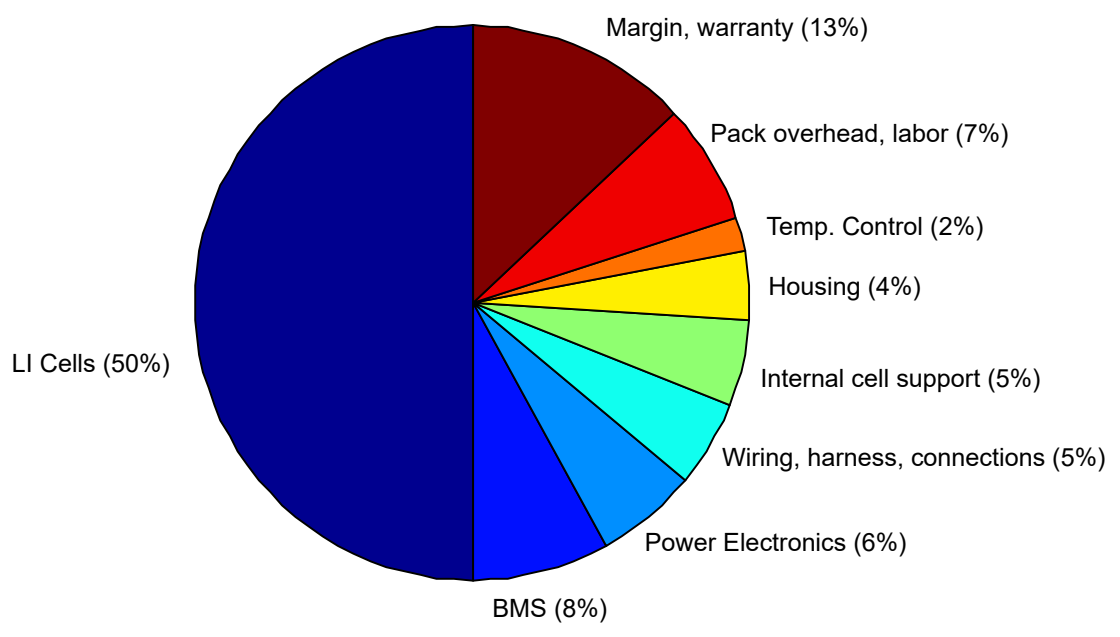

Figure 1.6: A cost breakdown of the EV lithium battery pack [23].

on the expected lifetime and usage of the vehicle and/or batteries. For example, the expected lifetime of a lead-acid battery is between 300 and 1000 cycles, while the lifetime of a lithium module is between 500 and 2000 cycles, depending on each battery's usage rate. A 2000 cycle lithium battery provides roughly four times the total energy of a 500 cycle lead-acid battery over its lifetime. Similarly, the life cycle of a utility vehicle is dependent on usage, proper mechanical maintenance and environmental conditions, and can range from hundreds of cycles to thousands cycles and may or may not live past its batteries. For fairer comparison, the usage and expected cycle life must be normalized to account for this variation.

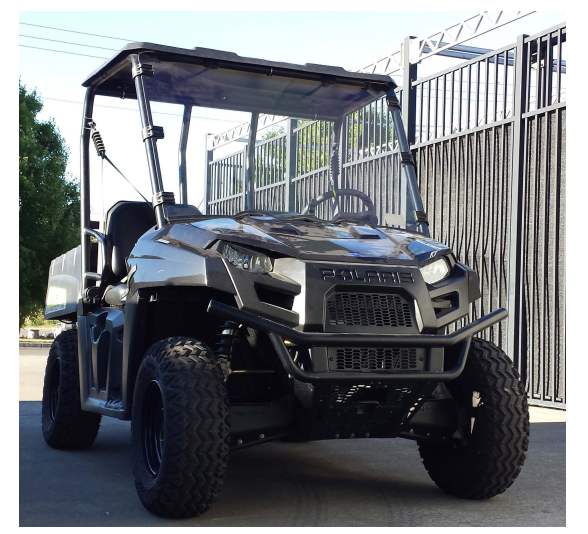

Figure 1.7: The Polaris Ranger EV. 
Table 1.2: Polaris Ranger EV specifications.

\begin{tabular}{lcc}
\hline Parameter & Value & Unit \\
\hline \hline Maximum speed & 25 & $\mathrm{MPH}$ \\
Wheel diameter & 63.5 & $\mathrm{~cm}$ \\
Length $\times$ Width $\times$ Height & $274 \times 143 \times 185$ & $\mathrm{~cm}^{3}$ \\
Vehicle mass & 793.8 & $\mathrm{~kg}$ \\
Battery bus & 48 & $\mathrm{~V}$ \\
Battery bank energy & 8.85 & $\mathrm{kWh}$ \\
Maximum motor power & 22.4 & $\mathrm{~kW}$ \\
\hline
\end{tabular}

\subsection{Single Energy Storage System Vehicle Compar- ison}

The Ranger EV is the target LEV for the HESS, as shown in Fig. 1.7. The commercial Ranger EV uses eight 12 V, 92.2 Ah lead-acid battery modules in a 4S2P (four series, two parallel) single-energy storage system lead-acid (SESS PbA) configuration, for a total vehicle $1 \mathrm{C}$ capacity of $8.85 \mathrm{kWh}$. The commercial vehicle specifications are shown in Table 1.2 [26]. A modified Ranger EV provided by Brammo, Inc. is a SESS LI configuration that uses three parallel $44 \mathrm{~V}, 70$ Ah Brammo lithium-ion battery modules as the energy source for a $1 \mathrm{C}$ capacity of $9.34 \mathrm{kWh}$. The parameters of the SESS LI and SESS PbA are detailed in Table 1.3.

\subsubsection{SESS Performance}

Since lead-acid batteries have lower specific energy than lithium batteries, the SESS LI vehicle is $231 \mathrm{~kg}$ lighter than the SESS PbA vehicle. The dramatic reduction in vehicle mass allows the SESS LI vehicle to achieve higher overall range. Initial range testing, conducted by Brammo, Inc. before the author's involvement, highlights the performance benefits of using lithium batteries over lead-acid batteries. In the testing, the SESS PbA and SESS LI vehicles were driven at near constant speeds on flat, dirt paths until the battery pack SOC reached $20 \%$ and $0 \%$, respectively. The difference in minimum SOC between battery chemistries is enforced to limit the effect of DOD on battery lifetime. The battery module parameters are specified in Table 1.3.

The results show that the SESS LI vehicle can achieve a $47 \%$ range improvement over the SESS PbA vehicle under similar driving conditions. The improvement can be 
Table 1.3: SESS PbA, SESS LI Parameters and Normalized Range Measurements

\begin{tabular}{lccc}
\hline Parameter & SESS PbA & SESS LI & Unit \\
\hline \hline Total vehicle mass including ESS & 777.9 & 547.0 & $\mathrm{~kg}$ \\
ESS 1C energy & 8.85 & 9.3 & $\mathrm{kWh}$ \\
ESS specific energy & 28.4 & 148.0 & $\mathrm{Wh} / \mathrm{kg}$ \\
ESS energy density & 10.1 & 179.7 & $\mathrm{Wh} / \mathrm{L}$ \\
ESS cost/kWh & 160 & 890 & $\$ / \mathrm{kWh}$ \\
Battery module expected cycle-life & 675 & 2000 & $\mathrm{cycles}$ \\
Unloaded range & 1 & 1.47 & $\mathrm{p} . \mathrm{u}$. \\
226kg loaded range & 0.91 & 1.23 & $\mathrm{p} . \mathrm{u}$. \\
Unloaded efficiency, $\quad$ [range/kWh] & 1 & 1.40 & $\mathrm{p} . \mathrm{u}$. \\
$\Gamma_{\text {noload }}$ & & & \\
226kg loaded efficiency, [range/kWh] & 0.91 & 1.17 & $\mathrm{p} . \mathrm{u}$. \\
$\Gamma_{\text {maxload }}$ & & & \\
\hline
\end{tabular}

attributed to several factors including differences in overall vehicle mass, higher overall battery pack energy, and higher usable ESS energy. Because the SESS LI has 5\% more energy in its battery pack than the SESS PbA, a range/kWh efficiency value, $\Gamma$, defined as the range divided by the total pack energy is used for fair ESS comparison. The SESS LI has a $40 \%$ increase in $\Gamma$ over the SESS PbA. These results show the importance of mass reduction in improving the range of electric vehicles.

\subsubsection{SESS Cost}

The range and efficiency improvements of the SESS LI comes at a steep cost. The $\$ 890 / \mathrm{kWh}$ LI modules cost more than five times that of the $\$ 160 / \mathrm{kWh} \mathrm{PbA}$ modules. When taking into account the recurring replacement cost associated with the lower PbA life-cycle count, the SESS LI costs roughly twice that of the SESS PbA. The battery pricing used for cost-analysis in this work are provided by Brammo, Inc. and Polaris Industries, and is a conservative cost figure.

\subsection{Thesis Objectives and Organization}

The goal of this work is to bridge the cost and performance gaps between the SESS PbA and the SESS LI vehicle with a hybrid battery system using lead-acid and lithium batteries, as shown in Fig. 1.8. The ideal HESS would not sacrifice too much performance 
from the SESS LI, would could cost midway between the SESS PbA and SESS LI configurations, and would have favorable volume and mass compared to the SESS vehicles. The cost figures shown are for the ESS, which is a fraction of the LEV cost.

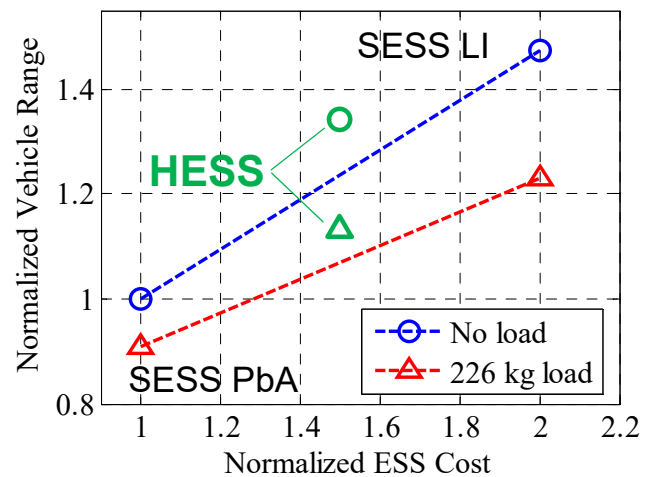

(a)

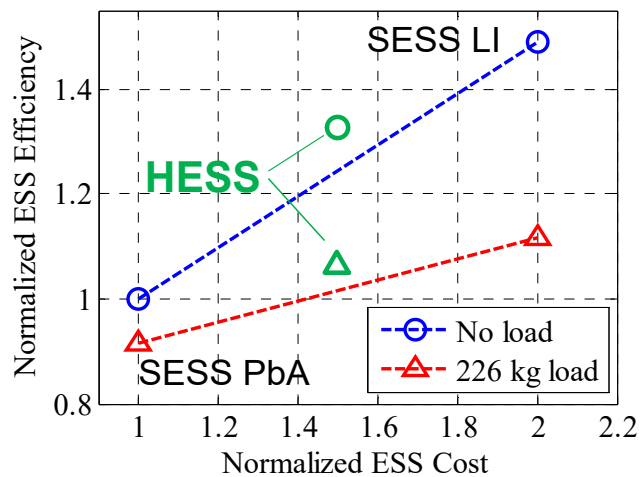

(b)

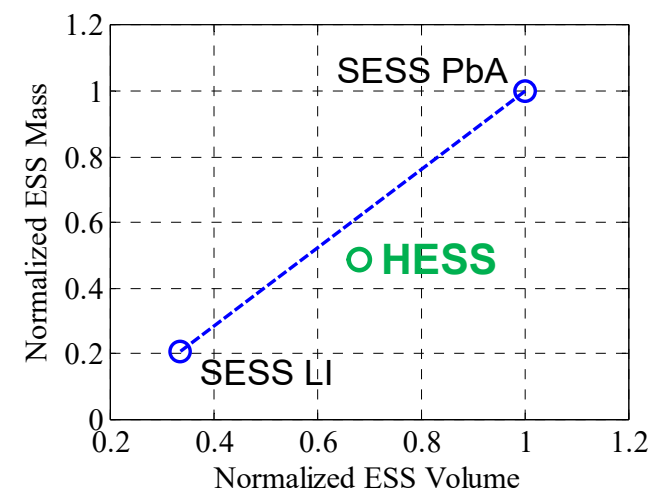

(c)

Figure 1.8: Projected HESS (a) range versus cost, (b) ESS efficiency versus cost, and (c) mass versus volume, compared to SESS vehicles.

To the best of the author's knowledge, no prior work has used multiple battery chemistries as dual energy storage devices in an EV drivetrain. Badam et al. focuses on the analyzes the benefits and tradeoffs of various battery chemistries based on power demand of common workloads of low-power, mobile applications [10]. Mukherjee et al. proposes a power-sharing control between multi-modular converters to integrate second-life EV batteries to grid-storage applications based on online internal resistance and capacity estimation [27, 28]. Hybrid batteries are also proposed to improve MPPT operation and improve control delay response in photovoltaic generation systems [29].

The proposed HESS architecture uses four modular intelligent hybrid battery managers (IHBMs) to interface the different battery chemistries, as shown in Fig. 1.9. Each IHBM consists of a dc-dc converter and controller. The scope of this thesis involves the design and implementation of the single intelligent hybrid battery manager dc-dc 
converter and controller.

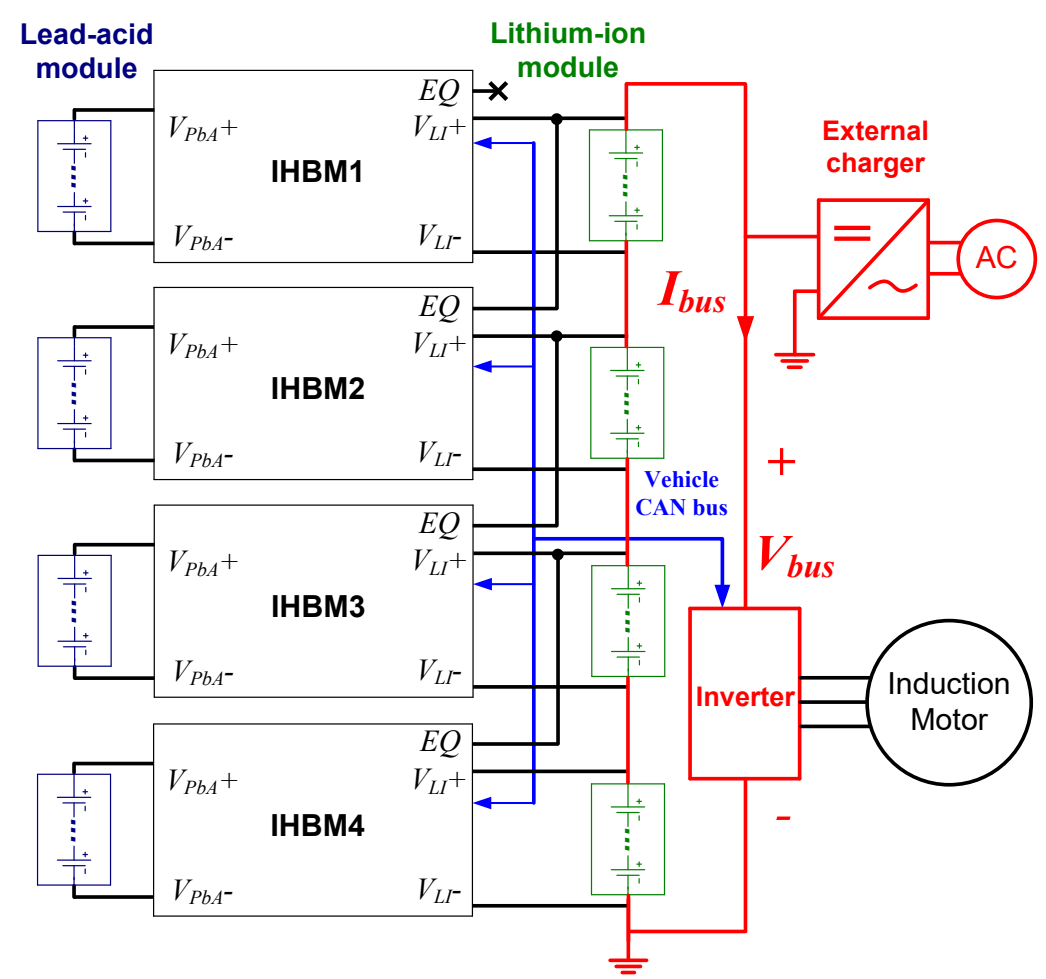

Figure 1.9: Proposed HESS vehicle architecture with four modular IHBMs.

The dc-dc converter interfaces each $\mathrm{PbA}$ module with a LI module. Due to overlapping battery voltage range, a non-inverting buck-boost (NIBB) topology is chosen to allow buck and boost capability, as well as bi-directional power transfer between the two battery chemistries [30]. Peak current mode control is used for tighter inductor current management. Traditional analog peak current mode control requires slope compensation, which has a number of disadvantages, including high parts count and lack of precise cycle-by-cycle current protection [31]. In this work, a novel combination of fully digital delay-locked loop (DLL) and a pair of phase-locked loops (PLLs) is used to control the converter off-time in each of the three dc-dc sub-converters. The NIBB topology is augmented with an additional switch that emulates the next-to-next topology to achieve both power-mix control and active series module balancing, while sharing the same inductance in order to reduce cost and size [32]. This next-to-next topology is described in more detail in Chapter 4.

The power-mix algorithm

- maximizes vehicle range for the drive-cycles of interest,

- accounts for variations in payload without prior knowledge of the drive-cycle, 
- takes coarse-grained actions based on relative battery SOC, and

- must not be computationally intensive.

A variable-step perturb and observe method, used in solar maximum power-point tracking (MPPT) applications [33, 34], is chosen to control the battery HESS power-mix. The performance versus control curves of the proposed HESS closely resembles the MPPT characteristic curves of a photo-voltaic cell, which motivated the use of the hill-climbing algorithm. Additionally, the algorithm is simple to implement in an embedded controller.

This thesis is organized as follows. The HESS architecture are proposed in Chapter 2. The drive-cycle testing and battery models are shown in Chapter 3. The hardware design is proposed in Chapter 4, and the power-mix algorithm and ESS drive-cycle comparisons are presented in Chapter 5. Finally, the hardware and algorithm are demonstrated with real drive-cycles in Chapter 6. 


\section{References}

[1] "Global trends in renewable energy investment 2016," Frankfurt School of Finance and Management, Tech. Rep., 2016. [Online]. Available: http://fs-unep-centre.org/sites/default/files/publications/ globaltrendsinrenewableenergyinvestment2016lowres_0.pdf

[2] B. Nykvist and M. Nilsson, "Rapidly falling costs of battery packs for electric vehicles," Nature Clim. Change, vol. 5, no. 4, pp. 329-332, Apr 2015, letter. [Online]. Available: http://dx.doi.org/10.1038/nclimate2564

[3] "Pump price for gasoline," The World Bank, Tech. Rep., 2015. [Online]. Available: http://data.worldbank.org/indicator/EP.PMP.SGAS.CD

[4] "Annual energy outlook 2013," US Energy Information Administration, Washington, DC, Tech. Rep., 2013.

[5] J. Krumm, "How people use their vehicles: Statistics from the 2009 national household travel study," in SAE Technical Paper, 2012, 2012.

[6] J. Axsen, S. Goldberg, J. Bailey, G. Kamiya, B. Langman, J. Cairns, M. Wolinetz, and A. Miele, "Electrifying vehicles: Insights from the canadian plug-in electric vehicle study," in Sustainable Transportation Research Team, Simon Fraser University, 2015.

[7] I. Buchmann, "What's the best battery?" 2016. [Online]. Available: http://batteryuniversity.com/learn/archive/whats_the_best_battery

[8] O. Tremblay, L.-A. Dessaint, and A.-I. Dekkiche, "A generic battery model for the dynamic simulation of hybrid electric vehicles," in Vehicle Power and Propulsion Conference, 200\%. VPPC 200\%. IEEE, Sept 2007, pp. 284-289.

[9] S. S. D. Doerffel, "A critical review of using the peukert equation for determining the remaining capacity of lead-acid and lithium-ion batteries," Journal of 
Power Sources, vol. 155, no. 2, pp. 395 - 400, 2006. [Online]. Available: http://www.sciencedirect.com/science/article/pii/S0378775305007093

[10] A. Badam, R. Chandra, J. Dutra, A. Ferrese, S. Hodges, P. Hu, J. Meinershagen, T. Moscibroda, B. Priyantha, and E. Skiani, "Software defined batteries," in Symposium on Operating Systems Principles (SOSP'15). ACM Association for Computing Machinery, October 2015. [Online]. Available: https: //www.microsoft.com/en-us/research/publication/software-defined-batteries/

[11] Deep-Cycle Battery Storage White Paper, Trojan Battery Company, 2012. [Online]. Available: http://www.trojanbattery.com/pdf/WP_DeepCycleBatteryStorage_ 0512.pdf

[12] R. Yamin and A. Rachid, "Modeling and simulation of a lead-acid battery packs in matlab/simulink: Parameters identification using extended kalman filter algorithm," in Computer Modelling and Simulation (UKSim), 2014 UKSim-AMSS 16th International Conference on, March 2014, pp. 363-368.

[13] N. K. Medora and A. Kusko, "An enhanced dynamic battery model of lead-acid batteries using manufacturers' data," in INTELEC 06 - Twenty-Eighth International Telecommunications Energy Conference, Sept 2006, pp. 1-8.

[14] N. Watrin, R. Roche, H. Ostermann, B. Blunier, and A. Miraoui, "Multiphysical lithium-based battery model for use in state-of-charge determination," Vehicular Technology, IEEE Transactions on, vol. 61, no. 8, pp. 3420-3429, Oct 2012.

[15] J. Kim and B. H. Cho, "State-of-charge estimation and state-of-health prediction of a li-ion degraded battery based on an ekf combined with a per-unit system," IEEE Transactions on Vehicular Technology, vol. 60, no. 9, pp. 4249-4260, Nov 2011.

[16] R. Dufo-Lpez, J. M. Lujano-Rojas, and J. L. Bernal-Agustn, "Comparison of different leadacid battery lifetime prediction models for use in simulation of standalone photovoltaic systems," Applied Energy, vol. 115, pp. 242 - 253, 2014. [Online]. Available: http://www.sciencedirect.com/science/article/pii/S0306261913009148

[17] C. J. Zhan, X. G. Wu, S. Kromlidis, V. K. Ramachandaramurthy, M. Barnes, N. Jenkins, and A. J. Ruddell, "Two electrical models of the lead-acid battery used in a dynamic voltage restorer," IEE Proceedings - Generation, Transmission and Distribution, vol. 150, no. 2, pp. 175-182, March 2003. 
[18] T. H. Phung, J. C. Crebier, and Y. Lembeye, "Voltage balancing converter network for series-connected battery stack," in IECON 2012 - 38th Annual Conference on IEEE Industrial Electronics Society, Oct 2012, pp. 3007-3013.

[19] T. Kim, W. Qiao, and L. Qu, "A series-connected self-reconfigurable multicell battery capable of safe and effective charging/discharging and balancing operations," in 2012 Twenty-Seventh Annual IEEE Applied Power Electronics Conference and Exposition (APEC), Feb 2012, pp. 2259-2264.

[20] Y. H. Hsieh, T. J. Liang, S. M. O. Chen, W. Y. Horng, and Y. Y. Chung, "A novel high-efficiency compact-size low-cost balancing method for series-connected battery applications," IEEE Transactions on Power Electronics, vol. 28, no. 12, pp. 5927-5939, Dec 2013.

[21] Electropaedia, "Battery and energy technologies, cell chemistries: How batteries work." [Online]. Available: http://www.mpoweruk.com/chemistries.htm

[22] "Batteries for electric cars: Challenges, opportunities, and the outlook to 2020," The Boston Consulting Group, Tech. Rep., 2010. [Online]. Available: https://www.bcg.com/documents/file36615.pdf

[23] "Road transport: The cost of renewable solutions," International Renewable Energy Agency (IRENA), Tech. Rep., 2013. [Online]. Available: http: //www.irena.org/DocumentDownloads/Publications/Road_Transport.pdf

[24] "Battery energy storage solutions for electro-mobility white paper," Association of European Automotive and Industrial Battery Manufacturers, Tech. Rep., 2012. [Online]. Available: http://www.eurobat.org/sites/default/files/eurobat_ white_paper_electro-mobility_-_annex_1_5.pdf

[25] T. T. M. Lowe, S. Tokuoka and G. Gereffi, "Lithium-ion batteries for electric vehicles: The us value chain," Center on Globalization, Governance and Competitiveness, Duke University, Tech. Rep., 2010. [Online]. Available: http://unstats.un.org/unsd/trade/s_geneva2011/refdocs/RDs/Lithium-Ion\% 20Batteries\%20(Gereffi\%20-\%20May\%202010).pdf

[26] Polaris Ranger EV Owner's Manual, Polaris Industries, 2010. [Online]. Available: \$http://cdn.polarisindustries.com/polaris/common/parts-manuals/ 9922614r03.pdf\$ 
[27] N. Mukherjee and D. Strickland, "Control of second-life hybrid battery energy storage system based on modular boost-multilevel buck converter," IEEE Transactions on Industrial Electronics, vol. 62, no. 2, pp. 1034-1046, Feb 2015.

[28] N. Mukherjee, D. Strickland, and M. A. Varnosfaderani, "Adaptive control of hybrid battery energy storage systems under capacity fade," in Power Electronics and Applications (EPE'14-ECCE Europe), 2014 16th European Conference on, Aug 2014, pp. $1-10$.

[29] T. Yamamoto, X. Yanbin, S. Hashimoto, N. Higuchi, K. Nara, and H. Yasue, "Operational simulation of pv generation system with hybrid batteries," in Smart Grid Technologies - Asia (ISGT ASIA), 2015 IEEE Innovative, Nov 2015, pp. 1-5.

[30] N. Mukherjee and D. Strickland, "Analysis and comparative study of different converter modes in modular second-life hybrid battery energy storage systems," IEEE Journal of Emerging and Selected Topics in Power Electronics, vol. 4, no. 2, pp. 547-563, June 2016.

[31] R. Erickson and D. Maksimović, Fundamentals of Power Electronics, Second Ed. Springer, 2001.

[32] T. H. Phung, A. Collet, and J.-C. Crebier, "An optimized topology for next-to-next balancing of series-connected lithium-ion cells," Power Electronics, IEEE Transactions on, vol. 29, no. 9, pp. 4603-4613, Sept 2014.

[33] N. Femia, G. Petrone, G. Spagnuolo, and M. Vitelli, "Optimization of perturb and observe maximum power point tracking method," IEEE Transactions on Power Electronics, vol. 20, no. 4, pp. 963-973, July 2005.

[34] F. A. O. Aashoor and F. V. P. Robinson, "A variable step size perturb and observe algorithm for photovoltaic maximum power point tracking," in 20124 th International Universities Power Engineering Conference (UPEC), Sept 2012, pp. 1-6. 


\section{Chapter 2}

\section{Hybrid Energy Storage Architectures for EVs}

The classical hybrid electric vehicle (HEV) marries the high specific energy and low cost of gasoline with the performance and efficiency of an electric battery for a lower cost, medium range, high fuel efficiency vehicle [1, 2]. The existing $\mathrm{HEV}$ architectures are variations of two basic power-sharing configurations: series and parallel power transfer. A power-split hybrid (combined series and parallel architecture) is used in newer generations of the popular Toyota Prius, as is shown in Fig. 2.1(a) [3].

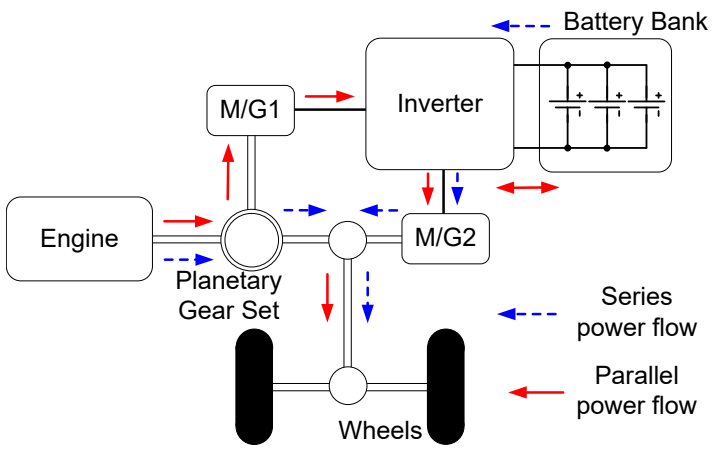

(a)

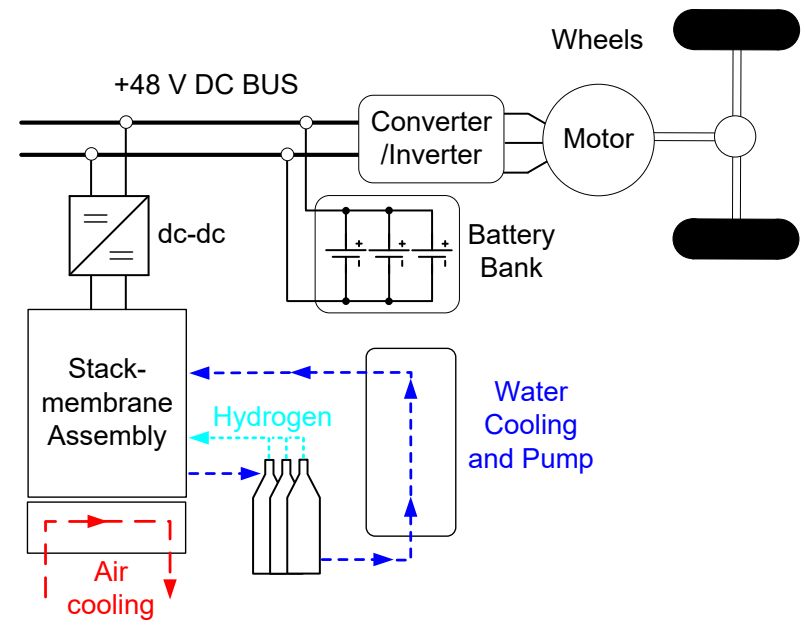

(b)

Figure 2.1: A (a) power-split hybrid architecture [3] and (b) parallel fuel cell and battery hybrid vehicle architecture [4].

The success of the Toyota Prius and other commercial HEVs has led to extensive research into the combination of alternate energy sources. For example, ultra-capacitors 
have been used in conjunction with batteries in a parallel architecture to improve power density and facilitate regenerative breaking $[5,6]$. Similarly, fuel cells have been combined with lithium batteries in a parallel architecture to extend EV range, as shown in Fig. 2.1 (b) $[4,7,8]$. Each variation of the basic parallel and series hybrid architectures has benefits and challenges that must be weighed for the application vehicle, and the hybrid battery architecture must leverage the advantages and disadvantages of the two battery chemistries.

To more fairly judge between the various energy storage systems, the HESS must adhere to the following system requirements:

- The total $1 \mathrm{C}$ energy must be within $10 \%$ of the SESS configurations,

- The inverter bus voltage must be in the range of $36 \mathrm{~V}$ to $60 \mathrm{~V}$,

- The HESS should be modular for testability and flexibility to adapt to other EV powertrains, and

- The HESS topology should facilitate active series battery balancing.

\subsection{Hybrid Battery Topologies}

The simplest approach is to directly connect the two energy sources in parallel, as shown in Fig. 2.2(a). Because lead-acid and lithium batteries have different voltage ranges, this configuration leads to high circulating currents within the HESS. For this reason, the topologies shown in Fig. 2.2(a) and Fig. 2.2(b) are undesirable. A dc-dc converter can be placed between the two battery chemistries to prevent internal currents, as shown in Fig. 2.2(c) and Fig. 2.2(d), with one of the battery chemistries sharing a voltage bus with the load $[4-6]$.

The two batteries can each be connected in parallel to the load bus through dedicated dc-dc converters, as shown in Fig. 2.2(e). Finally, dedicated dc-dc converters can also be placed in a series configuration with the batteries and load, as shown in Fig. 2.2(f) and Fig. 2.2(g). The latter three topologies allow for more control and optimization flexibility, but are more complex and costly, as additional hardware is required. These topologies may also have lower overall efficiencies due the dc-dc converters losses.

A variation of the topology shown in 2.2(e) is used in [9], where a single, multi-input dc-dc converter interfaces the multiple batteries to the load. This approach allows for more precise charge control and only uses a single dc-dc converter, but imposes higher power demands on the dc-dc. While this may be acceptable for a low power, mobile 


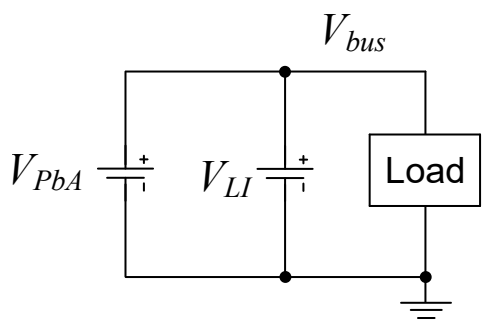

(a)

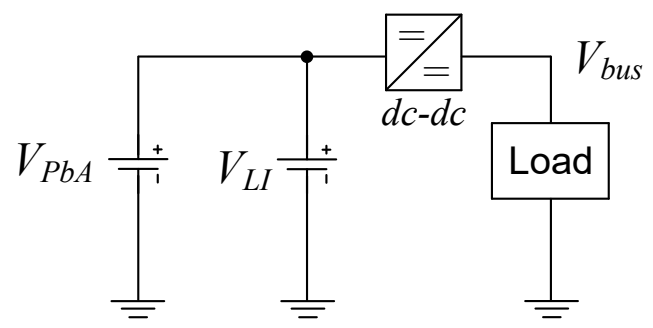

(b)

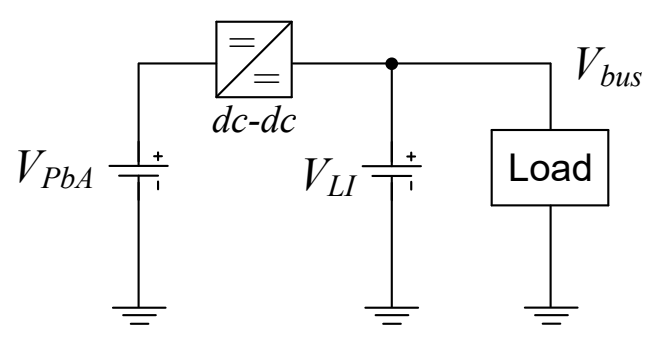

(c)

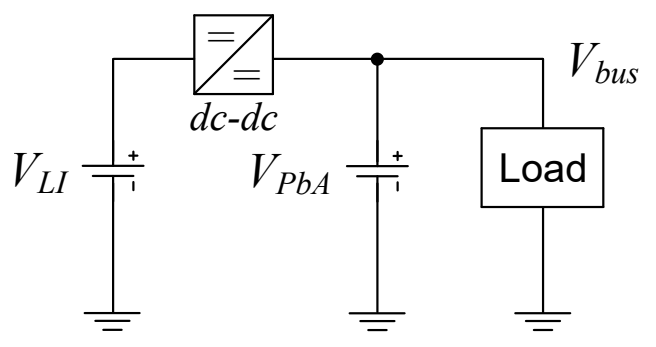

(d)

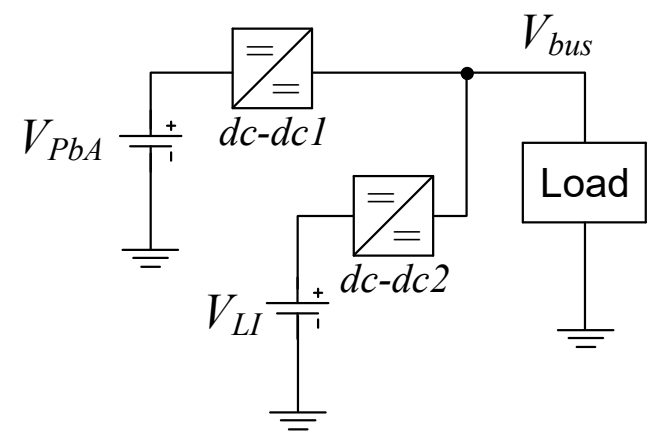

(e)

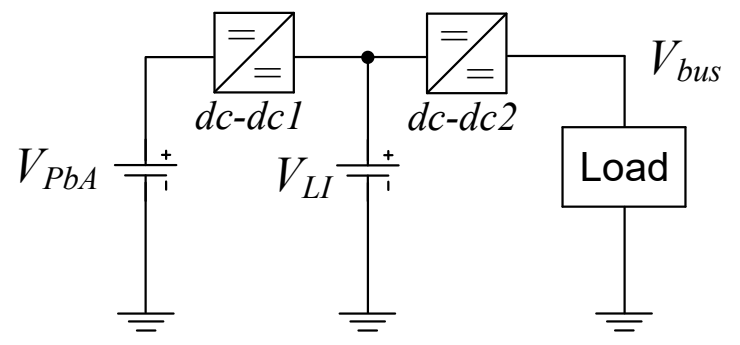

(f)

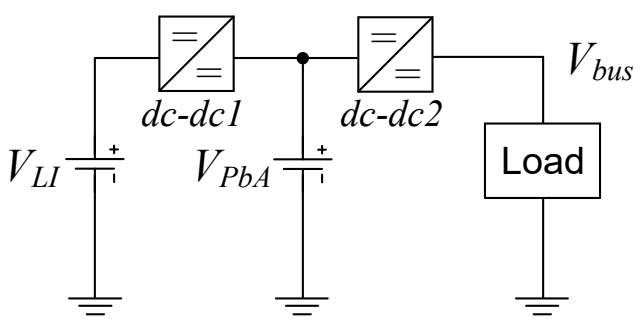

(g)

Figure 2.2: Seven possible configurations for a HESS containing two energy storage elements. Each configuration offers different trade-off of cost, dc-dc converter ratings and system performance.

application, it is inefficient for the hybrid battery EV because of the significantly higher current ratings. Mukherjee et. al uses a multi-modular converter topology with hybrid batteries for grid-tied energy storage applications that employs dedicated dc-dc converters between the batteries and the load bus in a series configuration, and mirrors the topology in Fig. 2.2(e) [10,11]. The series-stacked modular converters regulate the bus voltage to 
Table 2.1: LI and PbA Module Specifications

\begin{tabular}{lcccc}
\hline Parameter & LI-1 & LI-2 & PbA & Unit \\
\hline \hline Nominal voltage & 14.8 & 11.1 & 12 & $\mathrm{~V}$ \\
Voltage range & $12-16.6$ & $10-12.45$ & $11-12.8$ & $\mathrm{~V}$ \\
Capacity (1C rate) & 90 & 90 & 92 & $\mathrm{Ah}$ \\
Energy (1C rate) & 1.3 & 1.0 & 1.1 & $\mathrm{kWh}$ \\
Mass & 10.3 & 8.5 & 39 & $\mathrm{~kg}$ \\
Volume & 7.6 & 7.6 & 17.1 & $\mathrm{~L}$ \\
Specific energy & 127.4 & 117.3 & 28.4 & $\mathrm{Wh} / \mathrm{kg}$ \\
Energy density & 173.6 & 132.1 & 64.6 & $\mathrm{Wh} / \mathrm{L}$ \\
Cycles (80\% DOD) & 2000 & 2000 & 675 & \\
Approx. cost per kWh & 960 & 860 & 160 & $\$ / \mathrm{kWh}$ \\
\hline
\end{tabular}

reach higher inverter bus voltages, but must process the entirety of the battery power.

The topology shown in Fig. 2.2(c) is chosen such that the lower impedance lithium module shares a power bus with the inverter. With this configuration, only the $\mathrm{PbA}$ fraction of the total HESS power is processed through the dc-dc converter, and the system can achieve higher efficiencies with less dc-dc converter losses. As a result, the ESS can be made smaller and lighter due to a smaller thermal footprint, and can be made cheaper with components of lower current rating.

\subsubsection{Battery Selection}

Two lithium-ion batteries are considered for this work, and their parameters are detailed in Table 2.1. The first lithium module, LI-1, has a nominal voltage of $14.8 \mathrm{~V}$ and a module energy of $1.3 \mathrm{kWh}$, while the second lithium module, LI-2, has a nominal voltage of $11.1 \mathrm{~V}$ and a module energy of $1.0 \mathrm{kWh}$. The $12 \mathrm{~V}, 92 \mathrm{Ah}$ lead-acid module that is used in the commercial Polaris Ranger EV will be used as the PbA module in the hybrid system. The approximate battery costs are provided by Brammo, Inc. The HESS would employ a cost-effective combination of these battery modules as the vehicle's energy storage system.

One variant of the topology connects the $\mathrm{PbA}$ module through a dc-dc converter in parallel with the inverter bus, as shown in Fig. 2.3(a). In the figure, the inverter bus is made up of four $11.1 \mathrm{~V}$ LI modules to make up a $44.4 \mathrm{~V}$ bus voltage, though three 14.8 V LI modules can similarly be stacked in series. This variant decouples the differing 
battery voltages through the dc-dc converters, but is unable to actively balance the series LI modules without additional hardware. Additionally, this topology cannot easily be scaled up to higher voltage vehicle buses.

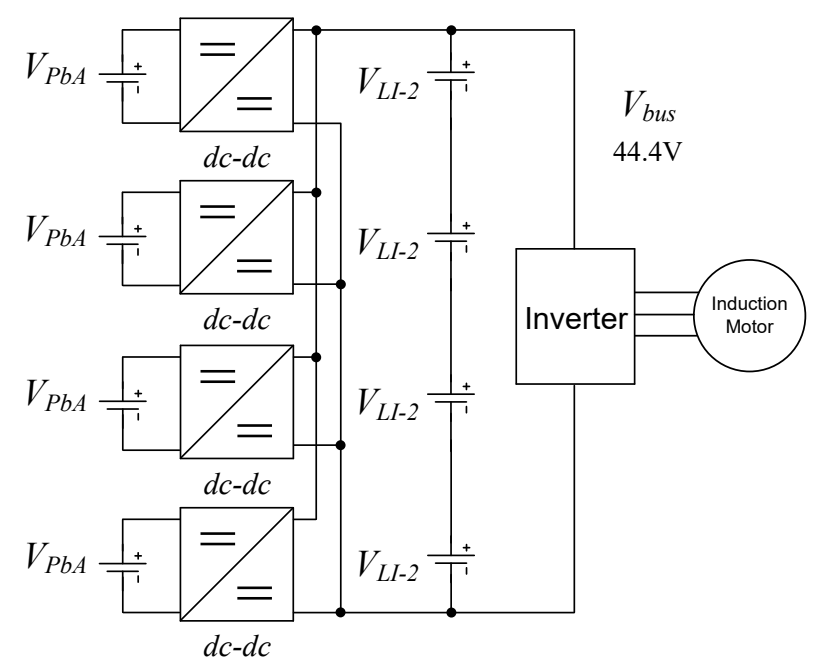

(a)

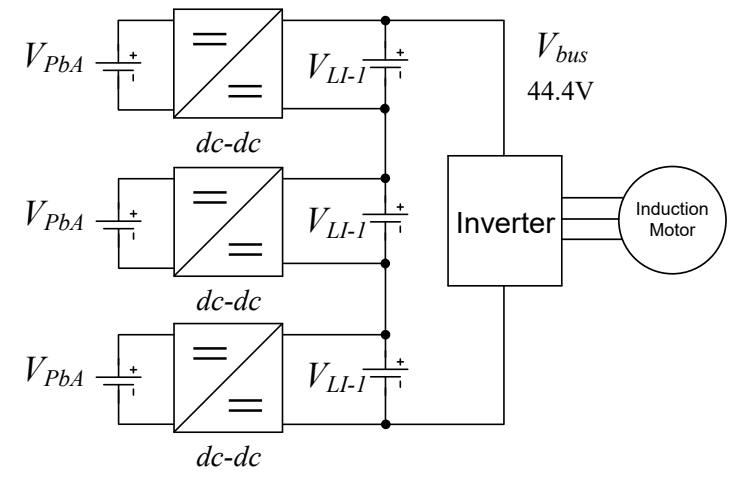

(b)

Figure 2.3: Two variants of the architecture in Fig. 2.2(c), with PbA modules and a dc-dc converter in parallel to (a) the inverter bus, variant-1, and (b) to each LI module, variant-2

A second variant of the topology places a PbA module in parallel with each LI module, as shown in Fig. 2.3(b). In the figure, the inverter bus is made up of three $14.8 \mathrm{~V}$ LI modules for an $44.4 \mathrm{~V}$ bus voltage, though four $11.1 \mathrm{~V}$ LI modules can similarly be stacked in series. This variant decouples the differing battery voltages through the dc-dc converters, and is able to actively balance series stacked lithium modules. This topology is modular and can be scaled up to higher voltage vehicle buses. Other such variants exist such as connecting a single $\mathrm{PbA}$ module across two series LI modules, but these are not considered because they complicate the balancing and control design.

\subsection{Configuration Comparisons}

The cost and parameter comparisons of the possible HESS configurations are detailed in Table 2.2 for the two variants and available battery modules. The various configurations each support a $44.4 \mathrm{~V}$ inverter bus.

Configurations 1, 3, and 5 have relatively low total energy, and thus are unfavorable for the HESS design. Configuration 2, using four PbA modules and three LI modules in a variant 1 topology, is cost competitive with an ESS cost of $\$ 424 / \mathrm{kWh}$. Configurations 
Table 2.2: Possible HESS Configurations

\begin{tabular}{lccccccc}
\hline \multirow{2}{*}{ Parameter } & \multicolumn{7}{c}{ Configuration } \\
& 1 & 2 & 3 & 4 & 5 & 6 & Unit \\
\hline \hline Variant & 1 & 1 & 1 & 1 & 2 & 2 & \\
Lithium module, LI & LI-1 & LI-1 & LI-2 & LI-2 & LI-1 & LI-2 & \\
Number of PbA modules & 3 & 4 & 3 & 4 & 3 & 4 & \\
Number of LI modules & 3 & 3 & 4 & 4 & 3 & 4 & \\
Active balancing & no & no & no & no & yes & yes & \\
ESS 1C energy & 7.32 & 8.42 & 7.32 & 8.42 & 7.32 & 8.42 & $\mathrm{kWh}$ \\
Energy ratio, $E_{\text {LI }} / E_{E S S}$ & 0.55 & 0.48 & 0.55 & 0.48 & 0.55 & 0.48 & \\
ESS mass & 147.9 & 186.9 & 151.1 & 190.1 & 147.9 & 190.1 & $\mathrm{~kg}$ \\
ESS volume & 74.1 & 91.2 & 81.7 & 98.8 & 74.1 & 98.8 & $\mathrm{~L}$ \\
ESS specific energy & 49.5 & 45.1 & 48.4 & 44.3 & 49.5 & 44.3 & $\mathrm{Wh} / \mathrm{kg}$ \\
ESS energy density & 98.7 & 92.3 & 89.6 & 85.2 & 98.7 & 85.2 & $\mathrm{Wh} / \mathrm{L}$ \\
ESS cost/kWh & 465 & 424 & 541 & 491 & 464 & 491 & $\$ / \mathrm{Wh}$ \\
\hline
\end{tabular}

4 and 6 use the same number of $\mathrm{PbA}$ and LI modules, and are different variants. With all factors considered, Configuration 6 is chosen for its relatively higher ESS energy and modularity.

Table 2.3: ESS Parameters and Normalized Range Measurements

\begin{tabular}{lcccc}
\hline Parameter & SESS PbA & SESS LI & HESS $^{*}$ & Unit \\
\hline \hline Total vehicle mass including ESS & 777.9 & 547.0 & 655.9 & $\mathrm{~kg}$ \\
ESS 1C energy & 8.85 & 9.3 & 8.42 & $\mathrm{kWh}$ \\
ESS specific energy & 28.4 & 148.0 & 44.3 & $\mathrm{Wh} / \mathrm{kg}$ \\
ESS energy density & 10.1 & 179.7 & 85.2 & $\mathrm{Wh} / \mathrm{L}$ \\
ESS cost/kWh & 160 & 890 & 491 & $\$ / \mathrm{kWh}$ \\
\hline
\end{tabular}

* Configuration 6 


\subsection{Intelligent Hybrid Battery Manager}

An Intelligent Hybrid Battery Manager, (IHBM), consisting of a dc-dc converter and controller, interfaces between each pair of LI and PbA batteries, as shown in Fig. 2.4. The IHBM controller has two control targets: 1) an FPGA, and 2) a micro-controller (MCU). The FPGA manages the high-speed dc-dc converter switching operation, while the MCU handles the system-level and battery-level power-mix. The MCU captures salient HESS parameters such as battery voltage and current, collects the LI module parameters reported in its BMS, calculates $\mathrm{PbA}$ SOC, and communicates with adjacent IHBMs.

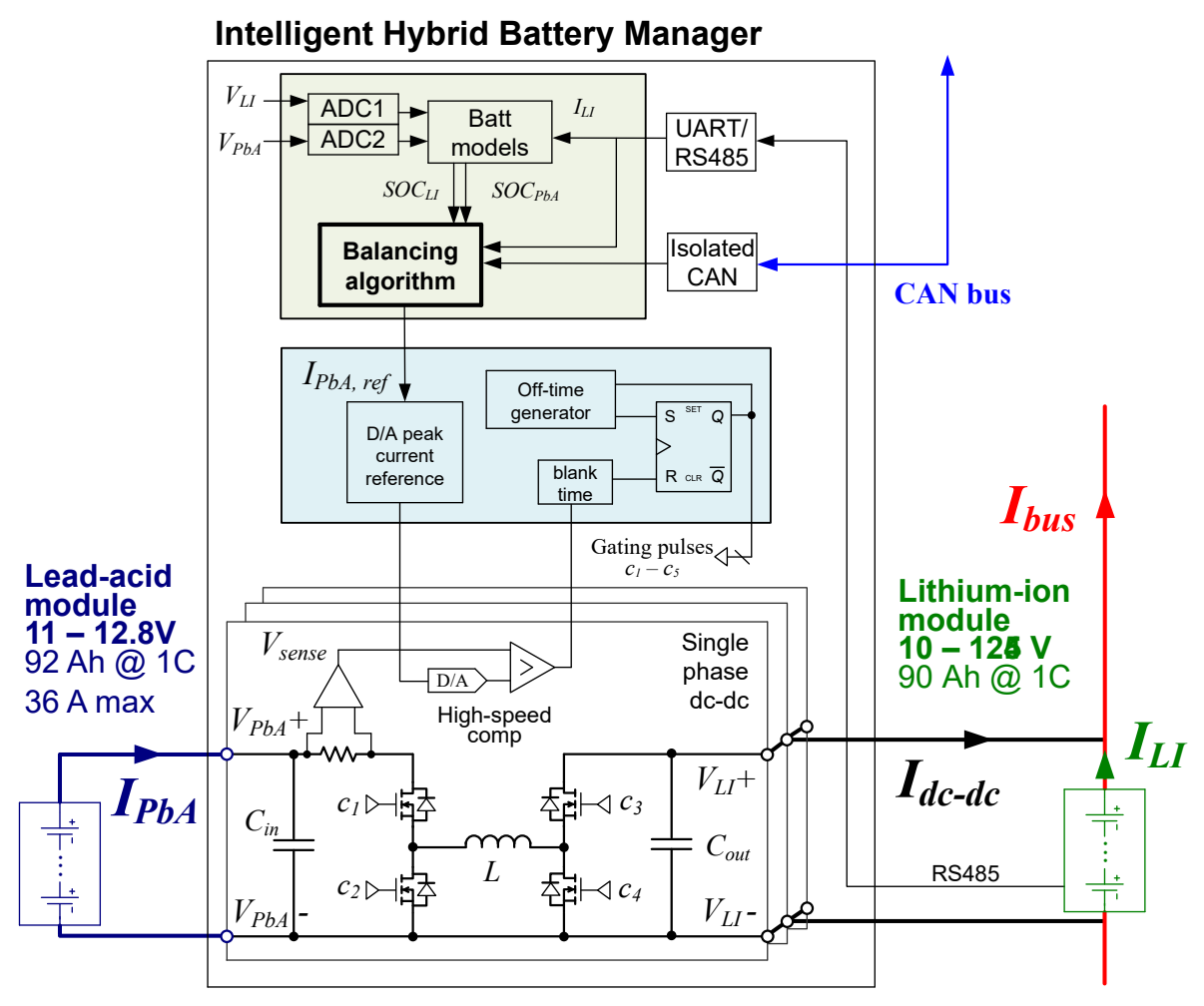

Figure 2.4: Proposed modular IHBM with dc-dc converter and controller.

With the proposed architecture, the current flow in the bus is governed by

$$
\begin{aligned}
& I_{b u s}=I_{L I}+I_{d c-d c}, \\
& I_{P b A}=\frac{V_{L I} \cdot I_{d c-d c}}{V_{P b A} \cdot \eta},
\end{aligned}
$$

where $I_{L I}$ is LI current, $I_{d c-d c}$ is dc-dc converter output current, and $I_{P b A}$ is $\mathrm{PbA}$ current. $V_{L I}$ and $V_{P b A}$ represent LI and PbA battery voltages, respectively, and $\eta$ is the converter efficiency. By controlling $I_{P b A}$, the currents $I_{d c-d c}$ and $I_{L I}$ are affected. A non-inverting 
buck-boost converter (NIBB) is proposed for bi-directional buck and boost conversion. The NIBB also allows for an active-series battery balancing implementation, which is described in more detail in Chapter 4.

The modularity of the proposed architecture allows the IHBM controller to both 1) make independent, local battery power-mix decisions and 2) use data from adjacent IHBMs to affect global HESS power flow and energy balance. This thesis focuses on the local power-mix algorithm, and assumes balancing in series HESS modules.

\subsection{Chapter Summary and Conclusions}

The LEV's hybrid battery architecture is derived in this chapter. The proposed HESS architecture uses four series $11.1 \mathrm{~V}, 90$ Ah lithium modules to make up a $44.4 \mathrm{~V}$ inverter bus, and a $12 \mathrm{~V}, 92.2 \mathrm{Ah}$ lead-acid module augments each lithium battery through an Intelligent Hybrid Battery Manager (IHBM), which consists of a dc-dc converter and controller. With the parallel power-sharing configuration, the dc-dc converter only processes power flow from the lead-acid battery, enabling lower converter power ratings, smaller thermal footprint, and lighter overall vehicle mass. The proposed architecture also facilitates active battery balancing. The dc-dc converter ratings are subject to the battery characteristics as well as inverter loading. The Ranger EV's drive-cycle loading and the LI and PbA battery models are explored in the next chapter. 


\section{References}

[1] S. Sasaki, "Toyota's newly developed hybrid powertrain," in Power Semiconductor Devices and ICs, 1998. ISPSD 98. Proceedings of the 10th International Symposium on, Jun 1998, pp. 17-22.

[2] L. Tribioli and S. Onori, "Analysis of energy management strategies in plug-in hybrid electric vehicles: Application to the gm chevrolet volt," in 2013 American Control Conference, June 2013, pp. 5966-5971.

[3] S. J. Moura, H. K. Fathy, D. S. Callaway, and J. L. Stein, "A stochastic optimal control approach for power management in plug-in hybrid electric vehicles," IEEE Transactions on Control Systems Technology, vol. 19, no. 3, pp. 545-555, May 2011.

[4] J. J. Hwang and W. R. Chang, "Characteristic study on fuel cell/battery hybrid power system on a light electric vehicle," Journal of Power Sources, vol. 207, pp. 111 - 119, 2012. [Online]. Available: http://www.sciencedirect.com/science/ article/pii/S0378775312003096

[5] M. Moshirvaziri, C. Malherbe, A. Moshirvaziri, and O. Trescases, "Power-mix optimization for a hybrid ultracapacitor/battery pack in an electric vehicle using realtime gps data," in Industrial Electronics Society, IECON 2013 - 39th Annual Conference of the IEEE, Nov 2013, pp. 4666-4671.

[6] L. Shao, M. Moshirvaziri, C. Malherbe, A. Moshirvaziri, A. Eski, S. Dallas, F. Hurzook, and O. Trescases, "Ultracapacitor/battery hybrid energy storage system with real-time power-mix control validated experimentally in a custom electric vehicle," in Applied Power Electronics Conference and Exposition (APEC), 2015 IEEE, March 2015, pp. 1331-1336.

[7] S. Aso, M. Kizaki, and Y. Nonobe, "Development of fuel cell hybrid vehicles in toyota," in Power Conversion Conference - Nagoya, 200\%. PCC 'O7, April 2007, pp. $1606-1611$. 
[8] M. Jain, C. Desai, N. Kharma, and S. Williamson, "Optimal powertrain component sizing of a fuel cell plug-in hybrid electric vehicle using multi-objective genetic algorithm," in Industrial Electronics, 2009. IECON '09. 35th Annual Conference of IEEE, Nov 2009, pp. 3741-3746.

[9] A. Badam, R. Chandra, J. Dutra, A. Ferrese, S. Hodges, P. Hu, J. Meinershagen, T. Moscibroda, B. Priyantha, and E. Skiani, "Software defined batteries," in Symposium on Operating Systems Principles (SOSP'15). ACM Association for Computing Machinery, October 2015. [Online]. Available: https: //www.microsoft.com/en-us/research/publication/software-defined-batteries/

[10] N. Mukherjee and D. Strickland, "Control of second-life hybrid battery energy storage system based on modular boost-multilevel buck converter," IEEE Transactions on Industrial Electronics, vol. 62, no. 2, pp. 1034-1046, Feb 2015.

[11] N. Mukherjee, D. Strickland, and M. A. Varnosfaderani, "Adaptive control of hybrid battery energy storage systems under capacity fade," in Power Electronics and Applications (EPE'14-ECCE Europe), 2014 16th European Conference on, Aug 2014, pp. $1-10$. 


\section{Chapter 3}

\section{Drive-cycle Testing and Battery Modeling}

The performance of an electric vehicle must be assessed in both the mechanical and the electrical domains. Mechanical disturbances such as terrain, vehicle mass, temperature and air drag affect electrical system performance, just as electrical system inefficiencies affect mechanical performance. Vehicle modeling is a means to map the mechanical constraints to the electrical system stresses, and requires an accurate mathematical model of the vehicle and environment. When available, drive-cycle data collection is preferred over vehicle modeling for its accuracy and because it is a realistic representation of realworld conditions.

MATLAB models of the lead-acid and lithium batteries are developed and used to aid the development of the power-mix algorithm. The drive-cycle data, which includes lithium battery voltage, current, and SOC measurements, is used to validate the accuracy and precision of the battery models. Once validated, the drive-cycle data is used 1) in MATLAB simulations as stimulus to the battery models to extrapolate vehicle speed and range, and 2) in experimental verification of the HESS batteries, dc-dc converter, and power-mix algorithm.

\subsection{Drive-cycle Testing}

Drive-cycle testing was conducted using a modified Ranger EV test vehicle provided by Brammo, Inc., and the real-time battery and vehicle data was logged. The drive-cycle data provides a realistic representation of the electrical system stresses without the need to develop a detailed mechanical vehicle model. 


\subsubsection{Test Vehicle and Methodology}

Standard drive-cycle data such as the LA92, FTP-75 and MVEG-A cycles are available from various government agencies $[1,2]$. These drive-cycles represent average driving conditions for a regions such as Los Angeles, New York, European cities, and sub-urban towns, and exist to streamline fuel-efficiency testing for new automobiles. The drivecycles have also been used in the literature to develop energy optimization algorithms of HEVs [3, 4]. The standard driving speeds and conditions of a commercial vehicle do not apply to an off-road utility vehicle such as the Polaris Ranger EV, which is the focus of this work. Furthermore, because utility vehicles are meant for a wide variety of use cases, new data must be collected for this work.

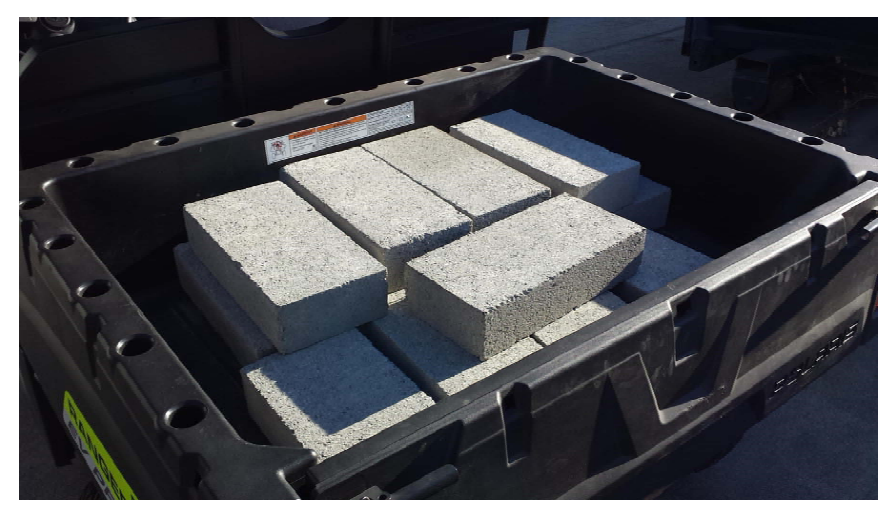

Figure 3.1: The bed of the Ranger EV test vehicle with $226 \mathrm{~kg}$ of bricks.

The modified Ranger EV test vehicle uses three parallel 44 V, 70 Ah Brammo lithiumion battery modules for an ESS $1 \mathrm{C}$ capacity of $9.34 \mathrm{kWh}$, and its parameters are detailed in Table 1.3. The test vehicle is an SESS LI vehicle, and is lighter than both the proposed HESS and the SESS PbA. Bricks are loaded into the bed of the Ranger to make up the difference in mass between the various ESS configurations, as shown in Fig. 3.1. In this way, the power demand of the test vehicle mimics that of the heavier vehicles. A snapshot of the drive-cycle measurements for a $15 \mathrm{MPH}$, unloaded drive-cycle is shown in Fig. 3.2. The drive-cycle routes were limited to a flat, paved road due to logistical constraints. As a result, the vehicle dynamics associated with hill climbing and varying terrain are not explored in the testing, and are not considered in this work.

Each lithium battery includes a battery management system (BMS) that

- measures battery voltage, current, and temperature,

- estimates real-time battery SOC based on sensor measurements,

- protects cells from overcurrent, overvoltage, and overtemperature faults, and 

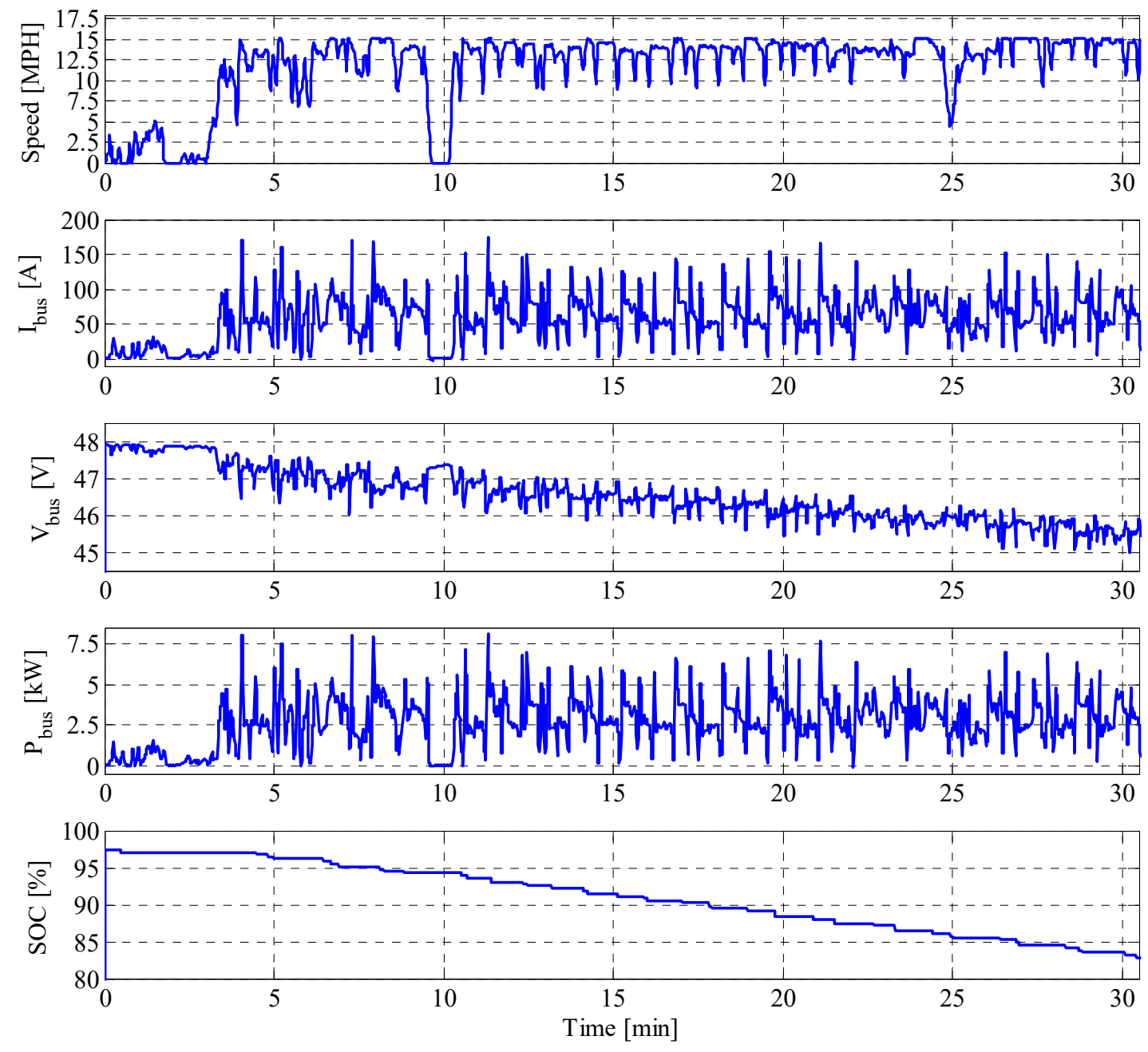

Figure 3.2: The measured drive-cycle data of the modified Polaris Ranger EV.

- communicates with a host controller over an RS-485 data bus.

The LI module BMS is linked to a larger vehicle CAN bus, where auxiliary components share real-time vehicle data, such as speed, temperature, motor RPM, etc. The battery and vehicle data are logged with 5 s resolution into a USB memory drive via the Vehicle Control Unit (VCU). The bus current and voltage, $I_{b u s}$ and $V_{b u s}$, respectively, are separately logged to a laptop PC at a $51.8 \mathrm{~ms}$ resolution through a high speed data-logger to examine the dynamic loading on the inverter bus, as shown in Fig. 3.3.

\subsubsection{Payload Variation}

To test the vehicle performance under load, the bed of the Ranger EV test vehicle is loaded with bricks. Three load levels are considered:

- No load, an unloaded SESS LI LEV, 


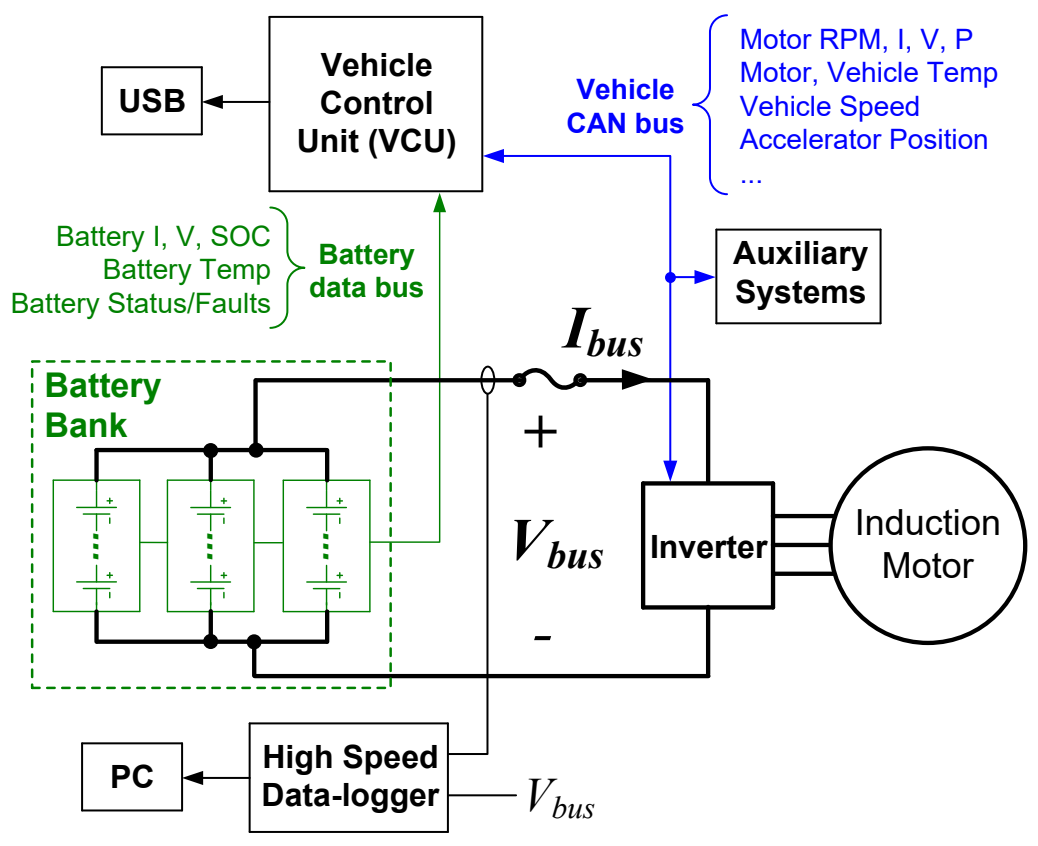

Figure 3.3: A simplified block diagram of the Ranger EV electrical system and data collection buses.

- $140 \mathrm{~kg}$ load, which represents vehicle weight of a HESS LEV, and

- $226 \mathrm{~kg}$ load, which represents vehicle weight of a SESS PbA LEV.

The driver adds a $78 \mathrm{~kg}$ load to all three test cases. The inverter bus power, $P_{\text {bus }}$, is shown for a zero to $15 \mathrm{MPH}, 25$ second straightaway drive-cycle in Fig. 3.4(a). The peak power during an acceleration event varies by more than $1 \mathrm{~kW}$ between the unloaded case and the $226 \mathrm{~kg}$ loaded case, from $6.24 \mathrm{~kW}$ to $7.53 \mathrm{~kW}$. The average rolling resistance power demand varies between $1.57 \mathrm{~kW}$ in the unloaded case, and $1.97 \mathrm{~kW}$ for the $226 \mathrm{~kg}$ loaded case. The data shows a high variation in peak acceleration power, and mild variation in power required rolling resistance between the three payload cases. The vehicle is driven under the load conditions for an extended duration, with vehicle speed fixed at near-constant $15 \mathrm{MPH}$, and the data is used towards battery modeling and algorithm development.

\subsubsection{Speed Variation}

The test vehicle was also driven at a lower, near-constant speed of $10 \mathrm{MPH}$ to investigate the effect of speed on power demand. With the same $112 \mathrm{~kg}$ payload, the average power demand was $1.8 \mathrm{~kW}$ for a $10 \mathrm{MPH}$ drive cycle, and $2.3 \mathrm{~kW}$ for a $15 \mathrm{MPH}$ drive cycle, as shown in Fig. 3.4(b). Driving at lower speeds results in lower average power demand as 


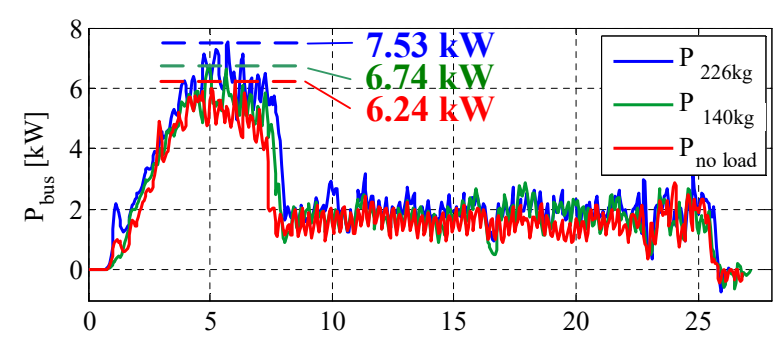

(a)

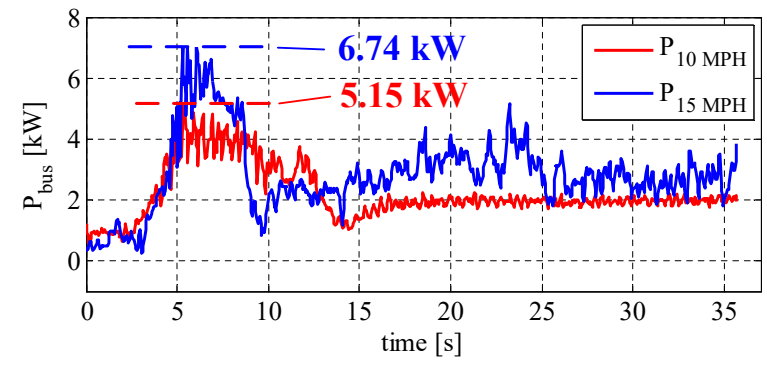

(b)

Figure 3.4: Measured vehicle bus power during an acceleration event on flat, straight pavement with (a) varying vehicle payloads and (b) varying maximum speeds.

well as fewer peak acceleration incidents. The absence of high power acceleration events is evident in the drive-cycle power histograms shown in Fig. 3.5.

\subsection{Battery Testing and Modeling}

The battery modules are individually tested under controlled conditions, and the measurements are used to develop SOC and voltage models. These models are used for the development of the power-mix algorithm, and to simulate the vehicle range for the various ESS.

\subsubsection{Lithium-Ion Battery Model}

The 11.1 V, 90 Ah lithium-ion battery uses 273.7 V, 10 Ah lithium-ion cells in a 3S9P configuration. The cell voltage is estimated using an equivalent $\mathrm{R}-\mathrm{C}$ circuit model. The module voltage is computed by multiplying the estimated cell voltage by the number of cells in series. Cell balancing is achieved within each LI module, and intra-module cell imbalance is assumed to be negligible for the purpose of the battery model. Current sharing between parallel LI cells is also assumed. Battery state-of-charge (SOC) is determined using the Coulomb counting method. 

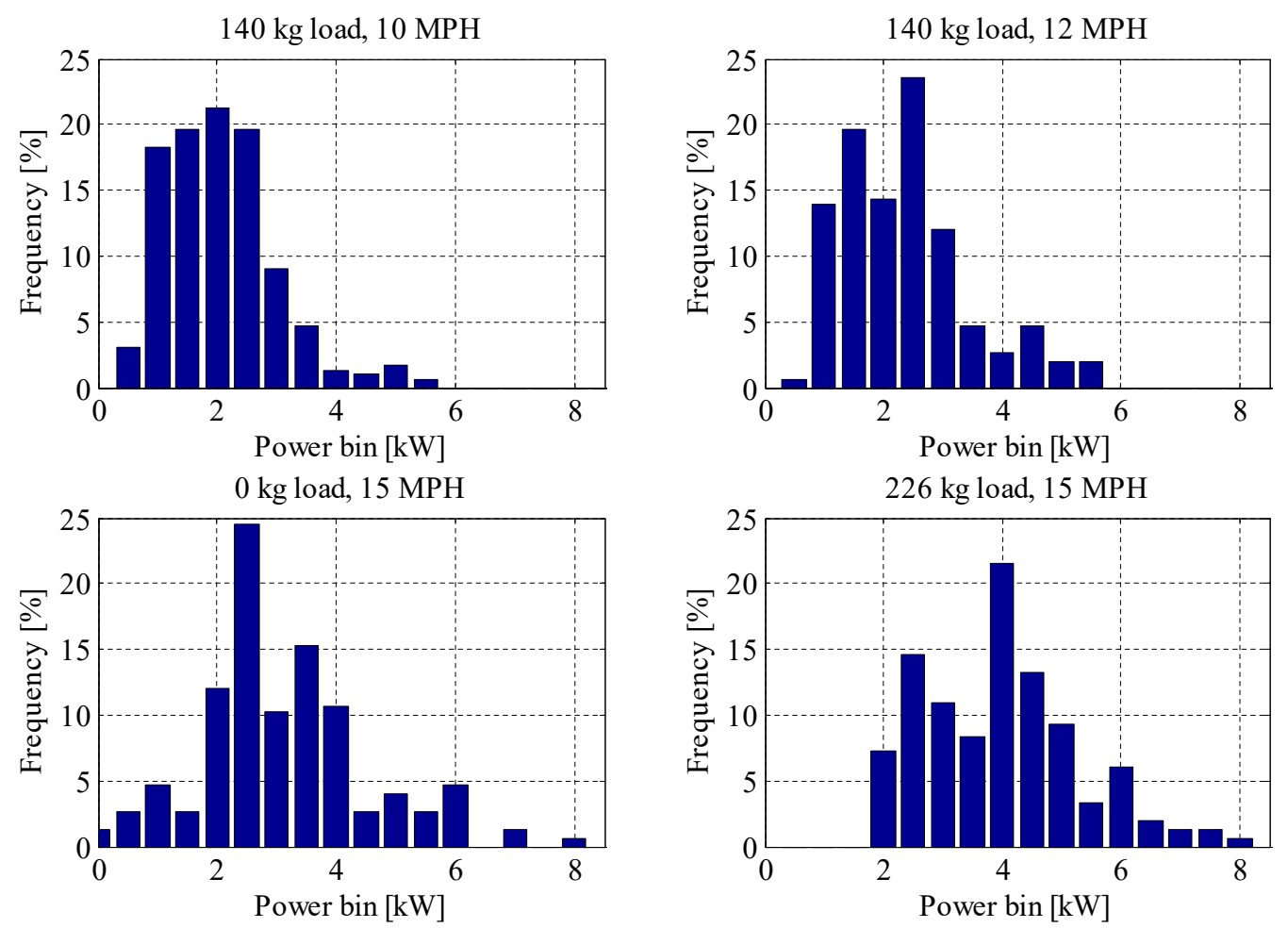

Figure 3.5: The distribution of power demand of the various drive conditions over 5 minute durations.

\subsubsection{Equivalent Circuit Model}

The dynamic battery model has four parameters: open circuit voltage (OCV), series resistance, concentration resistance, and plate capacitance, as shown in Fig. 3.6. The open circuit voltage represents the voltage across the battery terminals under a no load condition. The OCV of a battery varies with battery state-of-charge (SOC), and can only be measured after many hours of rest due to a voltage hysteresis effect [5]. The series resistance, $R_{\text {series }}$, or internal resistance, of the battery represents the Thevenin equivalent model of the battery source, and is a function of battery state-of-charge. The concentration resistance, $R_{s t}$, and plate capacitance, $C_{s t}$, model the dynamic voltage hysteresis behavior of the cells. The resistor and capacitor values of the model are empirically determined over many charge/discharge tests [6-8].

The drive-cycle current is fed into a variable current source, and the voltage dynamics of the R-C circuit model dictate the battery terminal voltages seen at the current source. The OCV of the cell is a function of SOC, and the OCV-SOC relationship is proprietary information provided by Brammo, Inc. 


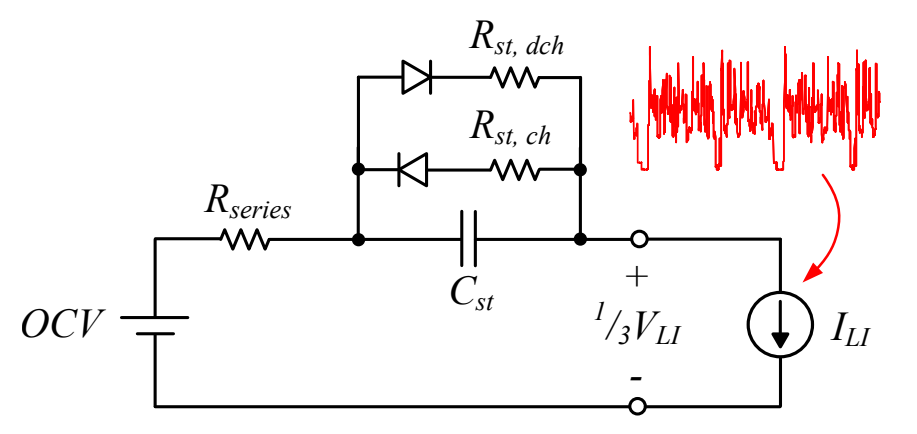

Figure 3.6: Lithium battery module circuit model.

\begin{tabular}{ccc} 
Table 3.1: LI Circuit & Model Paramet \\
\cline { 2 - 3 } Parameter & Value & Unit \\
\hline \hline$R_{\text {series }}$ & 1.07 & $\mathrm{~m} \Omega$ \\
$R_{s t, d c h}$ & 0.63 & $\mathrm{~m} \Omega$ \\
$R_{s t, c h}$ & 0.82 & $\mathrm{~m} \Omega$ \\
$C_{s t}$ & 65 & $\mathrm{~F}$ \\
\hline
\end{tabular}

\subsubsection{State-of-Charge Estimation}

Battery SOC is estimated 1) from open circuit voltage (OCV) as an initial condition, and 2) by using the Coulomb counting method,

$$
S O C_{L I}(t)=S O C_{L I}(0)-\frac{\chi_{\text {batt }}}{Q_{\text {batt }}} \int I_{L I}(t) d t,
$$

where $\chi_{\text {batt }}$ is a tuneable empirical constant, $Q_{\text {batt }}$ is the available battery capacity, and $I_{\text {batt }}(t)$ represents the battery current. The equation can be discretized to

$$
S O C_{L I}(k)=100 \cdot \frac{Q_{t o t}(k)-Q_{b a t t}(k) \cdot \chi_{b a t t}}{Q_{t o t}(k)},
$$

such that $Q_{b a t t}(\mathrm{k})$ is the discrete integral of battery current. The term $Q_{t o t}(\mathrm{k})$ represents the total usable battery capacity.

The Coulomb counting method is simple to implement, but susceptible to drift over large periods of time. Two sources of error leading to Coulomb counting inaccuracy are initial SOC determination, and measurement inaccuracies associated with battery current and timing. More robust and computationally expensive SOC estimation methods include the use of Extended Kalman Filters (EKFs) that require solving the partial differ- 
ential equations of a circuit-based battery model [6-8]. Implementation of such methods are outside the scope of this work.

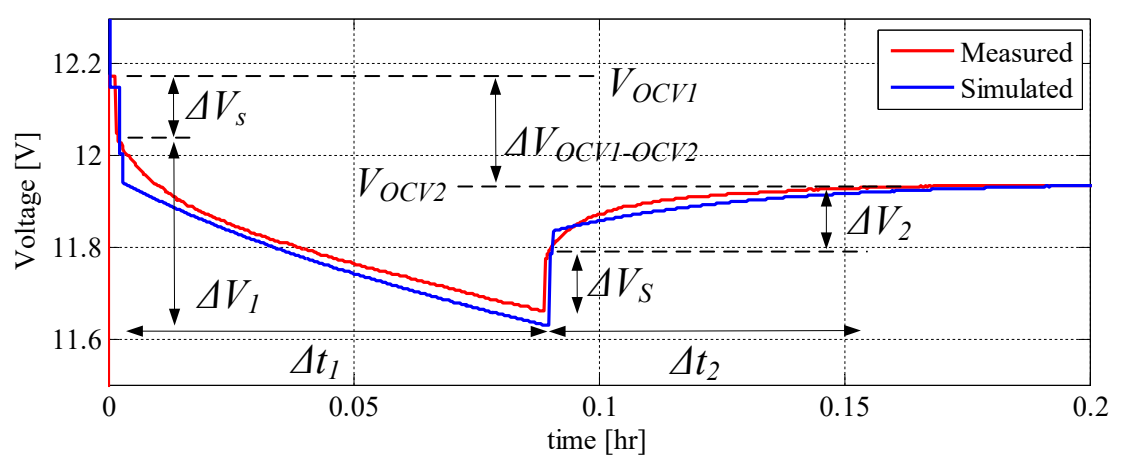

(a)

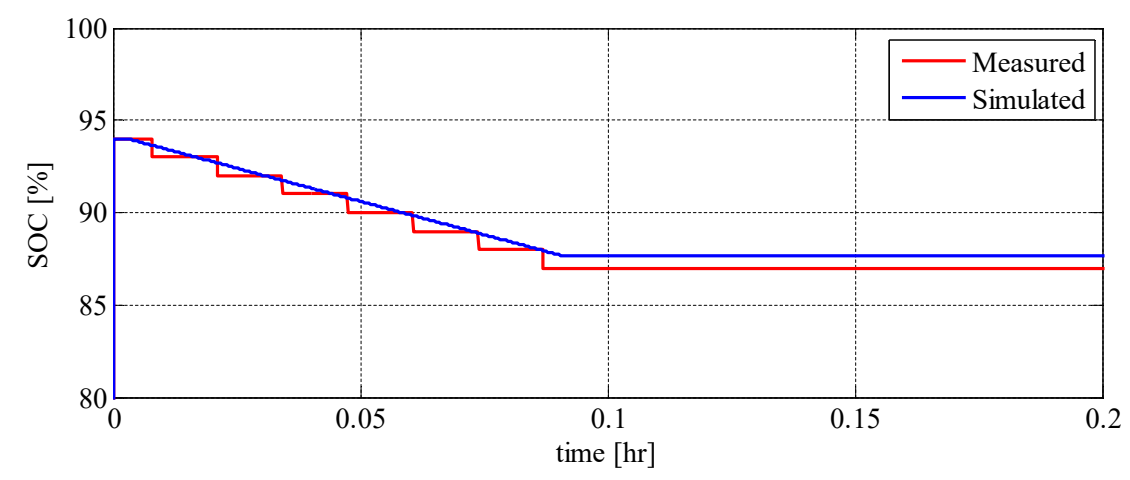

(b)

Figure 3.7: Measured and simulated lithium battery (a) voltage and (b) SOC during a pulsed load current of $65 \mathrm{~A}$.

\subsubsection{Stand-alone LI Module Testing and Validation}

The LI module is charged and discharged under constant and variable current conditions to extract parameters for the dynamic circuit and SOC model. The values of the R-C equivalent battery circuit model represents nine parallel LI cells and are extracted from the measured voltage behavior given controlled current pulses to the battery, as shown in Fig. 3.7(a) for a 5 minute constant current pulse of $65 \mathrm{~A}$. The series resistance $R_{\text {series }}$ can be found by measuring the immediate drop in battery voltage, $\Delta V_{s}$, and using Ohm's law given the current pulse. The values $\Delta V_{1,2}$ and $\Delta t_{1,2}$ are used to determine the discharge and charge hysteresis values of $R_{s t, d c h, c h}$ and $C_{s t}$, respectively [6, 7]. The extracted R-C values of the LI module equivalent circuit model are detailed in Table 3.1.

The measured and modeled battery voltage and SOC waveforms are shown in Fig. 3.7. For the constant current pulse of $65 \mathrm{~A}$, the modeled battery voltage tracks the simulated 


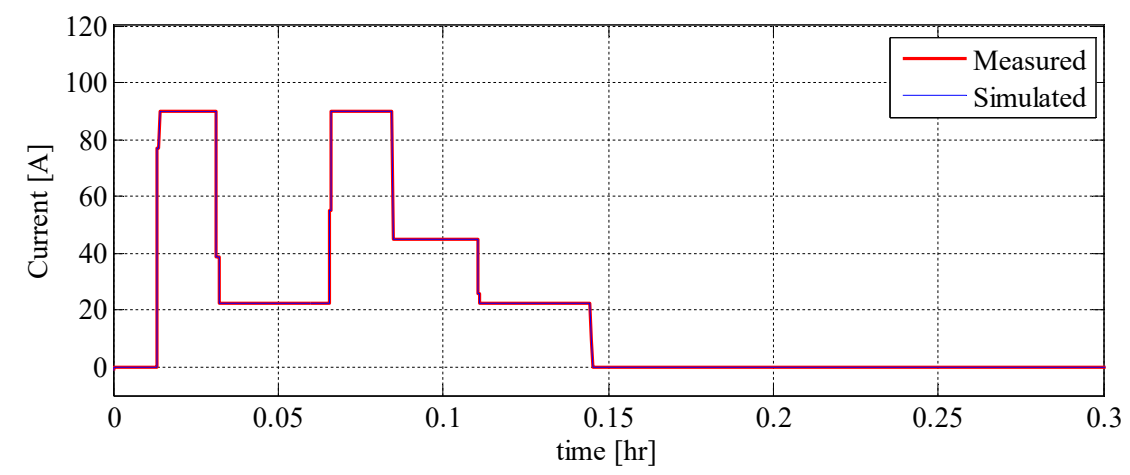

(a)

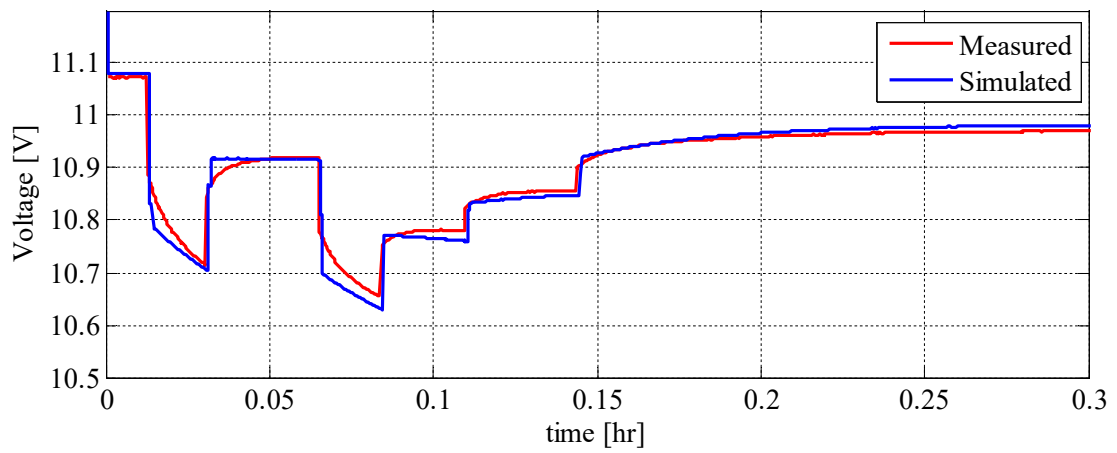

(b)

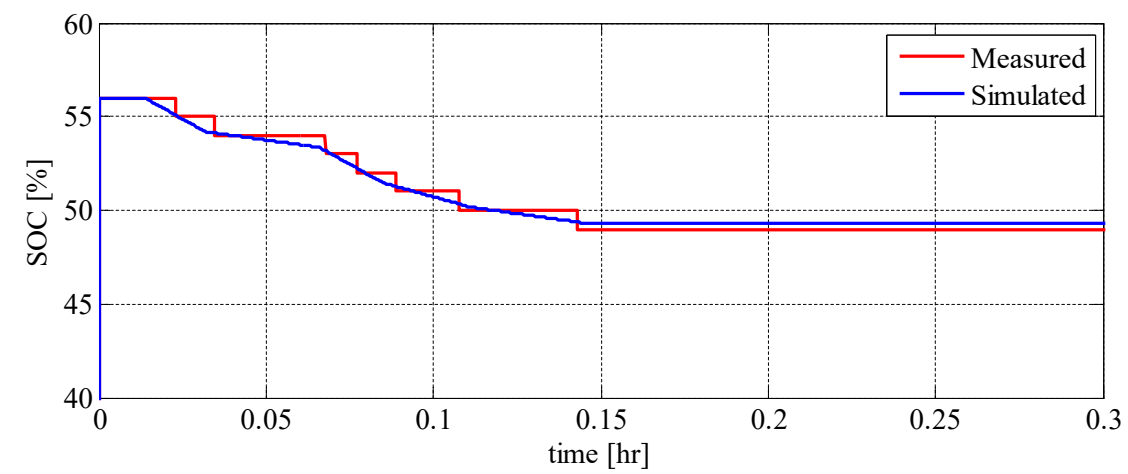

(c)

Figure 3.8: Measured and simulated lithium battery (a) current, (b) voltage and (c) SOC during varying current pulses.

voltage within $200 \mathrm{mV}$, and the estimated SOC tracks the reported SOC within 1\%. The battery model maintains accuracy when varying load currents are applied, as shown in Fig. 3.8.

The battery model is validated with the measured drive-cycle data for battery voltage and SOC. For the near-constant $15 \mathrm{MPH}$ drive-cycle on dry asphalt, the modeled bus voltage and battery SOC tracks the measured values within $1 \mathrm{~V}$, and within $1 \%$, respectively, as shown in Fig. 3.9. The modeled voltage remains within $\pm 400 \mathrm{mV}$ of the 


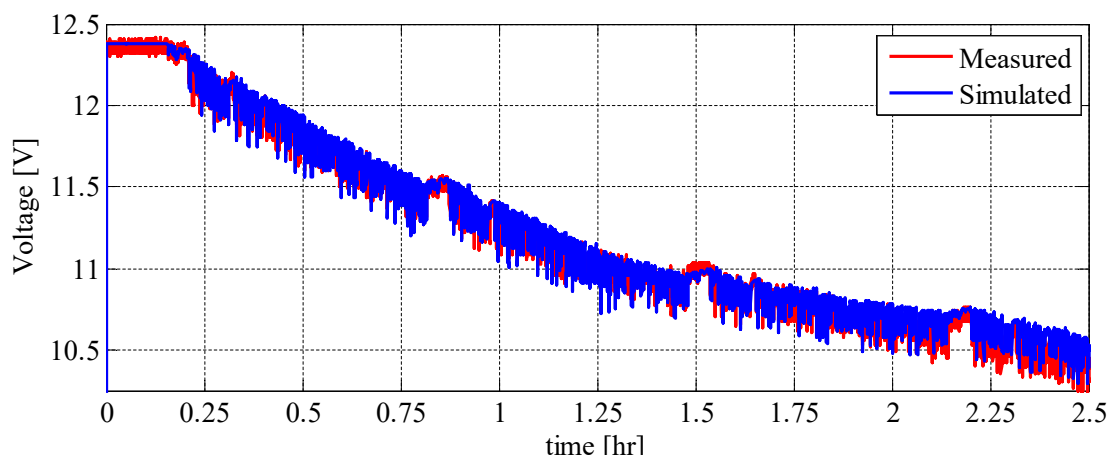

(a)

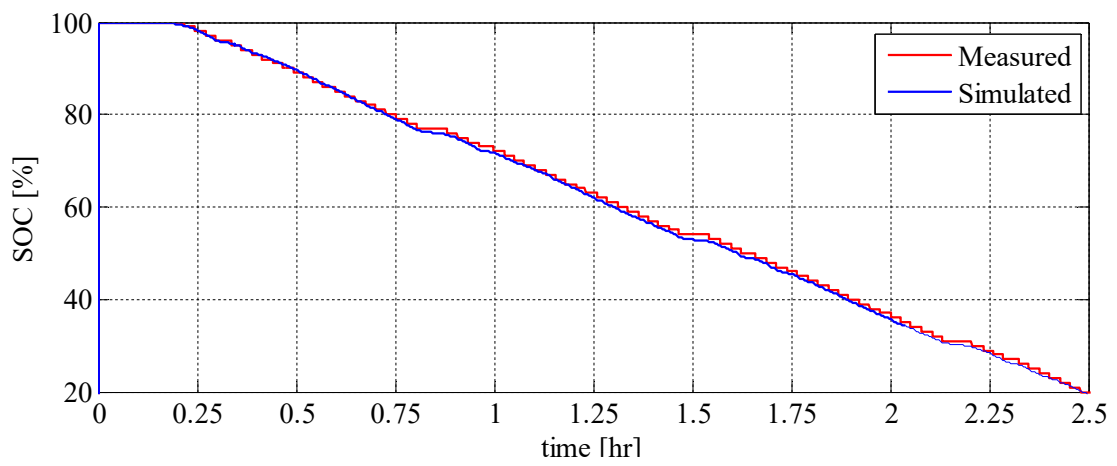

(b)

Figure 3.9: Measured and simulated lithium battery (a) voltage and (b) estimated SOC for the equivalent current of a $15 \mathrm{MPH}$ drive-cycle on flat asphalt.

measured voltage, with an average deviation of $-70 \mathrm{mV}$ for the simulation time.

\subsubsection{Lead-Acid Model}

The lead-acid battery is similarly modeled with a Thevenin equivalent circuit model $[9,10]$. In addition to the series resistance and capacitances, a parallel resistor, $R_{p}$ and capacitor, $C_{p}$, are used in the lead-acid battery circuit model to more accurately model the slower voltage hysteresis of the PbA, as shown in Fig. 3.10(a). The values of the R-C equivalent circuit are found empirically and by tuning the circuit model, and are detailed in Table 3.2. The series resistance $R_{\text {series }}$ is found to vary with load current and SOC, and has a range between $10 \mathrm{~m} \Omega$ and $25 \mathrm{~m} \Omega$. The linear SOC-OCV relationship is found experimentally and by tuning the circuit model, and is shown in Fig. 3.10(b).

\subsubsection{PbA State-of-Charge Estimation}

The capacity of the lead-acid battery varies widely depending on C-rates, a phenomenon known as the Peukert effect [11]. The Peukert effect describes the negative relationship 


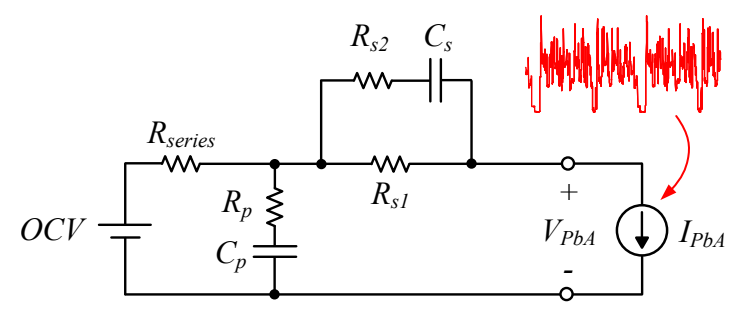

(a)

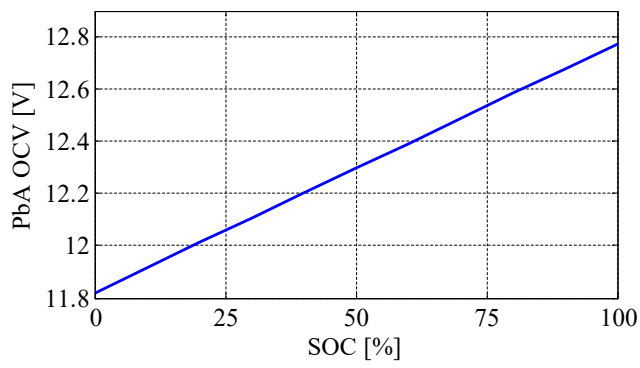

(b)

Figure 3.10: Lead-acid battery module (a) equivalent circuit model and (b) SOC-OCV linear relationship.

Table_3.2: PbA Circuit Model Parameters

\begin{tabular}{lcc}
\hline Parameter & Value & Unit \\
\hline \hline$R_{\text {series }}$ & $10-25$ & $\mathrm{~m} \Omega$ \\
$R_{s 1}$ & 3.52 & $\mathrm{~m} \Omega$ \\
$R_{s 2}$ & 1.85 & $\mathrm{~m} \Omega$ \\
$C_{s}$ & 1 & $\mathrm{~F}$ \\
$R_{p}$ & 19.5 & $\mathrm{~m} \Omega$ \\
$C_{p}$ & 1 & $\mathrm{~F}$ \\
\hline
\end{tabular}

between discharge current and usable capacity in a battery. The phenomenon of diminished capacity as a function of discharge current exists in every battery chemistry, but is most pronounced in the lead-acid battery. As a result, $\mathrm{PbA}$ manufacturers typically specify capacity of deep-cycle lead-acid batteries in hourly rates instead of C-rates. An hour rate quantifies the total available capacity of the $\mathrm{PbA}$ if discharged at a constant current for the specified number of hours. For example, the 1-hr rate of the chosen $\mathrm{PbA}$ module is $92 \mathrm{Ah}$, the 5 -hr rate is $122 \mathrm{Ah}$, and the 20-hr rate is $155 \mathrm{Ah}$. This varying capacity dictates that to determine the SOC for a lead-acid battery, the total available capacity, the value in the denominator of (3.2), must change as a function of time and discharge current. For a lead-acid battery, 3.2 becomes

$$
S O C_{P b A}(k)=100 \cdot \frac{Q_{\text {usable }}(k)-Q_{\text {utilized }}(k) \cdot \eta_{\text {batt }}}{Q_{\text {usable }}(k)},
$$


such that

$$
Q_{\text {usable }}(k)=Q_{\text {max }}-\sum_{k=1}^{\infty} Q_{\text {wasted }}(k) .
$$

In (3.3) and (3.4), $Q_{\text {usable }}$ replaces $Q_{t o t}, Q_{\max }$ is the maximum available capacity given in the battery datasheet, and $Q_{\text {wasted }}(\mathrm{k})$ represents the cumulative wasted charge over time due to the Peukert effect curve, as depicted in Fig. 3.11 [12]. The waste function, given by

$$
Q_{\text {waste }}(k)=\left(20.77 \cdot \ln \left(I_{P b A}(k)\right)-16.79\right) \cdot t_{m} \cdot C_{\text {rate }}(k),
$$

is found through curve fitting the data given in the manufacturer data-sheet, where $t_{m}$ is a sample time. This relationship quantifies the loss of capacity with increasing $I_{P b A}$.

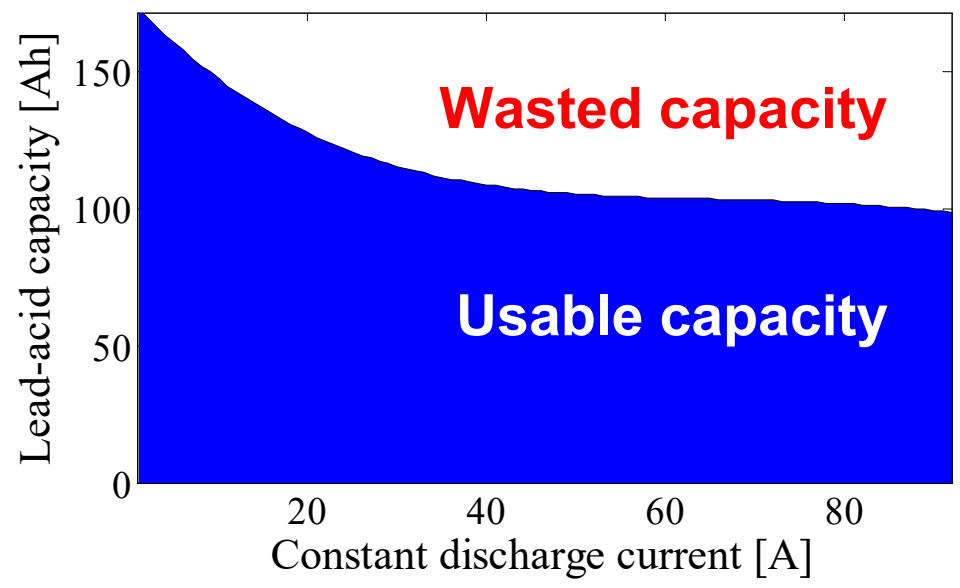

Figure 3.11: Lead-acid battery capacity versus discharge current due to the Peukert effect [12].

\subsubsection{Stand-alone PbA Module Testing and Validation}

Careful attention must also be taken with the value of total capacity. The remaining capacity is especially difficult to estimate for a lead-acid battery because available capacity is subject to variations in temperature, aging, cyclic capacity fade, and discharge rates. Variations between cells, general wear-and-tear of battery terminals, chemical impurities, and uncontrollable environment further act to complicate the estimation [13-15]. The voltage model are validated by comparing the simulated and measured results using the 
same constant current and drive-cycle discharge conditions, as shown in Fig. 3.12. The modeled voltage remains within $\pm 500 \mathrm{mV}$ of the measured voltage, with an average deviation of $-120 \mathrm{mV}$ for the simulation time.

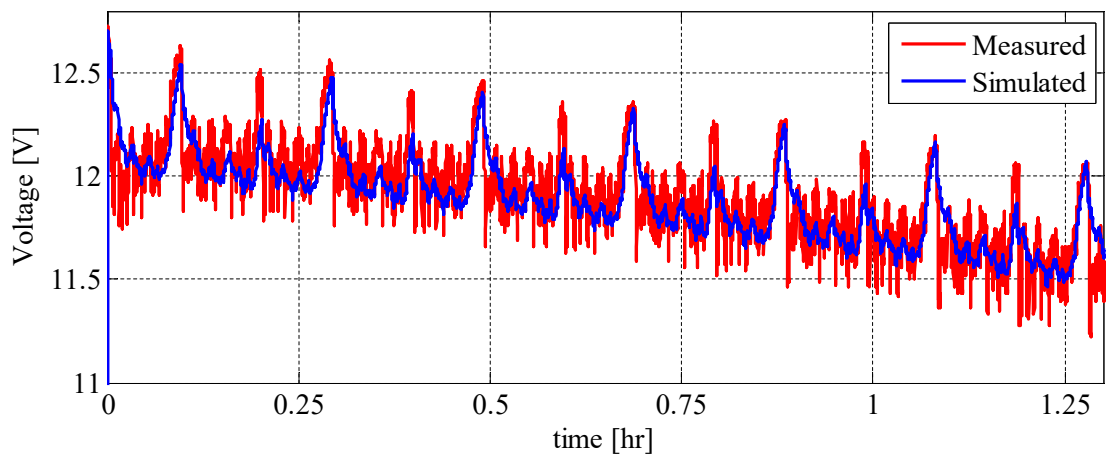

(a)

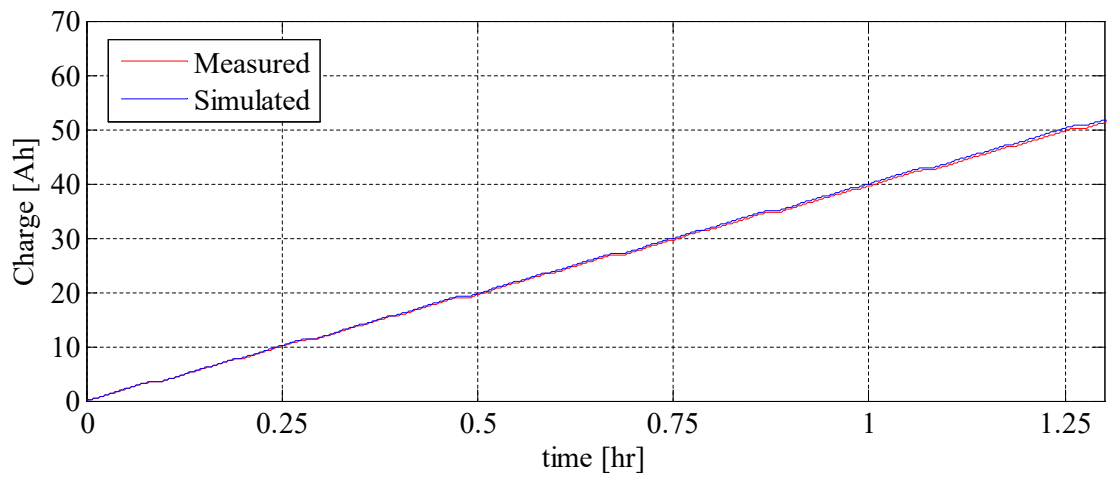

(b)

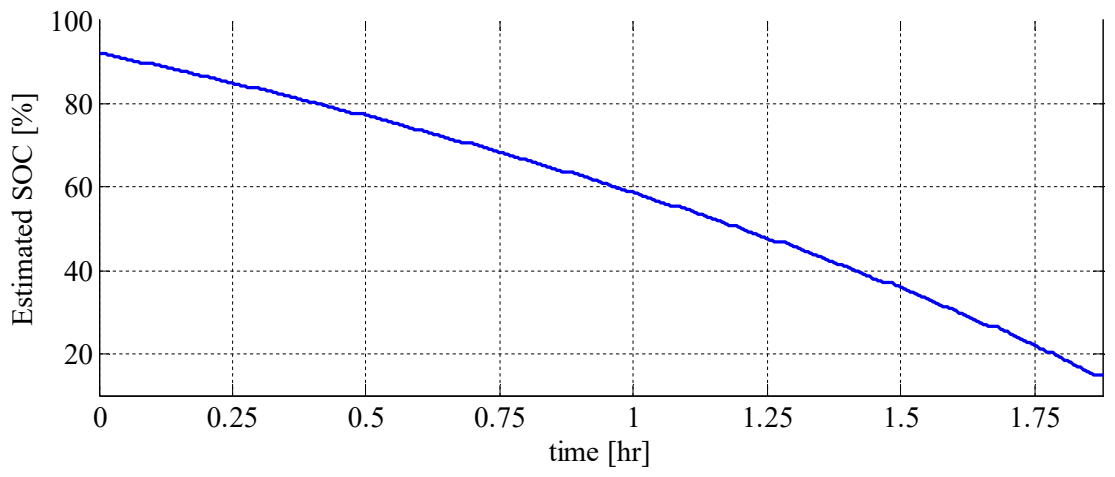

(c)

Figure 3.12: Measured and simulated lead-acid battery (a) voltage, (b) capacity, and (c) estimated SOC for the equivalent current of a $15 \mathrm{MPH}$ drive-cycle on flat asphalt.

The cumulative charge parameters $Q_{\text {utilized }}, Q_{\text {wasted }}$, and $Q_{\text {usable }}$, described in (3.3),(3.4), and (3.5) are shown in Fig. 3.12(b). To check the estimated SOC, the specific gravity of the $\mathrm{PbA}$ cells was measured using a hydrometer after each charge or discharge cycle. 
A maximum capacity $Q_{\max }=135$ Ah was used, which is roughly the nominal capacity advertised for the $\mathrm{PbA}$ module at the 10-hr rate.

\subsection{Chapter Summary and Conclusions}

In this chapter, the real vehicle loading and energy storage elements are examined in depth to develop a clearer understanding of the HESS system. The power dynamics of the test vehicle are measured under various driving conditions and the measurements help dictate the size and topology of the HESS architecture. The drive-cycle data and battery models are used in the MATLAB simulations so that the vehicle speed and range can be accurately estimated in the power-mix algorithm development. The drive-cycle data is used as stimulus to the batteries and dc-dc converter in the physical bench test-setup to experimentally verify the power-mix algorithm.

The coulomb-counting method, while not known for its accuracy, is most widely utilized SOC extraction method for its simplicity, and is sufficiently accurate on a cycleby-cycle basis. To minimize accumulated error in the experimental setup, the lead-acid module is allowed to rest for over 12 hours after charge and discharge before measuring battery terminal voltage to determine the initial and final SOC using OCV methods. These practices help to eliminate long term drift-related errors in SOC estimation. 


\section{References}

[1] EPA, "Dynamometer drive cycles," 2016. [Online]. Available: https://www.epa.gov/ vehicle-and-fuel-emissions-testing/dynamometer-drive-schedules

[2] "International test cycles for emissions and fuel economy," 2016. [Online]. Available: http://www.unep.org/transport/gfei/autotool/approaches/information/ test_cycles.asp

[3] C. Vagg, S. Akehurst, C. J. Brace, and L. Ash, "Stochastic dynamic programming in the real-world control of hybrid electric vehicles," IEEE Transactions on Control Systems Technology, vol. 24, no. 3, pp. 853-866, May 2016.

[4] R. Wang and S. M. Lukic, "Review of driving conditions prediction and driving style recognition based control algorithms for hybrid electric vehicles," in 2011 IEEE Vehicle Power and Propulsion Conference, Sept 2011, pp. 1-7.

[5] O. Tremblay, L.-A. Dessaint, and A.-I. Dekkiche, "A generic battery model for the dynamic simulation of hybrid electric vehicles," in Vehicle Power and Propulsion Conference, 200\%. VPPC 200\%. IEEE, Sept 2007, pp. 284-289.

[6] N. Watrin, R. Roche, H. Ostermann, B. Blunier, and A. Miraoui, "Multiphysical lithium-based battery model for use in state-of-charge determination," Vehicular Technology, IEEE Transactions on, vol. 61, no. 8, pp. 3420-3429, Oct 2012.

[7] R. Yamin and A. Rachid, "Modeling and simulation of a lead-acid battery packs in matlab/simulink: Parameters identification using extended kalman filter algorithm," in Computer Modelling and Simulation (UKSim), 2014 UKSim-AMSS 16th International Conference on, March 2014, pp. 363-368.

[8] R. C. Anirudh Badam, J. Dutra, A. Ferrese, S. Hodges, P. Hu, J. Meinershagen, T. Moscibroda, B. Priyantha, and E. Skiani, "Software defined batteries," in Symposium on Operating Systems Principles (SOSP'15). ACM 
Association for Computing Machinery, October 2015. [Online]. Available: https: //www.microsoft.com/en-us/research/publication/software-defined-batteries/

[9] N. K. Medora and A. Kusko, "An enhanced dynamic battery model of lead-acid batteries using manufacturers' data," in INTELEC 06 - Twenty-Eighth International Telecommunications Energy Conference, Sept 2006, pp. 1-8.

[10] C. J. Zhan, X. G. Wu, S. Kromlidis, V. K. Ramachandaramurthy, M. Barnes, N. Jenkins, and A. J. Ruddell, "Two electrical models of the lead-acid battery used in a dynamic voltage restorer," IEE Proceedings - Generation, Transmission and Distribution, vol. 150, no. 2, pp. 175-182, March 2003.

[11] S. S. D. Doerffel, "A critical review of using the peukert equation for determining the remaining capacity of lead-acid and lithium-ion batteries," Journal of Power Sources, vol. 155, no. 2, pp. 395 - 400, 2006. [Online]. Available: http://www.sciencedirect.com/science/article/pii/S0378775305007093

[12] U. Battery, "Us battery product datasheet," 2013. [Online]. Available: \$http://usbattery.com/wp-content/uploads/2015/01/usb\_12V\_data \ _sheet \_2015\_web.pdf\$

[13] R. Dufo-Lpez, J. M. Lujano-Rojas, and J. L. Bernal-Agustn, "Comparison of different leadacid battery lifetime prediction models for use in simulation of standalone photovoltaic systems," Applied Energy, vol. 115, pp. 242 - 253, 2014. [Online]. Available: http://www.sciencedirect.com/science/article/pii/S0306261913009148

[14] Effects of Impurities on Lead-Acid Batteries White Paper, Trojan Battery Company, 2012. [Online]. Available: http://www.trojanbattery.com/pdf/WP EffectOfImpurities_0612.pdf

[15] Deep-Cycle Battery Storage White Paper, Trojan Battery Company, 2012. [Online]. Available: http://www.trojanbattery.com/pdf/WP_DeepCycleBatteryStorage_ 0512.pdf 


\section{Chapter 4}

\section{Converter Design}

The Intelligent Hybrid Battery Manager (IHBM) interfaces between the hybrid battery modules, as shown in Fig. 1.9. The specifications of the chosen HESS architecture are detailed in Table 2.3. Because of the overlapping range of battery voltages, a noninverting buck-boost (NIBB) topology is chosen for buck and boost capability, as well as bi-directional power transfer between the two battery chemistries, as shown in Fig. $4.1[1]$.

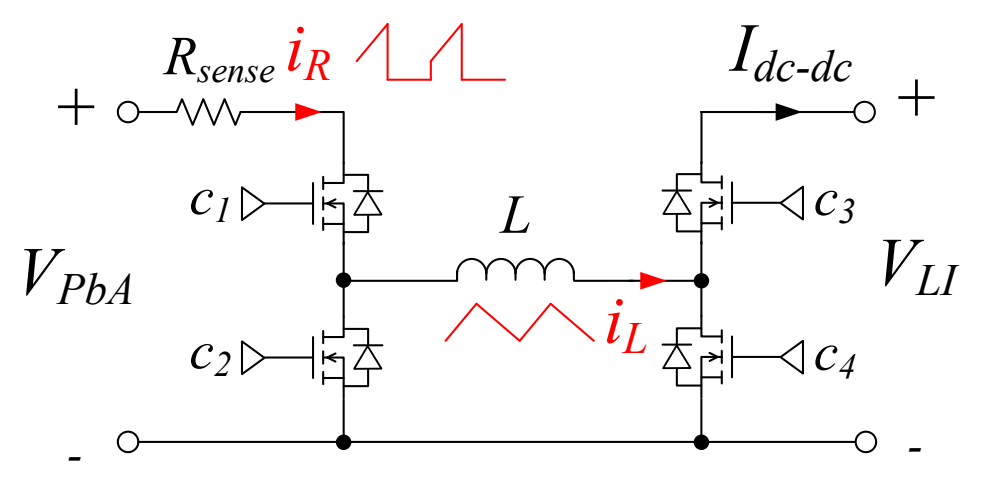

Figure 4.1: A non-inverting buck-boost converter.

\subsection{Converter Sizing}

Given the drive-cycle data collected, the HESS vehicle is expected to draw an average of $53 \mathrm{~A}$ for the near-constant $15 \mathrm{MPH}$ drive-cycle with no additional payload. For the $226 \mathrm{~kg}$ loaded condition, the HESS vehicle is expected to draw an average of $59 \mathrm{~A}$. The unloaded drive-cycle defines the average power rating of the HESS, and the loaded drive-

cycle defines the peak power rating of the HESS. Some overhead is added to the peak current rating for a conservative estimate. 
Table 4.1: dc-dc Converter Specifications.

\begin{tabular}{lcc}
\hline Parameter & Value & Unit \\
\hline \hline Input voltage, $\left(V_{P b A}\right)$ & $11-12.8$ & $\mathrm{~V}$ \\
Output voltage, $\left(V_{L I}\right)$ & $10-12.45$ & $\mathrm{~V}$ \\
Current range, $\left(I_{d c-d c}\right)$ & $0-36$ & $\mathrm{~A}$ \\
Average power & 270 & $\mathrm{~W}$ \\
Peak power & 360 & $\mathrm{~W}$ \\
Switching Frequency range $\left(f_{s w}\right)$ & $500-600$ & $\mathrm{kHz}$ \\
\hline
\end{tabular}

Because the two batteries have similar energy and capacity, it can be assumed that each battery contributes roughly equal energy. This suggests that $I_{L I} \approx I_{d c-d c}$, and the average current rating of the dc-dc is $27 \mathrm{~A}$ for a nominal power rating of $270 \mathrm{~W}$, and the peak current rating, with some overhead, is $36 \mathrm{~A}$ for a peak power rating of $360 \mathrm{~W}$. The dc-dc converter specifications are detailed in Table 4.1. The power-mix algorithm, described in Chapter 5, ultimately decides how much power is processed in the dc-dc converter.

A multi-phase, dc-dc converter approach is chosen to spread the converter hot-spots and to flatten the efficiency curve over the load range. The three, $120 \mathrm{~W}$, parallel subconverters can be enabled depending on load, commonly referred to as phase-shedding $[2,3]$. The multi-phase approach also allows for the use of components with smaller current and power rating, though higher circuit complexity is required.

\subsection{Peak Current-mode Control}

In peak current-mode-control (PCMC), the inductor current, $i_{L}$, is detected by sensing voltage across the high-side sense resistor, $R_{\text {sense }}$. The current across $R_{\text {sense }}, i_{R}$, tracks $i_{L}$ for the period when $c_{1}$ and $c_{4}$ conduct, as shown in Fig. 4.1. When $i_{L}$ reaches its peak at the reference current, $I_{r e f}$, the comparator triggers, resets an SR flip-flop, and turns off MOSFET switches $c_{1}$ and $c_{4}$. The gating switches $c_{2}$ and $c_{3}$ then conduct for an off-time, $t_{\text {off }}$, which can be controlled with a variety of methods.

The average inductor current, $I_{L, a v g}$, and lead-acid battery current, $I_{P b A}$, are related to the reference current by

$$
\begin{aligned}
& I_{\text {peak }}=I_{\text {ref }}=I_{L, \text { avg }}+\frac{\Delta i_{L}}{2}, \\
& I_{P b A}=D \cdot I_{L, \text { avg }} .
\end{aligned}
$$


The NIBB inductor current slopes are governed by

$$
\begin{aligned}
& m_{1}=\frac{V_{P b A}}{L}, \text { and } \\
& m_{2}=\frac{-V_{L I}}{L} .
\end{aligned}
$$

The roughly $50 \%$ converter duty ratio, $D$, dictates that the $I_{L, \text { avg }}$ must be nearly twice that of $I_{P b A}$.

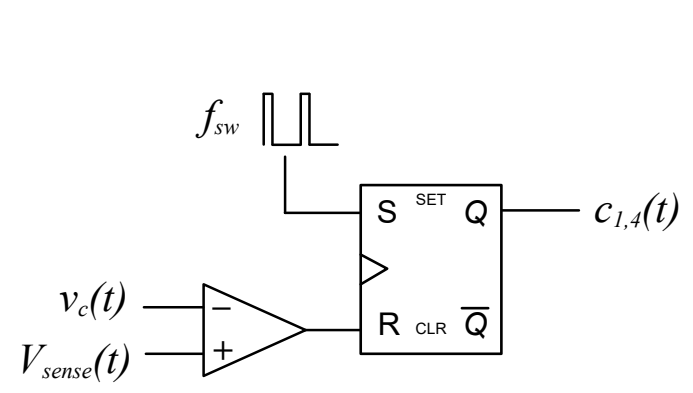

(a)

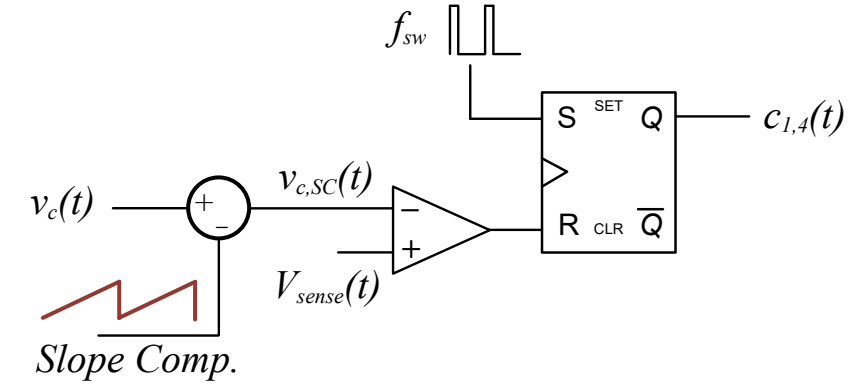

(b)

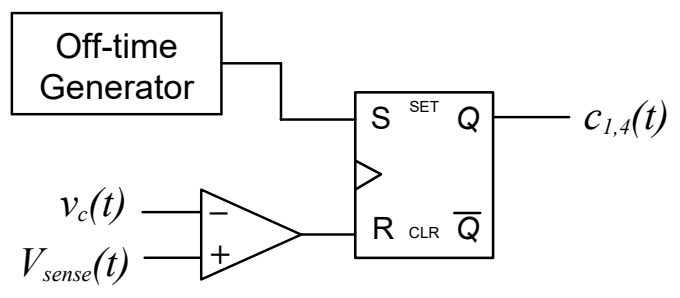

(c)

Figure 4.2: The circuit diagram of (a) traditional PCMC, (b) PCMC with slope compensation, and (b) PCMC with off-time control.

\subsubsection{Digital Off-time Control}

Traditional peak current mode operation uses a fixed frequency clock to set the SR flipflop, as shown in Fig. 4.2(a), but this method is unstable for $D>50 \%$, as depicted in Fig. 4.3(a). In this condition, the inductor current is not given enough time to fall to the level necessary for steady-state operation. The fixed switching period approach is also intolerant to transients in the current reference, as shown in Fig. 4.3(d). The aforementioned instability can be remedied with the slope compensation (SC) method, which introduces an artificial ramp of slope $-m_{A}$ to the current reference signal to restore stability to the current loop, as shown in Fig. 4.2(b) [4]. The dotted artificial ramp limits the inductor current peak to a value lower than $I_{r e f}$ and makes accurate average inductor 


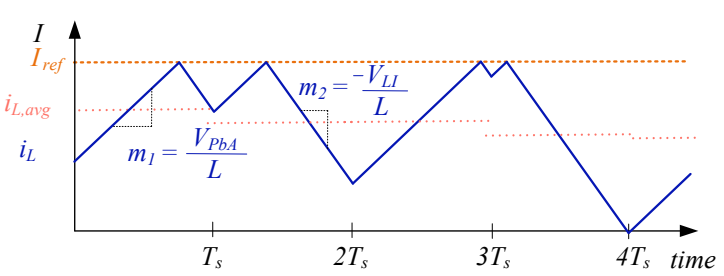

(a)

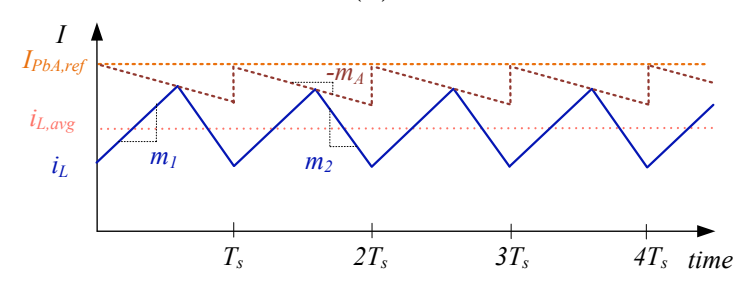

(b)

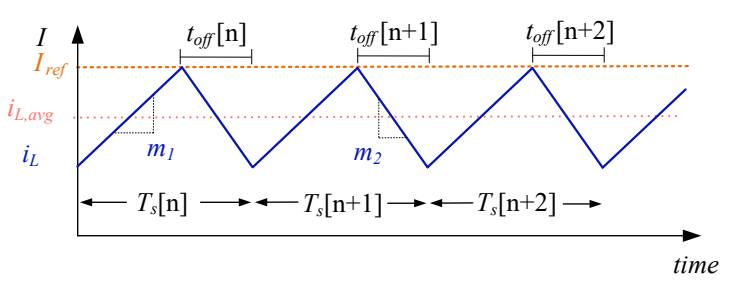

(c)

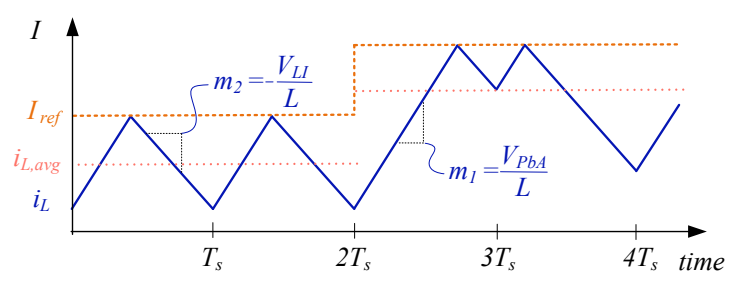

(d)

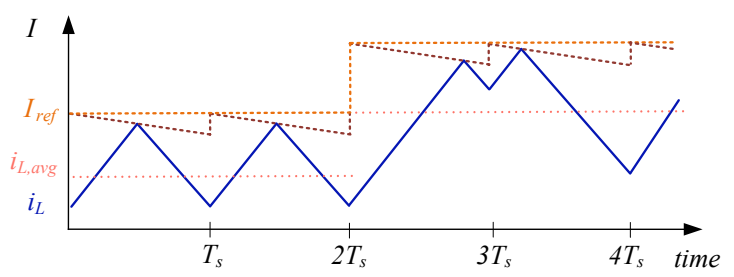

(e)

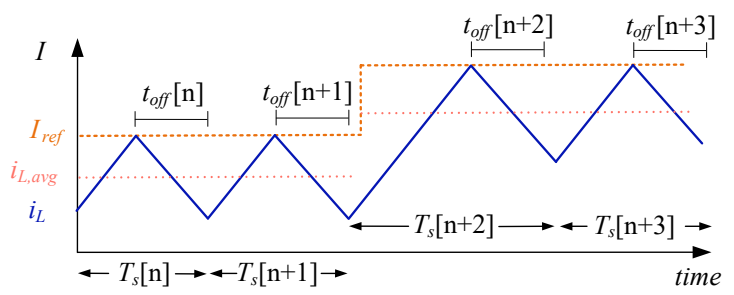

(f)

Figure 4.3: Steady-state operation of (a) traditional PCMC with $D>0.5$, (b) the SC method, and (c) the OTG method, and a transient reference current step using (d) traditional PCMC, (e) the SC method, and (f) the OTG.

current, $I_{L, a v g}$, estimation difficult, which is critical accurate battery SOC estimation, as shown in Fig. 4.3(b). Slope compensation is also highly complex to implement in the digital domain, and degrades dynamics and line regulation.

An off-time generator, (OTG), is an attractive alternative, where converter off-time, $t_{o f f}$, is adjusted on a cycle-by-cycle basis to avoid inductor current instability, as shown in Fig. 4.3(c). The circuit implementation of the OTG is shown in Fig. 4.2(c). The value of $D$ is dependent on battery voltages such that

$$
D=\frac{V_{L I}}{V_{L I}+V_{P b A}}
$$

$t_{o f f}$ is related to $I_{P b A}$ and duty ratio by

$$
\begin{aligned}
t_{o f f} & =D^{\prime} \cdot T_{S}=\frac{T_{S}}{M+1}-t_{d e a d, 1}-t_{d e a d, 2}, \text { and } \\
I_{r e f} & =\frac{I_{P b A} \cdot(M+1)}{M}+\frac{V_{L I} \cdot t_{o f f}}{2 L}
\end{aligned}
$$


Table 4.2: Dc-dc converter components [8, 9].

\begin{tabular}{cccl}
\hline Component & Manufacturer & Part Number & Parameters \\
\hline \hline MOSFETs & Infineon & BSC009NE2LS5 & $V_{D}=25 \mathrm{~V}, R_{o n} 1.05 \mathrm{~m} \Omega, Q_{G}$ \\
& & & $=28 \mathrm{nC}$ \\
Inductor & Coilcraft & SER1412-501ME & $L=500 \mathrm{nH}, D C R=1.5$ \\
& & & $\mathrm{~m} \Omega, I_{S A T}=50 \mathrm{~A}$ \\
\hline
\end{tabular}

The OTG method also has superior step current reference behavior compared to traditional PCMC and the SC methods [5-7]. For the traditional and SC methods, a step in $I_{r e f}$ leads to subharmonic oscillations, as shown in Fig. 4.3(d) and Fig. 4.3(e), respectively. The variable switching frequency nature of the off-time controlled converter makes the switching operation resilient to steps in $I_{r e f}$, as shown in Fig. 4.3(f). The OTG, leading edge blanking and adapted dead-time control are implemented in the FPGA controller with 5 ns resolution timing.

\subsubsection{Component Selection and Loss Analysis}

An inductor of $500 \mathrm{nH}, 1.5 \mathrm{~m} \Omega \mathrm{DCR}$, and 50 A saturation current with a Ferrite core is chosen for its low DCR, high saturation current and relatively small footprint [8]. The high saturation current sets a high peak current ceiling for the reference current. The converter is designed with $25 \mathrm{~V}, 1.05 \mathrm{~m} \Omega$ MOSFETs with a $R_{o n} Q_{\text {gate }}$ figure-of-merit (FOM) of $29.4 \mathrm{~m} \Omega \cdot \mathrm{nC}$ for low conduction and switching losses [9]. The MOSFET and inductor component parameters are detailed in Table 4.2. The total dc-dc converter loss is the sum of MOSFET and inductor losses and can be approximated by

$$
P_{\text {tot }}=P_{M, c o n d}+P_{M, s w}+P_{L, c o n d}+P_{L, a c}+P_{L, c o r e}+P_{m i s c}
$$

where filter capacitor losses, resistive losses in the PCB, interconnects and busbars make up $P_{\text {misc }}$. Losses in the PCB and interconnects can be approximated by calculating the sheet resistance of copper in the PCB, interconnects, and busbars. The loss equations are detailed in Table 4.3 [4].

The ac and dc resistances of the inductor are calculated with the equations detailed in 4.3 and by using Power Inductor Analysis and Comparison Tool on the Coilcraft Inc. website $[10,11]$. Due to high values of $I_{L, \text { avg }}$ and high $\Delta I_{L}$, there is high DC resistance loss and high AC winding loss, respectively, in the NIBB inductor. The low battery voltages and relatively low inductances value requires high switching frequency, $f_{s w}$, to 
Table 4.3: Converter Losses

\begin{tabular}{lcl}
\hline Loss component & Symbol & Equation \\
\hline \hline MOSFET conduction & $P_{M, \text { cond }}$ & $I_{D, r m s}^{2} R_{o n}$ \\
MOSFET turn on & $P_{M, s w, o n}$ & $\frac{1}{2} I_{L, v l y} V_{L I} t_{o n} f_{s w}$ \\
MOSFET turn off & $P_{M, s w, o f f}$ & $\frac{1}{2} I_{L, p k} V_{P b A} t_{o f f} f_{s w}$ \\
MOSFET capacitive & $P_{M, s w, c a p}$ & $C_{o s s} V_{P b A}^{2} f_{s w}$ \\
Inductor conduction & $P_{L, c o n d}$ & $I_{L, r m s}^{2} R_{D C}$ \\
Inductor ac winding & $P_{L, a c}$ & $I_{L, a c}^{2} R_{A C}$ \\
Inductor core $[10]$ & $P_{L, c o r e}$ & $K_{1} f_{s w}^{x} B^{y} v_{\text {core }}$ \\
PCB, interconnect & $P_{\text {misc }}$ & $I_{r m s}^{2} \cdot \rho_{\text {Width.Thickness }}$ \\
\hline
\end{tabular}

limit ac winding loss and prevent the inductor core from saturating.

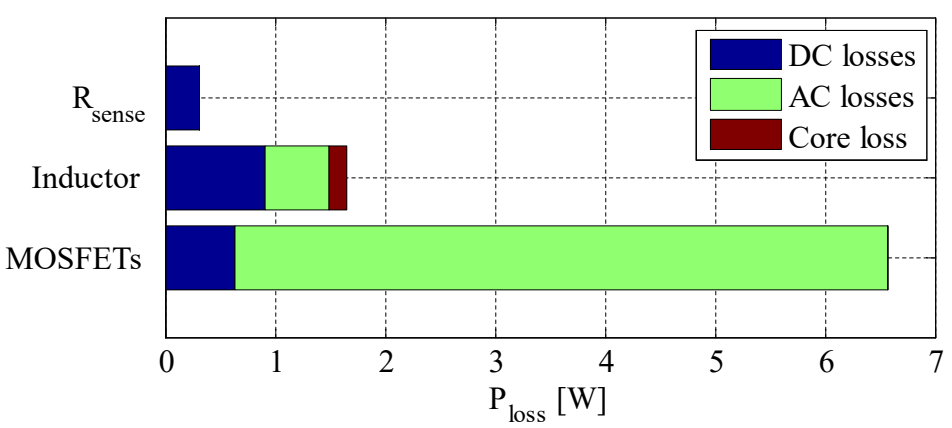

Figure 4.4: A breakdown of losses of a single sub-converter at $90 \mathrm{~W}$.

While adaptive dead time control of the MOSFET gating signals can be used, only partial soft switching can be achieved with the NIBB topology. As a result, the MOSFETs incur significant switching loss with the high $f_{s w}$ necessary to limit inductor ripple current. The loss breakdown of the four MOSFET switches, the inductor, and $R_{\text {sense }}$ are shown in Fig. 4.4. At roughly $270 \mathrm{~W}$ power with three parallel sub-converters, the efficiency can be estimated to be roughly $90.5 \%$. This efficiency is acceptable for a low-voltage, high-current application.

\subsection{Switching Frequency Control using DLL and PLL}

Balanced current sharing and even heat distribution are challenges associated with operating parallel sub-converters. Localized heating diminishes converter efficiency, while oscillating battery currents reduces current measurement accuracy, compromises the SOC 
estimation, and leads to instability. Interleaving the inductor ripple currents, as shown in Fig. 4.3, allows for tighter control of dc-dc converter currents and can address these issues.

To achieve inductor current interleaving, the switching period, $T_{s}$ of the off-time controlled converters must be regulated. Frequency synchronization between sub-converters is simpler with the traditional peak-current mode and slope compensation methods because the switching action is tied to an absolute frequency and phase. With the off-time control method, the converter has superior dynamics and current accuracy, but switching frequency regulation is a challenge.

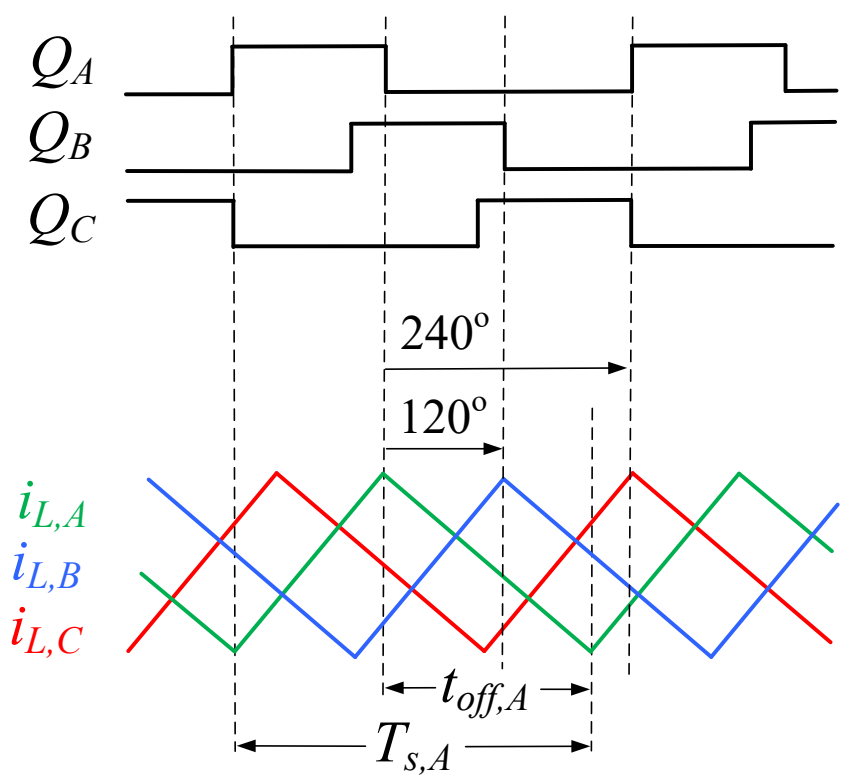

Figure 4.5: Ideal interleaving between three sub-converters.

Two frequency regulation schemes are explored, the phase-locked loop (PLL) and the delay-locked loop (DLL). PLLs have previously been demonstrated for interleaving on-time and off-time controlled current mode dc-dc converters [12, 13], and DLLs have been demonstrated for hysteretic controlled multi-phase integrated dc-dc converters and VRM applications $[14,15]$.

The PLL and the DLL methods are similar in principle. The PLL uses an absolute phase and frequency reference signal, and the DLL uses a delay line to generate a reference signal of desired switching period, $T_{s}^{\prime}$. The phase of $T_{s}^{\prime}$ is not locked to an external clock, and as such, the DLL requires only a first-order compensator, while a second order compensator is required for PLL operation. The small-signal model of the DLL and PLL are derived in [16], which concludes that the two frequency control schemes offer comparable bandwidth while the DLL offers superior robustness and smoother dynamics. 


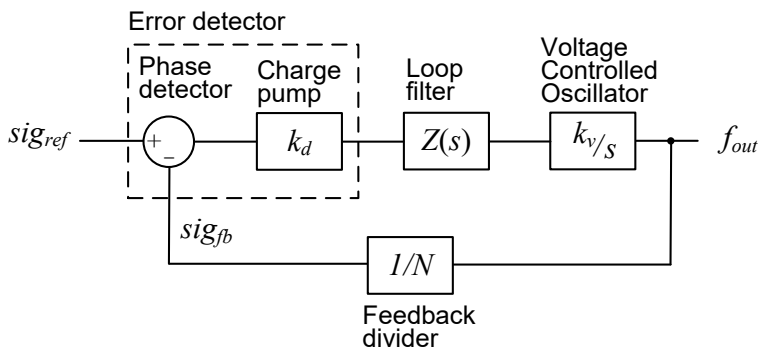

(a)

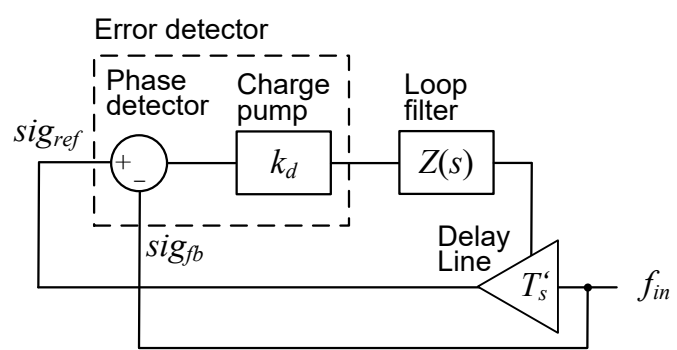

(b)

Figure 4.6: A closed-loop block diagram of (a) a phase-locked loop (PLL), and (b) a delay-locked loop (DLL).

The block diagram form of the PLL and DLL are shown in Fig. 4.6(a) and Fig. 4.6(b), respectively.

\subsubsection{Quasi-Fixed Frequency Operation with a DLL}

Fixed frequency operation is not mandatory for inductor ripple current interleaving, but it facilitates more precise interleaving. The master sub-converter uses a DLL to lock its own switching operation to a pre-defined target switching period, $T_{s}^{\prime}$. A DLL is chosen because there is no need to lock to an absolute phase reference. Compared to a PLL, this reduces circuit complexity, and also results in faster frequency locking. With a DLL, the master sub-converter can quickly frequency-lock to $T_{s}^{\prime}$ and achieve quasi-fixed frequency (QFF) operation, and the slave sub-converter PLLs have a reliable, fixed frequency phase to use as a reference signal for interleaving.

The DLL controls the master sub-converter off-time, $t_{o f f, A}$, based on the phase difference between a feedback signal, $\operatorname{sig}_{r e f, A}=T_{s, A}$, and a reference signal, sigref,A , which is $T_{s, A}$ delayed by $T_{s}^{\prime}$. The DLL loop filter adjusts $t_{o f f, A}$ up or down until $T_{s, A}$ is frequencylocked to $T_{s^{\prime}}$, at which point QFF operation is achieved. Minimum and maximum off-time values are enforced, based on the converter operating range.

\subsubsection{Multi-phase Synchronization using PLLs}

The inductor ripple current interleaving is implemented with a PLL whose reference clock is derived from delayed versions of $\operatorname{sig}_{r e f, A}$, as shown in Fig. 4.7. Two PLLs adaptively control slave sub-converter off-times, $t_{o f f, B}$ and $t_{o f f, C}$, to phase lock with the reference signals, $s i g_{r e f, B}$ and $s i g_{r e f, C}$. When three parallel sub-converters process power, the slave reference signals, sigref,B and $s i g_{r e f, C}$, are phase-shifted $120^{\circ}$ and $240^{\circ}$ with respect to 


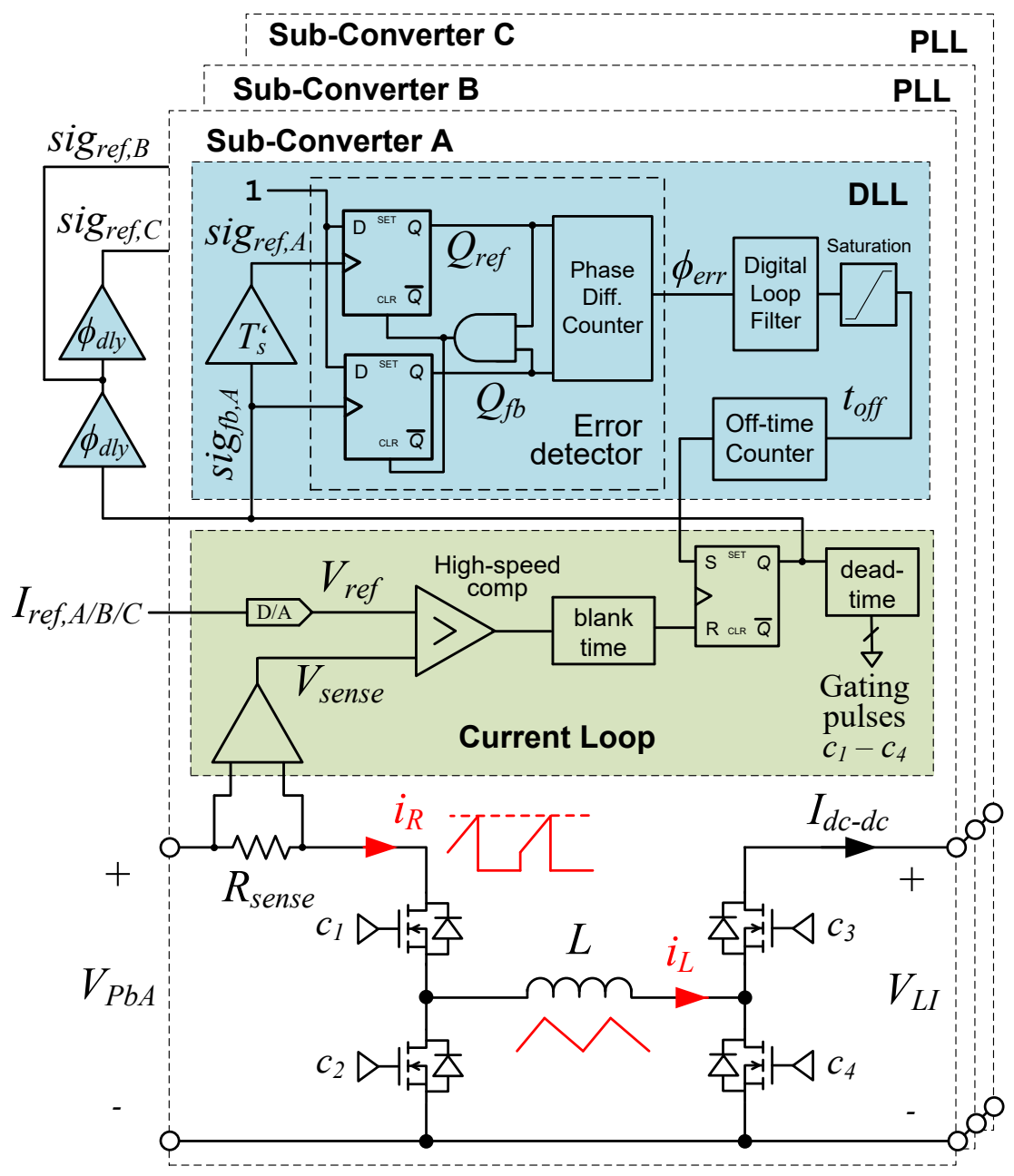

Figure 4.7: An IHBM dc-dc with a peak current mode control loop and DLL/PLL-fed off-time generator.

sig $_{r e f, A}$. During phase shedding at light loads, when only two dc-dc converters process power, the reference signal $\operatorname{sig}_{r e f, B}$ lags $\operatorname{sig}_{r e f, A}$ by $180^{\circ}$.

\subsection{Delta Converter Topology}

By adding a single transistor to the conventional NIBB topology, active balancing can be achieved for series lithium-ion modules in the battery stack. The drain of the additional transistor is connected to the adjacent, upper battery's positive terminal, and its source connects to the NIBB inductor, $L$, as shown in blue in Fig. 4.8(a). The additional transistor creates an alternate current flow path to transfer energy between unbalanced series battery modules, and allows for series battery balancing without adding additional magnetic components or control circuitry. The equalization mode operation emulates 
the next-to-next topology $[17,18]$, used for active series battery balancing, and the delta converter topology [19], used for series photovoltaic applications.

In equalization mode, the gate signals $c_{2}$ and $c_{5}$ switch at high frequency, while gate signal $c_{3}$ is held on to direct ripple current flow through the NIBB inductor, $L$. Energy flows in the direction away from the higher voltage battery and into the lower voltage battery. The simplest implementation of equalization mode involves fixing the $c_{2}$ and $c_{5}$ duty cycle, $D$, to 0.5 , and allowing the difference in battery voltage dictate the direction of current flow. The target lithium battery modules are modeled in MATLAB, and simulations with $D=0.50$ and $T_{s}=600 \mathrm{kHz}$ using a single dc-dc phase show that a $5 \%$ difference in battery state-of-charge (SOC) can be reduced to zero within 3 hours, and a $1 \%$ difference in SOC can be reduced to zero within 40 minutes. Perturbing $D$ from the nominal $50 \%$ can decrease the equalization time.

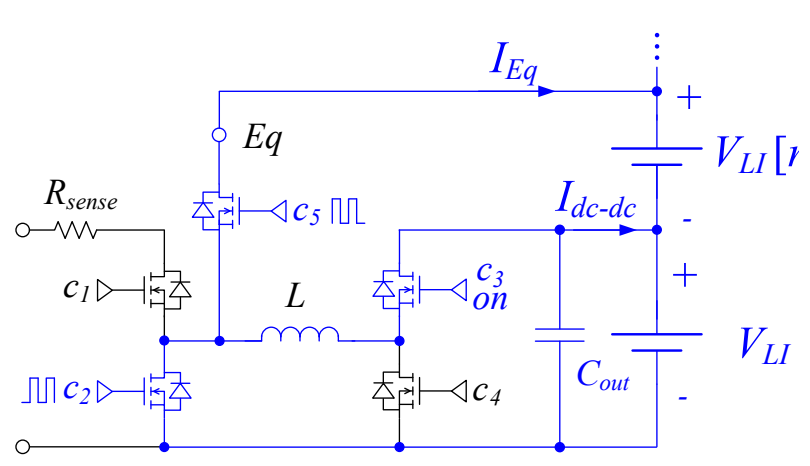

(a)

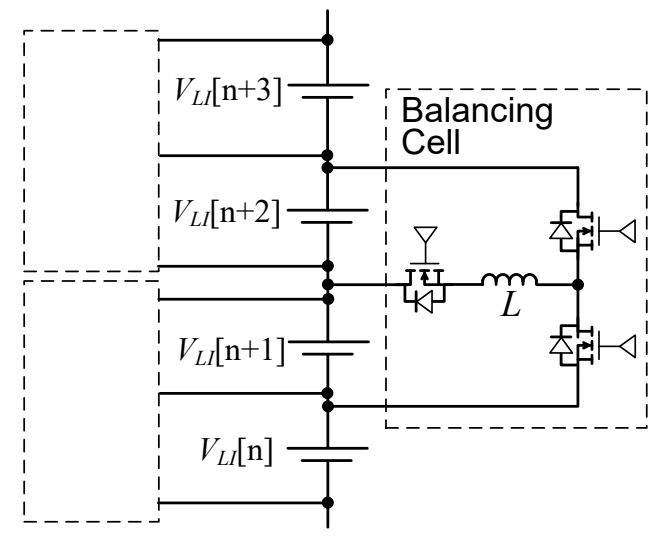

(b)

Figure 4.8: An (a) NIBB with added delta-converter connection, and (b) four series batteries with the balancing cells.

A circuit simulation of four unbalanced series capacitors is shown in Fig. 4.8(b), and the capacitor voltages are shown in and Fig. 4.9. Capacitor $[n]$ has an initial condition of $12 \mathrm{~V}$, while capacitor $[n+1],[n+2]$, and $[n+3]$ have an initial conditions of 11.5 $\mathrm{V}, 11.75 \mathrm{~V}$, and $11.8 \mathrm{~V}$, respectively. The charge from the various storage devices is shuttled around and the capacitor voltages converge to the average value of $11.75 \mathrm{~V}$ over time. Capacitors are used to limit the simulation time, and the average inductor current is extracted and used to simulate convergence time for the lithium batteries. 


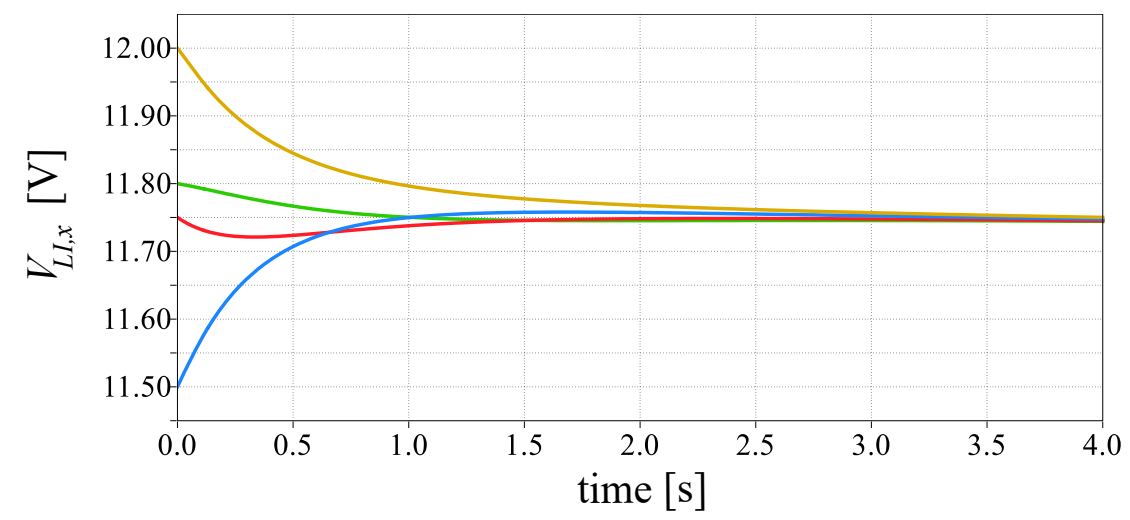

Figure 4.9: Simulations of the balancing cells on four unbalanced capacitors.

\subsection{Chapter Summary and Conclusions}

The proposed HESS architecture is designed to minimize the amount of processed power in the system, and the multi-phase dc-dc converter topology is designed to allow maximum power-flow flexibility between battery chemistries while offering the following advantages:

- improved testability with modular sub-converters,

- smaller component ratings per sub-converter,

- a flatter efficiency curve over the load range with phase-shedding, and

- reduction in localized heating by spreading the heat generation.

The less stringent thermal management requirements may also reduce overall system mass, which contributes to improving vehicle range. The aforementioned benefits come with the disadvantage of higher part-count and increased control complexity. To address synchronization of the sub-converters, a novel DLL and PLL based PCMC off-time control scheme is proposed. The fully-digital OTG and frequency control loops are realized on an FPGA controller. This scheme allows for quasi-fixed frequency (QFF) operation and inductor ripple current interleaving between sub-converters with minimal analog control circuitry, which reduces PCB area and volume.

The proposed modified NIBB topology also integrates a series battery balancing topology into the existing hardware with the addition of a single transistor switch and gatedrive circuit without the need for additional magnetics. The simulation results show that a $5 \%$ difference in battery state-of-charge (SOC) can be reduced to zero within 3 hours, and a $1 \%$ difference in SOC can be reduced to zero within 40 minutes. 


\section{References}

[1] N. Mukherjee and D. Strickland, "Analysis and comparative study of different converter modes in modular second-life hybrid battery energy storage systems," IEEE Journal of Emerging and Selected Topics in Power Electronics, vol. 4, no. 2, pp. 547-563, June 2016.

[2] A. Costabeber, P. Mattavelli, and S. Saggini, "Digital time-optimal phase shedding in multiphase buck converters," Power Electronics, IEEE Transactions on, vol. 25, no. 9, pp. 2242-2247, Sept 2010.

[3] J.-T. Su and C.-W. Liu, "A novel phase-shedding control scheme for improved light load efficiency of multiphase interleaved dc-dc converters," Power Electronics, IEEE Transactions on, vol. 28, no. 10, pp. 4742-4752, Oct 2013.

[4] R. Erickson and D. Maksimović, Fundamentals of Power Electronics, Second Ed. Springer, 2001.

[5] M. C. Lee, X. Jing, and P. K. T. Mok, "A 14v-output adaptive-off-time boost converter with quasi-fixed-frequency in full loading range," in 2011 IEEE International Symposium of Circuits and Systems (ISCAS), May 2011, pp. 233-236.

[6] R. Fernandes and O. Trescases, "A multimode 1-mhz pfc front end with digital peak current modulation," IEEE Transactions on Power Electronics, vol. 31, no. 8, pp. 5694-5708, Aug 2016.

[7] L. Cheng, J. Ni, Z. Hong, and B. Y. Liu, "A constant off-time controlled boost converter with adaptive current sensing technique," in ESSCIRC (ESSCIRC), 2011 Proceedings of the, Sept 2011, pp. 443-446.

[8] Shielded Power Inductors - SER1400, Datasheet, Coilcraft Inc., 9 2015, rev. 2.0.

[9] OptiMOS 5 Power-MOSFET, 25V Datasheet, Infineon Technologies AG, 3 2015, rev. 2.0. 
[10] Determining Inductor Power Losses, Coilcraft Inc., 2 2009. [Online]. Available: http://www.coilcraft.com/pdfs/doc486_inductorlosses.pdf

[11] Power Inductor Analysis and Comparison Tool, Coilcraft Inc., 2 2016. [Online]. Available: http://www.coilcraft.com/apps/compare/compare_power.cfm

[12] C. Umminger and R. Flatness, "Circuits and methods for synchronizing nonconstant frequency switching regulators with a phase locked loop," Nov. 5 2002, uS Patent 6,476,589. [Online]. Available: http://www.google.com/patents/US6476589

[13] P. H. Liu, F. C. Lee, and Q. Li, "Hybrid interleaving with adaptive pll loop for adaptive on-time controlled switching converters," in 2014 IEEE Energy Conversion Congress and Exposition (ECCE), Sept 2014, pp. 4110-4117.

[14] M. K. Song, M. F. Dehghanpour, J. Sankman, and D. Ma, "A vhf-level fully integrated multi-phase switching converter using bond-wire inductors, on-chip decoupling capacitors and dll phase synchronization," in 2014 IEEE Applied Power Electronics Conference and Exposition - APEC 2014, March 2014, pp. 1422-1425.

[15] P. Li, L. Xue, P. Hazucha, T. Karnik, and R. Bashirullah, "A delay-locked loop synchronization scheme for high-frequency multiphase hysteretic dc-dc converters," IEEE Journal of Solid-State Circuits, vol. 44, no. 11, pp. 3131-3145, Nov 2009.

[16] Y. Wen and O. Trescases, "Analysis and comparison of frequency stabilization loops in self-oscillating current mode dc x2013;dc converters," IEEE Transactions on Power Electronics, vol. 28, no. 10, pp. 4753-4766, Oct 2013.

[17] T. H. Phung, A. Collet, and J.-C. Crebier, "An optimized topology for next-to-next balancing of series-connected lithium-ion cells," Power Electronics, IEEE Transactions on, vol. 29, no. 9, pp. 4603-4613, Sept 2014.

[18] Y. H. Hsieh, T. J. Liang, S. M. O. Chen, W. Y. Horng, and Y. Y. Chung, "A novel high-efficiency compact-size low-cost balancing method for series-connected battery applications," IEEE Transactions on Power Electronics, vol. 28, no. 12, pp. 5927-5939, Dec 2013.

[19] H. Bergveld, D. Buthker, C. Castello, T. Doorn, A. de Jong, R. Van Otten, and K. de Waal, "Module-level dc/dc conversion for photovoltaic systems: The deltaconversion concept," Power Electronics, IEEE Transactions on, vol. 28, no. 4, pp. 2005-2013, April 2013. 


\section{Chapter 5}

\section{Power-Mix Algorithm and Simulation Results}

Aside from difference in mass, the most prominent difference between the SESS PbA and SESS LI is the drop in capacity with higher discharge currents due to the Peukert effect. To maximize HESS vehicle range, the IHBM controller 1) manages HESS power flow by adjusting the dc-dc converter reference current, $I_{r e f}$, and 2) minimizes $Q_{\text {waste }}$, which is quantified in (3.4) and illustrated as the unshaded region in Fig. 3.11. The algorithm uses the battery SOCs as feedback and alters the battery power-mix on the inverter bus by means of (2.1), ultimately affecting the relative SOC of the two battery chemistries. Because changes in SOC occur on the order of minutes or even hours, the controller must make coarse-grained decisions. Since the PbA module does not include a BMS, the task of accurately estimating $\mathrm{PbA}$ module SOC falls to the IHBM controller. The controller must continually perform current integration for PbA SOC determination, as well as other communication related tasks. Thus, an algorithm that is low computational cost is preferred. To summarize, the IHBM controller shall:

- maximize usable capacity of the energy storage elements,

- account for variations in payload without prior knowledge of the drive-cycle,

- take coarse-grained actions based on relative battery SOC, and

- not be computationally intensive. 


\subsection{Power and Energy Mix}

In the literature, heuristic control schemes and rule-based cost functions have been used extensively to control ultra-capacitor and lithium battery hybrid energy systems $[1,2]$. These rule-based schemes are largely empirical and do not guarantee optimality, however, they are often simpler to implement and less computationally expensive than other methods. Neural networks (NN) have also been used to optimize hybrid energy systems, but they require large, precise datasets, are not probabilistic, are difficult to troubleshoot, and the algorithm becomes a black box once learned [3, 4].

Deterministic dynamic programming (DDP) and stochastic dynamic programming (SDP) are global optimization strategies that have been applied to HEVs to minimize fuel consumption [5], to maximize fuel efficiency and for average commuter government drive-cycles to increase HEV performance over commercial controllers [6], and to reduce HEV electrical system stress without compromising fuel efficiency [7, 8]. These dynamic programming algorithms require very accurate assessment of system states, state transition probabilities, and rewards to accurately define the cost functions. These DP methods are better suited to handle cases with a well defined and repeatable drive-cycle such as bus routes and the standard LA92, FTP-75 and MVEG-A drive-cycles [9, 10].

The effectiveness of neural networks and dynamic programming methods largely depend on the accuracy of the drive-cycle loading profile. Because of the non-standard use cases of a light utility vehicle, the neural network and DP methods are unsuitable for the HESS power-mix algorithm. The heuristic approach is chosen because it not dependent on drive-cycle datasets, and is simpler to implement.
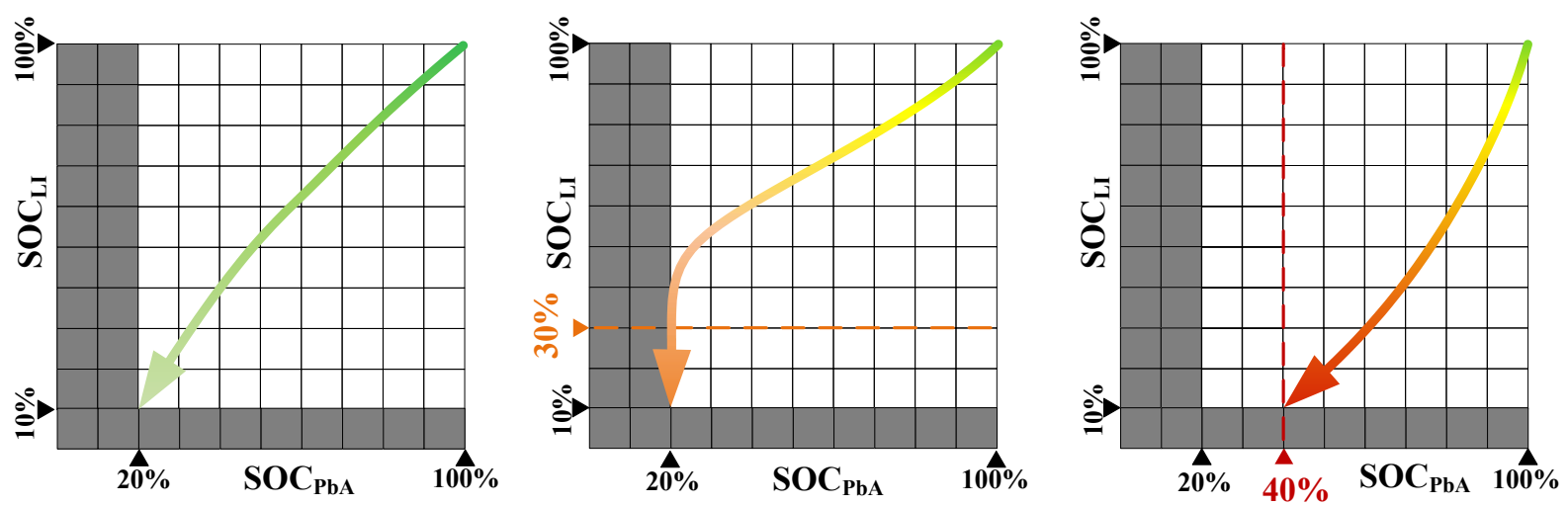

Figure 5.1: From left to right, the ideal path, the over-utilization path, and the underutilization path. 


\subsubsection{The SOC Path}

The relative HESS SOC can take several paths from full charge, as shown in Fig. 5.1. The highest efficiency path is realized when the battery SOCs reach their respective minimum values while maintaining the lowest average lead-acid current, $I_{P b A}$. A less efficient path occurs when $S O C_{P b A}$ reaches its minimum value before the lithium battery reaches $S O C_{L I, \text { min }}$, referred to as over-utilization. In this scenario, the lead-acid battery is discharged at a higher rate than necessary, and more $\mathrm{PbA}$ capacity is wasted due to the Peukert effect. Additionally, more energy is lost in the IHBM since the dc-dc converter processes higher power than necessary. The least efficient outcome occurs when $S O C_{L I, \min }$ is reached before $S O C_{P b A, \min }$ is reached because there is remaining capacity in the $\mathrm{PbA}$ module, resulting in under-utilization of the ESS. When $S O C_{P b A}$ reaches $S O C_{P b A, \min }$, the IHBM shuts off the dc-dc converters. The ESS reaches endof-life when $S O C_{L I, \min }$ is reached, regardless of $S O C_{P b A}$. This limitation is imposed due to the maximum power limitation of the dc-dc converter. Unless otherwise stated, $S O C_{P b A, \min }$ is $20 \%$, and $S O C_{L I, \min }$ is $10 \%$.

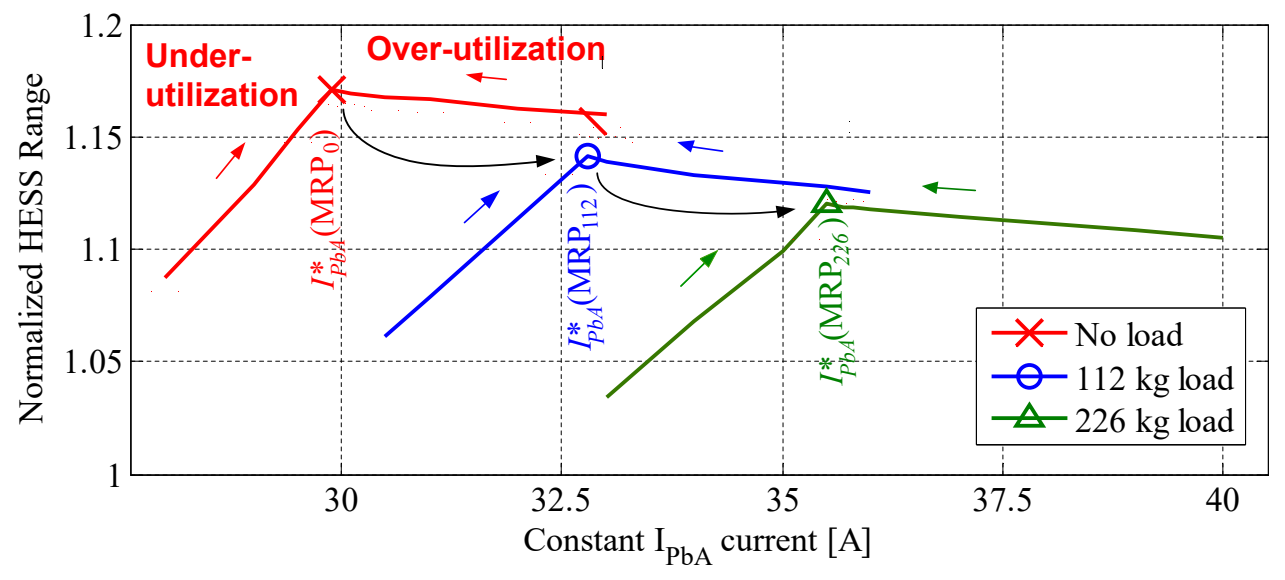

Figure 5.2: Simulated HESS range versus constant current for near constant $15 \mathrm{MPH}$ drive-cycles and varying vehicle payloads.

With the modeled batteries, the HESS performance is analyzed with a series of controlled simulations. The control variable, $I_{r e f}$, which corresponds to an $I_{P b A}$ according to (4.4), is fixed for a near constant, $15 \mathrm{MPH}$ drive-cycle with three loading conditions, 0 $\mathrm{kg}, 112 \mathrm{~kg}$, and $225 \mathrm{~kg}$, to extract the HESS range, and the simulations are repeated with different fixed current values. The results show that a maximum range point, (MRP), exists at each drive-cycle condition for some ideal lead-acid discharge current, $I_{P b A}^{*}$, as shown in Fig. 5.2.

With a negative deviation from $I_{P b A}^{*}$, the HESS suffers a significant dropoff in range 
from the MRP due to under-utilization of the battery. Conversely, the HESS suffers a mild dropoff in range from the MRP with a positive deviation from $I_{P b A}^{*}$ due to increased $Q_{\text {waste }}$, over-utilization of the battery. At the MRP, both batteries reach their respective minimum SOCs with the least amount of wasted charge accumulation, $Q_{\text {waste. }}$. This suggests that hill-climbing algorithms can be used for range maximization in a HESS LEV. The challenge is to determine $I_{P b A}^{*}$ as a function of time for a dynamic drive-cycle, where the MRP is unknown, and the speed, vehicle payload, terrain, road grade, and driver aggressiveness are uncertain.

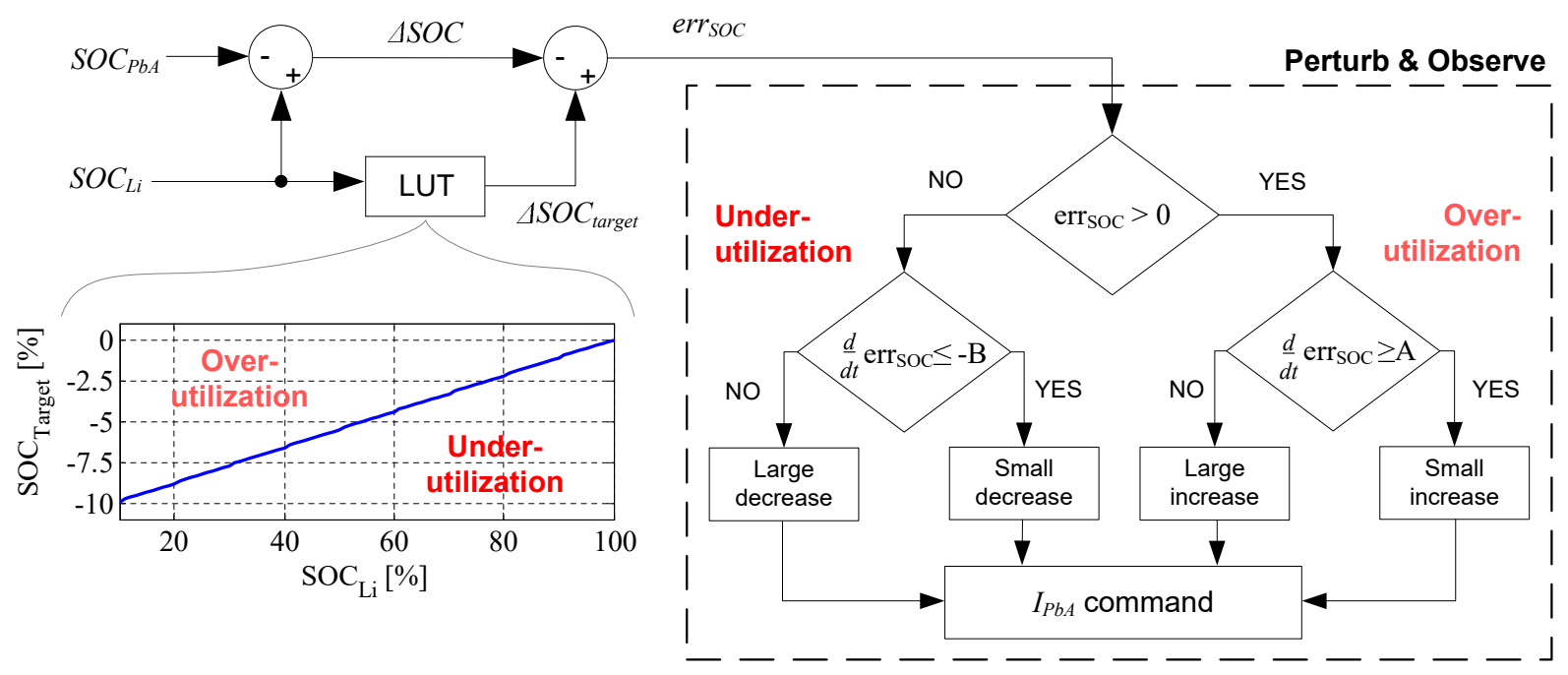

Figure 5.3: Block diagram of $\operatorname{err}_{S O C}$ computation and perturb-and-observe algorithm.

\subsubsection{The Perturb and Observe Method}

The perturb-and-observe method is straightforward, easy to implement, requires minimal computation, and inherently adapts to varying vehicle load conditions. The algorithm perturbs the value of $I_{r e f}$, and observes the resulting change in relative SOC, as illustrated in Fig. 5.3. The variable $\triangle S O C$ is defined as the difference between $S O C_{P b A}$ and $S O C_{L I}$. A preprogrammed look-up table, (LUT), takes $S O C_{L I}$ as an input and identifies the target difference in state-of-charge, $\triangle S O C_{\text {target }}$, the desired difference in SOC between the $\mathrm{LI}$ and $\mathrm{PbA}$ batteries. $\triangle S O C$ is compared to $\triangle S O C_{\text {target }}$, and this difference is defined as $\operatorname{err}_{S O C}$. The magnitude and direction of the $I_{P b A}$ perturbation is dependent on the magnitude and sign of $\operatorname{err}_{S O C}$. The updated current reference value is given by

$$
I_{\text {ref }}(k)=I_{r e f}(k-1)+I_{a d j}(k)
$$


where $I_{a d j}$ is an small adjustment to the reference current. The value of $I_{a d j}(k)$ is set to one of seven positive or negative constants based on $\operatorname{err}_{\Delta}(k)$ and the rate of change of the error, $\frac{d}{d k} \operatorname{err}_{\Delta}(k)$, given by

$$
I_{a d j}(k)= \begin{cases}a_{1} & \operatorname{err}_{\Delta}(k)>1.2 \\ a_{2} & \operatorname{err}_{\Delta}(k)<-1.2 \\ a_{3} & -1.2>\operatorname{err} \Delta(k)>0 \\ b_{1} & \operatorname{err}_{\Delta}(k)>0 \text { and } \frac{d}{d k} \operatorname{err}_{\Delta}(k)>0.1 \\ b_{2} & \operatorname{err}_{\Delta}(k)>0 \text { and } \frac{d}{d k} \operatorname{err}_{\Delta}(k)>0.05 \\ b_{3} & \operatorname{err}_{\Delta}(k)<0 \text { and } \frac{d}{d k} \operatorname{err}_{\Delta}(k)<-0.1 \\ b_{4} & \operatorname{err}_{\Delta}(k)<0 \text { and } \frac{d}{d k} \operatorname{err}_{\Delta}(k)<-0.05,\end{cases}
$$

where the coefficient values and control limits are found empirically. The $a$ coefficients are tailored to rapidly increase $I_{r e f}(k)$ when more energy is needed, and to slowly allow $I_{r e f}(k)$ to decay when $\operatorname{err}_{\Delta}(k)$ is negative. This discourages under-utilization to avoid the steep dropoff in range seen in Fig. 5.2. The $b$ coefficients make minor adjustments to the reference current based on the rate of change of $\operatorname{err}_{\Delta}(k)$. The interval time, $T_{k}$ is another degree of freedom, and is fixed to 10 seconds for each drive-cycle unless otherwise stated. By minimizing $\operatorname{err}_{S O C}$, maximum energy utilization can be achieved.

The hill-climbing technique is often paired with other MPPT methods to enhance the control. One such method, known as fractional $V_{O C}$, relies on the maximum power-point of a photo-voltaic cell to be roughly 0.76 of the peak open circuit voltage [11-13]. For the case of the HESS, the value of $I_{P b A}^{*}$ is expected to be between $25 \mathrm{~A}$ and $35 \mathrm{~A}$ for any given load. An initial condition of $25 \mathrm{~A}$ can be used for the current reference, which reduces the tracking time and minimizes the aforementioned long term over- and under-utilization battery errors.

\subsection{Controller Tuning}

The framework for the HESS control algorithm is shown in Fig. 5.4. The two batteries' SOCs are used as feedback, and the IHBM controller sets $I_{r e f}$, which corresponds to an $I_{P b A}$. The measured drive-cycle voltage and current are inputs to the model and define the inverter bus load. The lithium battery voltage is multiplied by four to make up the inverter bus. Series HESS modules are assumed to be balanced, and the control 


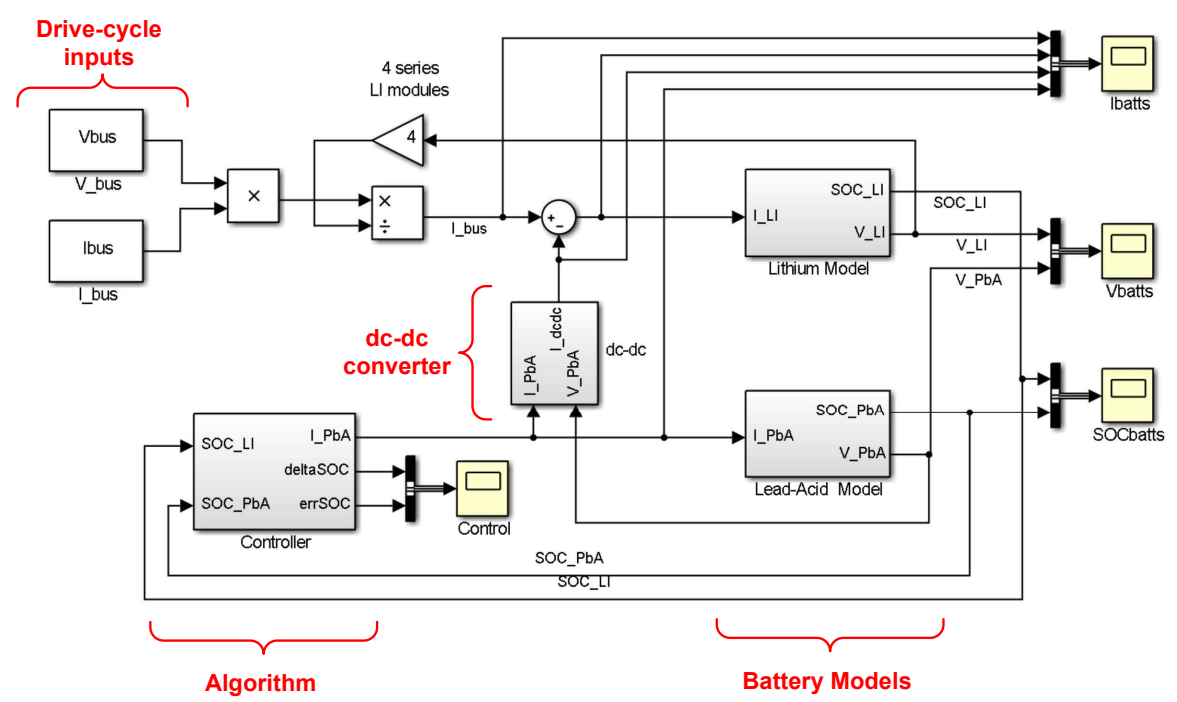

Figure 5.4: A simplified block diagram of the MATLAB/Simulink simulation.

implementation of series battery balancing is outside the scope of this paper.

The perturb and observe algorithm is simulated under two driving conditions to test the robustness of the algorithm: 1) a near constant-speed, continuous drive-cycle, and 2) a fragmented, start-stop drive-cycle that includes durations of rest. The results of the continuous drive-cycle are used as a metric to compare the HESS to the SESS vehicles. The start-stop drive-cycle is simulated to test the robustness of the algorithm under more realistic driving conditions and to show the effect of tuning the control coefficients. In both cases, the controller has no prior knowledge of future loading, driving duration, or rest time. The battery models are discharged from a 100\% SOC initial condition to their respective minimum SOC values.

\subsubsection{Continuous Drive-Cycle}

This drive-cycle is used for a one-to-one comparison between the HESS and SESS vehicles. The controller must find the $I_{P b A}^{*}$ that corresponds to a static MRP. The MRP is static because a near-constant speed is held for the duration of the continuous drive-cycle. The algorithm continually adjusts $I_{r e f}$, and as a result, $I_{P b A}$, to oscillate around $I_{r e f}^{*}$ and $I_{P b A}^{*}$, respectively, as $S O C_{P b A}$ and $S O C_{L I}$ traverses the highest efficiency path, as shown in Fig. 5.5. In practice, the value of $I_{P b A}^{*}$ adjusts slightly downwards in this particular drive-cycle due to the error of the relative battery SOCs. In the first half of the drivecycle, the average value of $I_{P b A}$ is slightly higher than $I_{P b A}^{*}$, meaning that the lead-acid battery is over-discharged. The actual ideal current, $I_{P b A, a c t}^{*}$, corrects itself downwards for the latter part of the drive-cycle as a result. 

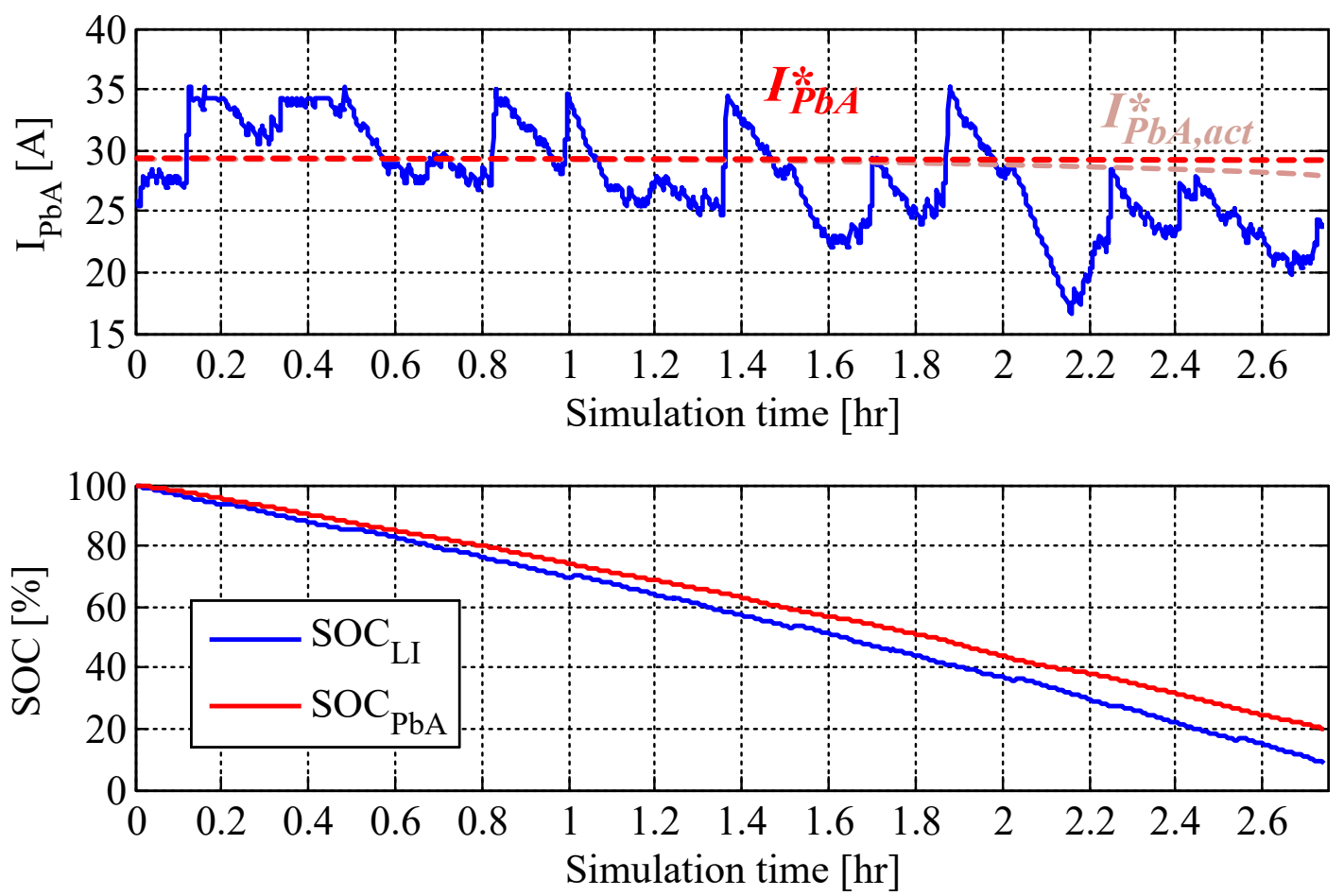

Figure 5.5: $I_{P b A}$ over a simulated drive-cycle as the battery SOCs follow their target trajectories.

The substantial low frequency ripple in $I_{r e f}$ is due to the slow changing battery stateof-charge values and causes the skew in $I_{P b A}^{*}$. Because the algorithm does not have prior knowledge of the drive-cycle, can be reduced by further tuning the coefficients.

\subsubsection{Start-stop Drive-Cycle}

The following scenario is considered for the start-stop drive cycle. The Ranger EV is loaded with $226 \mathrm{~kg}$ of bricks at point $\mathrm{A}$. The vehicle is then driven for thirty minutes at a near-constant $12 \mathrm{MPH}$ to point B, where the bricks are unloaded, and the vehicle sits at rest for 30 minutes. The vehicle returns to point A to load more bricks, and the cycle continues, as shown in Fig. 5.6(a). The power demand for such a drive-cycle is shown in Fig. 5.6(b). This drive-cycle tests how the perturb and observe algorithm adapts to a moving MRP. The dynamic behavior of $I_{r e f}$ is a critical trait of the power-mix algorithm for changing loads.

For continuous driving, both batteries must continuously supply current to the load bus, and the effect of the battery voltage sag is sustained. The sagging bus voltage leads to increased bus current for the same power draw, which further contributes to battery discharge. In the start-stop drive-cycle, the vehicles rests for an extended duration, giving 


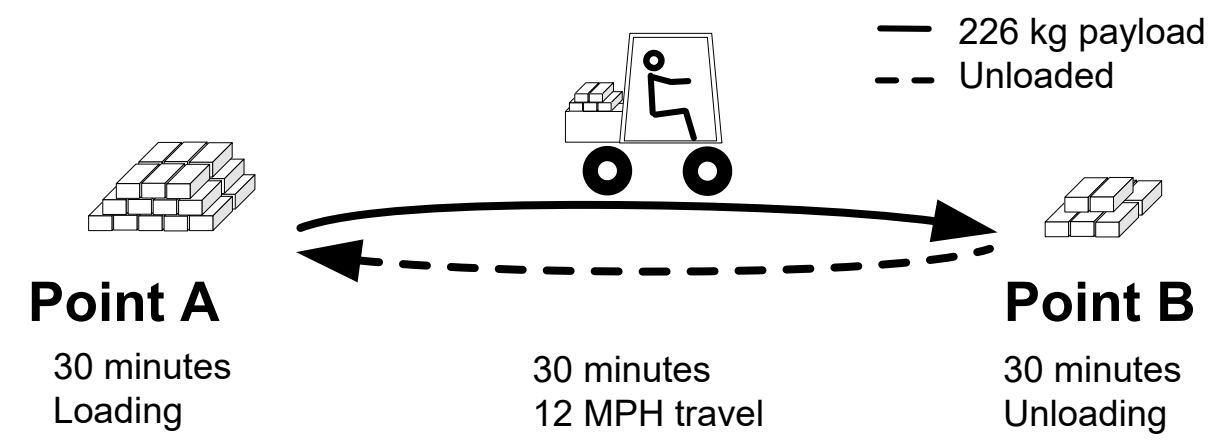

(a)

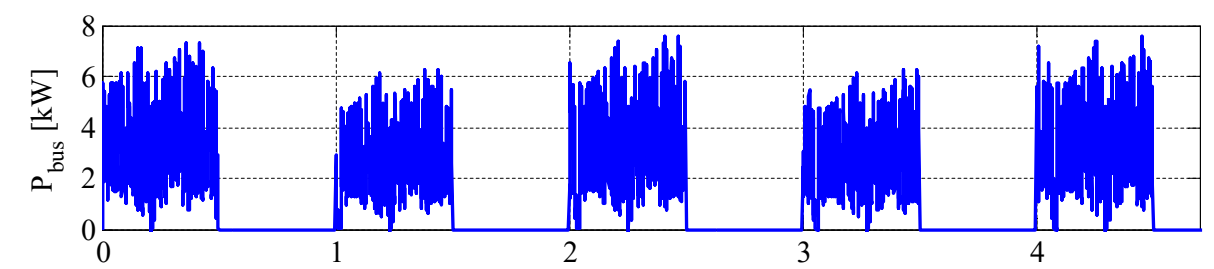

(b)

Figure 5.6: A (a) start-stop emulated drive-cycle and (b) power demand.

the battery voltages time to recover from discharge. Depending on the duration of rest, the battery voltages may recuperate several hundred $\mathrm{mV}$. For the start-stop drive-cycle, the $\mathrm{PbA}$ module also uses the rest time to trickle-charge the LI module, further increasing the bus voltage and reducing the bus current stress.

The drive-cycle is simulated with varying values of the coefficient $a_{2}$ and time interval $T_{k}$. The value of $a_{2}$ represents how quickly $I_{a d j}$ decays when the $\operatorname{err}_{S O C}$ is negative, and it is of interest when examining the more beneficial use of the resting time. A more negative value of $a_{2}$ leads to a faster decay in $I_{r e f}$, and less lithium battery charging during the rest. A less negative value of $a_{2}$ results in a more gradual decay, and more lithium battery

Table 5.1: $I_{a d j}$ Coefficients of the Perturb and Observe Algorithm

\begin{tabular}{ccc}
\hline Parameter & Continuous & Start-stop \\
\hline \hline$a_{1}$ & 2.00 & 2.00 \\
$a_{2}$ & -0.50 & -0.25 \\
$a_{3}$ & -0.25 & -0.10 \\
$b_{1}$ & 1.00 & 1.00 \\
$b_{2}$ & 0.50 & 0.50 \\
$b_{3}$ & -0.25 & -0.10 \\
$b_{4}$ & -0.25 & -0.05 \\
\hline
\end{tabular}



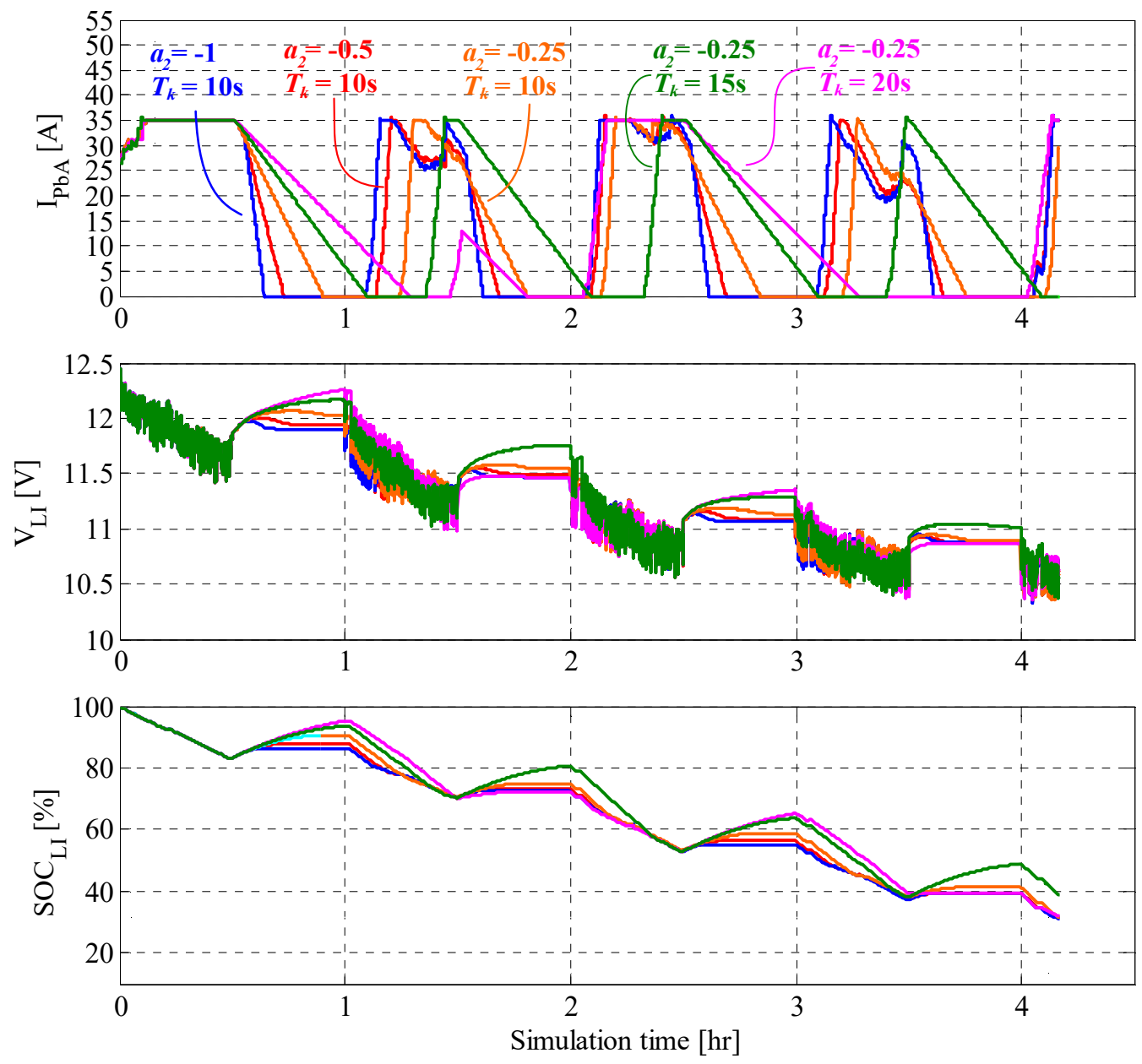

Figure 5.7: Simulated start-stop drive-cycle with varying $a_{2}$ and $T_{k}$.

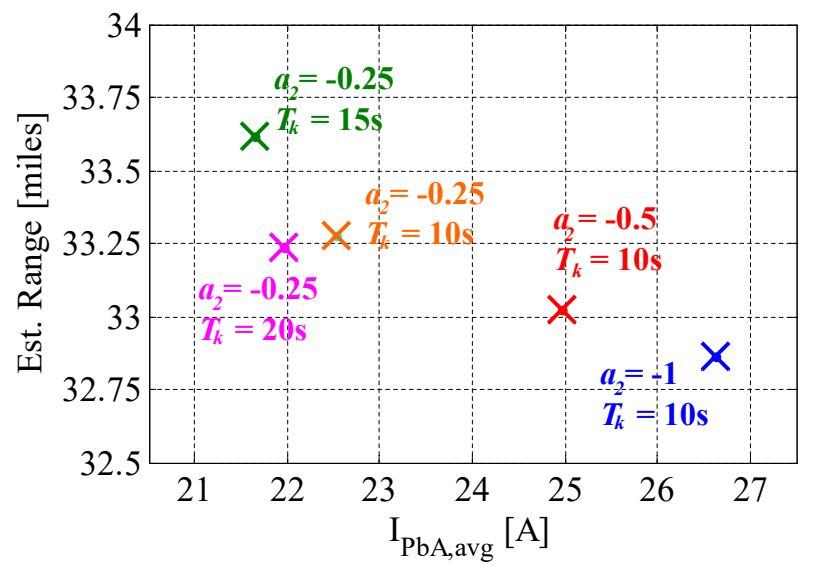

Figure 5.8: Estimated range versus $I_{P b A, \text { avg }}$ with varying $a_{2}$ and $T_{k}$ for the start-stop drive-cycle.

charging. The simulations show the difference in the $a_{2}$ and $T_{k}$ parameters affect $I_{P b A}$, and the resulting effects on lithium battery voltage, and relative battery SOC, as shown 


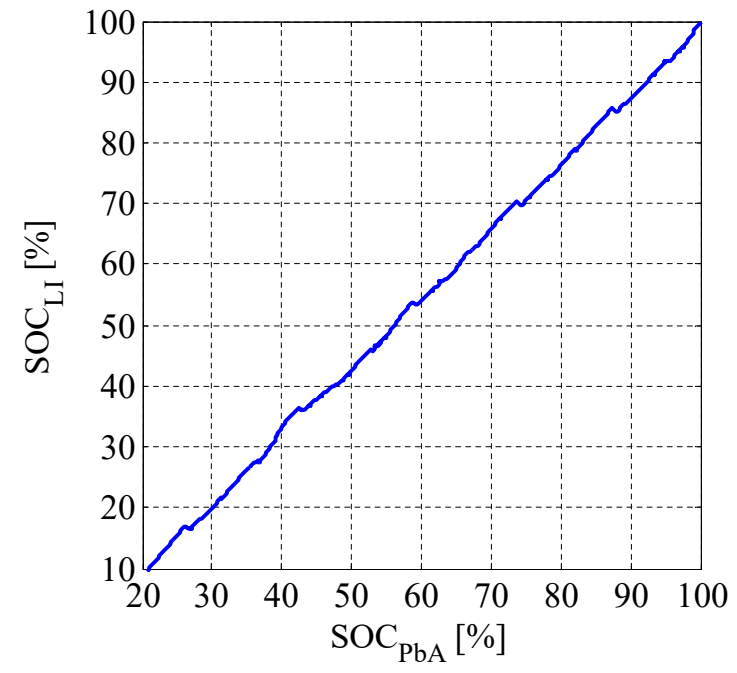

(a)

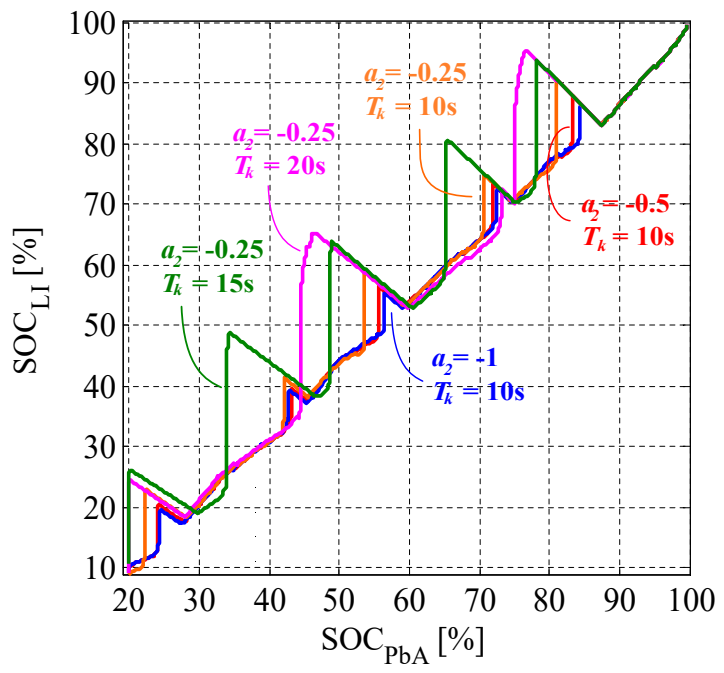

(b)

Figure 5.9: The relative SOC path of the batteries for (a) a continuous drive-cycle, and (b) start-stop drive-cycle.

in Fig. 5.7.

A slower decay leads to lower overall $I_{P b A}$ current, which minimizes the Peukert effect in the lead-acid battery. The total estimated range achieved versus average lead-acid battery current, $I_{P b A, a v g}$, is shown in Fig. 5.8 with these various coefficient values. These results suggest that, for a drive-cycle with frequent stops, it is more beneficial to allow the relative $\mathrm{SOC}$ path to deviate from $S O C_{\text {target }}$ to charge the lithium battery during rest.

The $I_{\text {adj }}$ coefficients used for the continuous and start-stop drive-cycles are detailed in Table 5.1. The simulated relative SOC paths of the continuous and start-stop drive-cycles are shown in Fig. 5.9(a) and Fig. 5.9(b).

\subsection{Simulated ESS Comparisons}

The vehicle range is simulated using the continuous drive-cycles to compare the HESS range with the SESS PbA and SESS LI range. The effect of vehicle mass, driving speed, and battery DOD are also explored. Since total available battery energy is vital to the ESS performance, two hybrid configurations of varying total ESS energy, HESS-1 and HESS-2, are considered. SESS LI-1 and SESS LI-2 are comparable full lithium configurations, respectively, in terms of total energy. The various ESS configuration parameters and their simulation results are detailed in Table 5.2. 
Table 5.2: Comparison of Simulated ESS Configuration

\begin{tabular}{lcccccc}
\hline Parameter & SESS PbA & SESS LI-1 & SESS LI-2 & HESS-1 & HESS-2 & Unit \\
\hline \hline 1C energy & 8.85 & 9.34 & 8.06 & 9.71 & 8.45 & $\mathrm{kWh}$ \\
ESS mass & 312 & 64.2 & 68.1 & 197 & 190 & $\mathrm{~kg}$ \\
Ratio, $E_{\text {Li }} / E_{E S S}$ & 0.00 & 1.00 & 1.00 & 0.545 & 0.486 & \\
Unloaded range & 1.00 & 1.50 & 1.27 & 1.35 & 1.18 & p.u. \\
112kg loaded range & 0.94 & 1.33 & 1.17 & 1.23 & 1.06 & p.u. \\
226kg loaded range & 0.87 & 1.21 & 1.06 & 1.12 & 0.97 & p.u. \\
$\Gamma_{\text {noload }}$ & 1.00 & 1.42 & 1.40 & 1.23 & 1.23 & p.u. \\
$\Gamma_{112 \mathrm{~kg}}$ & 0.94 & 1.26 & 1.29 & 1.12 & 1.11 & p.u. \\
$\Gamma_{226 \mathrm{~kg}}$ & 0.87 & 1.14 & 1.16 & 1.02 & 1.01 & p.u. \\
\hline
\end{tabular}

Because the expected life cycles of the lithium batteries exceeds the expected life cycles of lead-acid batteries, an additional recurring cost of replacing the lead-acid battery must be taken into account $[14,15]$. The expected life-cycles of both battery chemistries are derived from datasheet parameters of depth-of-discharge (DOD) versus cycle life. The total calculated ESS costs assume a minimum of 1900 cycles to match the expected lifecycles of a single LI module. The costs amount to two PbA battery replacements to a single lithium module for any ESS. The reduction in range of operating near the $\mathrm{PbA}$ battery end-of-life is not considered in this work.

\subsubsection{Effect of Payload}

The effect of adding additional mass to the LEV is explored by simulating three loading conditions: no load, $112 \mathrm{~kg}$ load, and $226 \mathrm{~kg}$ load. The simulated range of the various ESS are normalized to the SESS PbA unloaded range, as shown in Fig. 5.10(a). More overall energy leads to higher range estimates for the ESS-1 cases compared to the ESS-2 cases, while the range/kWh efficiency of the HESS modules are similar, as shown in Fig. 5.10(b).

\subsubsection{Effect of Depth-of-Discharge}

The cycle life of each battery must be taken into account to reflect a more realistic cost of the HESS system. As described in Chapter 1, the end-of-life of a battery is defined as the moment its usable capacity reaches $80 \%$ of its nominal capacity. The battery capacity is affected by its usage, environment, and age. A lead-acid battery typically has a lower 


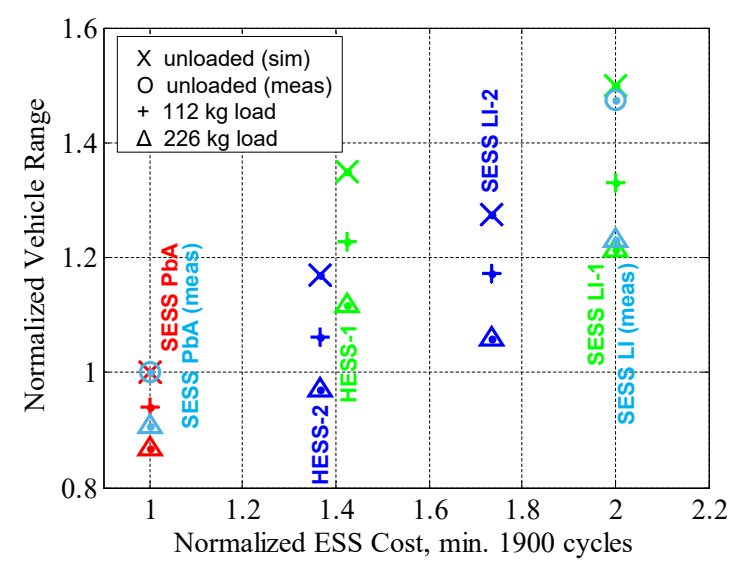

(a)

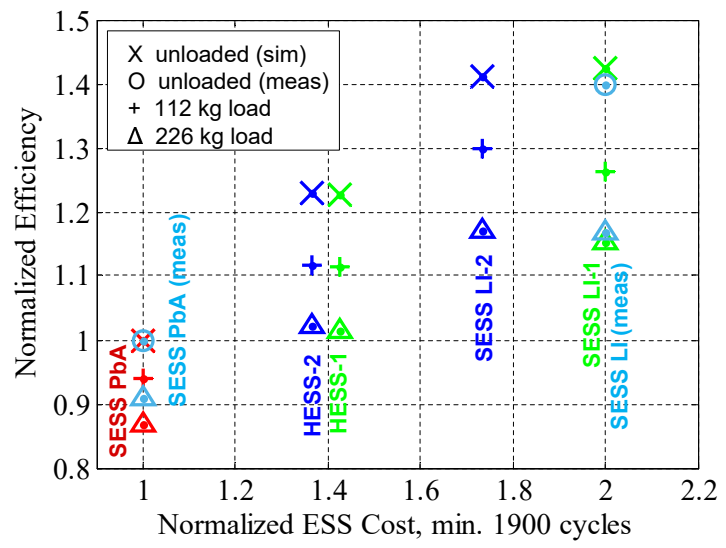

(b)

Figure 5.10: Simulated vehicle (a) range and (b) efficiency versus cost of measured SESS and simulated ESS vehicles, normalized to the no-load SESS PbA.

lifetime than a lithium-ion battery, and this is true for the two chosen battery modules. The expected life-cycles of the LI module exceeds 2000 cycles, while the expected lifecycles of the PbA module falls below 1000 cycles if discharged below 50\% SOC, as shown in Fig. 5.11.

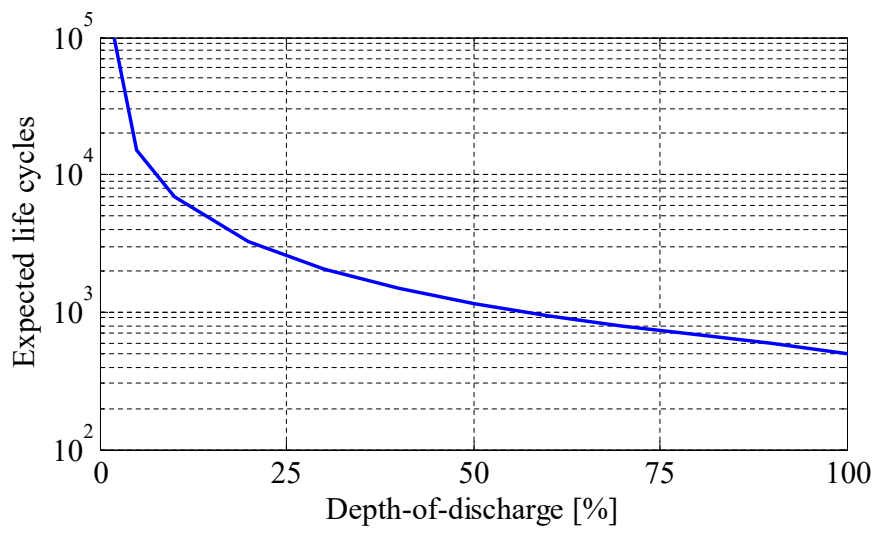

Figure 5.11: Lead-acid battery expected life cycles versus DOD [16].

To explore the tradeoff between life-cycle, overall HESS cost, and expected range of a given cycle, the DOD of the lead-acid battery is varied from $80 \%$ for the HESS-2 and SESS LI-2 cases. With 60\% DOD, the lead-acid battery yields 950 cycles, and only one replacement $\mathrm{PbA}$ is necessary to achieve 1900 life-cycles for the HESS. With less usable energy, however, the range of the HESS is dramatically decreased, as shown in Fig. 5.12. A similar decrease in range is seen with 70\% DOD. In this comparison, 80\% DOD is used for the SESS PbA lead-acid batteries. 


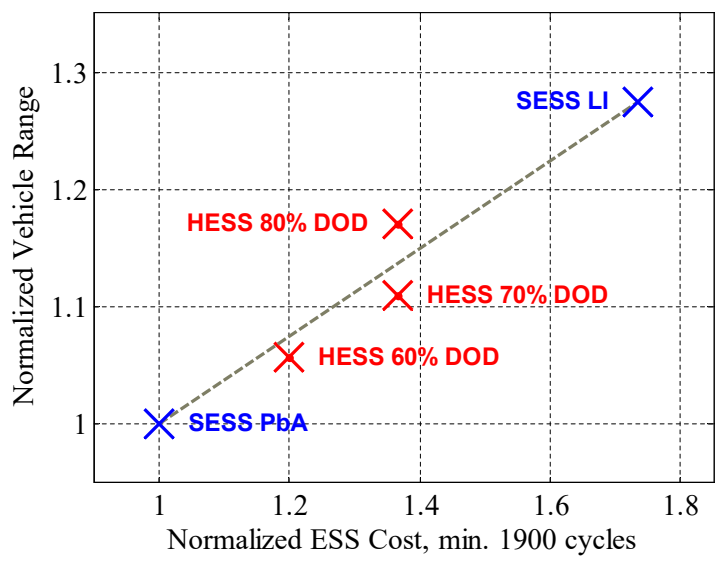

Figure 5.12: The effect of HESS DOD on simulated range and cost.

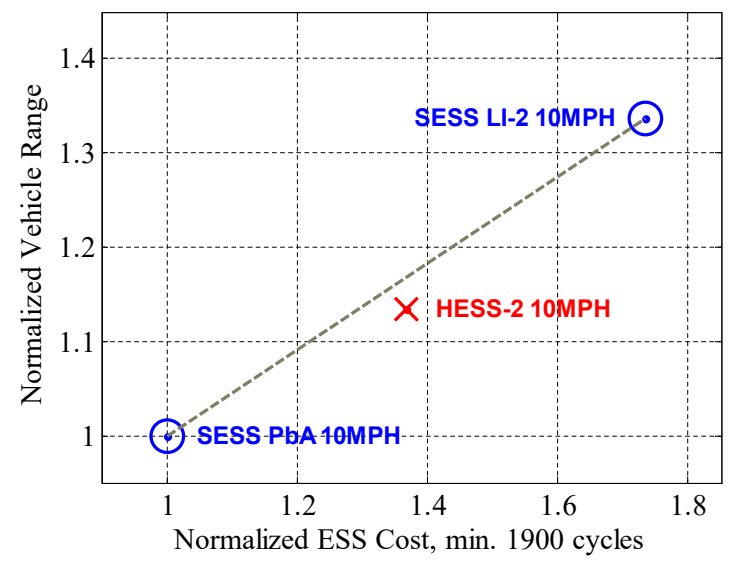

Figure 5.13: The effect of slower speed and total pack energy on simulated range and cost.

\subsubsection{Effect of Speed}

A near constant, $15 \mathrm{MPH}$ drive-cycle has been used thus far. When reducing the maximum speed by $1 / 3$ to $10 \mathrm{MPH}$, the performance benefits of using LI batteries is diminished, as shown in Fig. 5.13. With a less demanding drive-cycle, the impact of the Peukert effect is less apparent. There are still modest range improvements in the HESS-2 and SESS LI-2 configurations compared to the SESS PbA due to lower overall vehicle mass.

\subsection{Chapter Summary and Conclusions}

A perturb and observe based algorithm is proposed to handle the power-mix of the batteries, and the algorithm tackles the different drive-cycles in different ways. For the continuous drive-cycle, the algorithm maintains the battery SOCs close to a target SOC path and finds $I_{r e f}^{*}$ by minimizing err $_{S O C}$. For the start-stop drive-cycle, a higher range path is found by imposing a gradual decay in $I_{r e f}$ to minimize $I_{P b A}$. The simulations show that different coefficient values of $a_{2}$ and $T_{k}$ are optimal for different durations of rest. In the next chapter, the algorithm is demonstrated for the two types of drive-cycle.

The simulated results show that the HESS-2 vehicle is expected to achieve a $18 \%$ increase in range with an 36\% increase in cost compared to the SESS PbA vehicle. Meanwhile, the SESS LI-2 vehicle is expected to achieve a $27 \%$ increase in range with a $75 \%$ increase in cost. The range improvement can be attributed to the decrease in mass of the HESS, as well as improved capacity utilization of the $\mathrm{PbA}$ module of the HESS. Increasing the total ESS energy and using a higher ratio of LI energy in the energy 
storage system ultimately leads to improved range and $\Gamma$ efficiency.

Because system cost is dependent on many non-technical factors, a simplified estimate is used, which is sufficient for the purpose of this work. For example, the assumption of 1900 minimum cycles is convenient for ESS comparison, but may not reflect the actual lifetime of a light utility EV. 1900 cycles is approximately 5.2 years of service if fully charged and discharged on a daily basis. When considering a minimum lifetime of 1200 cycles, the 18\% improvement of the HESS comes with $80 \%$ increase in cost compared to the SESS PbA, while the SESS LI costs 160\% more than that of the SESS PbA. In both cases, the HESS cost increase is roughly $50 \%$ that of the SESS LI cost increase. 


\section{References}

[1] M. Moshirvaziri, C. Malherbe, A. Moshirvaziri, and O. Trescases, "Power-mix optimization for a hybrid ultracapacitor/battery pack in an electric vehicle using realtime gps data," in Industrial Electronics Society, IECON 2013 - 39th Annual Conference of the IEEE, Nov 2013, pp. 4666-4671.

[2] L. Shao, M. Moshirvaziri, C. Malherbe, A. Moshirvaziri, A. Eski, S. Dallas, F. Hurzook, and O. Trescases, "Ultracapacitor/battery hybrid energy storage system with real-time power-mix control validated experimentally in a custom electric vehicle," in Applied Power Electronics Conference and Exposition (APEC), 2015 IEEE, March 2015, pp. 1331-1336.

[3] C. j. Xie, S. h. Quan, and Q. h. Chen, "Control strategy of hybrid power system for fuel cell electric vehicle based on neural network optimization," in 2008 IEEE International Conference on Automation and Logistics, Sept 2008, pp. 753-757.

[4] L. Feldkamp, M. Abou-Nasr, and I. V. Kolmanovsky, "Recurrent neural network training for energy management of a mild hybrid electric vehicle with an ultracapacitor," in Computational Intelligence in Vehicles and Vehicular Systems, 2009. CIVVS '09. IEEE Workshop on, March 2009, pp. 29-36.

[5] L. V. Prez, G. R. Bossio, D. Moitre, and G. O. Garca, "Optimization of power management in an hybrid electric vehicle using dynamic programming," Mathematics and Computers in Simulation, vol. 73, no. 14, pp. 244 - 254, 2006, applied and Computational Mathematics - Selected Papers of the Fifth PanAmerican Workshop - June 21-25, 2004, Tegucigalpa, Honduras. [Online]. Available: http://www.sciencedirect.com/science/article/pii/S0378475406001807

[6] D. F. Opila, X. Wang, R. McGee, J. A. Cook, and J. W. Grizzle, "Performance comparison of hybrid vehicle energy management controllers on real-world drive cycle data," in 2009 American Control Conference, June 2009, pp. 4618-4625. 
[7] S. J. Moura, H. K. Fathy, D. S. Callaway, and J. L. Stein, "A stochastic optimal control approach for power management in plug-in hybrid electric vehicles," IEEE Transactions on Control Systems Technology, vol. 19, no. 3, pp. 545-555, May 2011.

[8] C. Vagg, S. Akehurst, C. J. Brace, and L. Ash, "Stochastic dynamic programming in the real-world control of hybrid electric vehicles," IEEE Transactions on Control Systems Technology, vol. 24, no. 3, pp. 853-866, May 2016.

[9] EPA, "Dynamometer drive cycles," 2016. [Online]. Available: https://www.epa.gov/ vehicle-and-fuel-emissions-testing/dynamometer-drive-schedules

[10] "International test cycles for emissions and fuel economy," 2016. [Online]. Available: http://www.unep.org/transport/gfei/autotool/approaches/information/ test_cycles.asp

[11] A. F. Murtaza, H. A. Sher, M. Chiaberge, D. Boero, M. D. Giuseppe, and K. E. Addoweesh, "A novel hybrid mppt technique for solar pv applications using perturb amp; observe and fractional open circuit voltage techniques," in MECHATRONIKA, 2012 15th International Symposium, Dec 2012, pp. 1-8.

[12] T. Esram and P. L. Chapman, "Comparison of photovoltaic array maximum power point tracking techniques," IEEE Transactions on Energy Conversion, vol. 22, no. 2, pp. 439-449, June 2007.

[13] J. J. Schoeman and J. D. v. Wyk, "A simplified maximal power controller for terrestrial photovoltaic panel arrays," in Power Electronics Specialists conference, 1982 IEEE, June 1982, pp. 361-367.

[14] T. Dragievi, H. Pandi, D. krlec, I. Kuzle, J. M. Guerrero, and D. S. Kirschen, "Capacity optimization of renewable energy sources and battery storage in an autonomous telecommunication facility," IEEE Transactions on Sustainable Energy, vol. 5, no. 4, pp. 1367-1378, Oct 2014.

[15] P. Poonpun and W. T. Jewell, "Analysis of the cost per kilowatt hour to store electricity," IEEE Transactions on Energy Conversion, vol. 23, no. 2, pp. 529-534, June 2008.

[16] U. Battery, "Us battery product datasheet," 2013. [Online]. Available: \$http://usbattery.com/wp-content/uploads/2015/01/usb \_12V \_data \ _sheet\_2015\_web.pdf\$ 


\section{Chapter 6}

\section{Experimental Results}

The hardware implementation of IHBM dc-dc converter and controller is presented, and the simulation and experimental drive-cycle results are shown. For proper comparison between HESS and SESS LI and SESS PbA configurations, the range estimates of the various ESS are normalized to the SESS PbA. The continuous drive-cycles are used for the ESS comparison, and the start-stop drive-cycle is run to demonstrate the dynamic perturb and observe algorithm. The efficiency, $\Gamma$, defined as range/kWh, of each configuration is used as a metric to compare the different ESS due to variations in total battery pack energy.

\subsection{DC-DC Converter Experimental Results}

The sub-converter power stages, gate drives, and analog sensing circuits are realized on separate PCBs. The four-layer, $3.5 \times 2.6$ inch PCBs use 3 oz copper for improved conductivity, and the inductor and switching elements sit on the top side of each subconverter PCB, as shown in Fig. 6.1(a). A heatsink is placed on the reverse side to conduct heat through the PCB, and forced-air cooling is used above the three subconverters to remove heat from the system. The three sub-converters are connected to the battery terminals via copper busbars, and each power stage PCB connects to a dedicated controller PCB that houses the 32-bit PIC MCU and Xilinx FPGA, as shown in Fig. 6.1(b). The lead-acid battery and lithium-ion battery are pictured in Fig. 6.1(c).

\subsubsection{Measured Efficiency}

The dc-dc converter achieves a peak efficiency of $88.5 \%$ at $100 \mathrm{~W}$ output power with single sub-converter operation, $88 \%$ efficiency at $180 \mathrm{~W}$ with dual sub-converter operation, and 


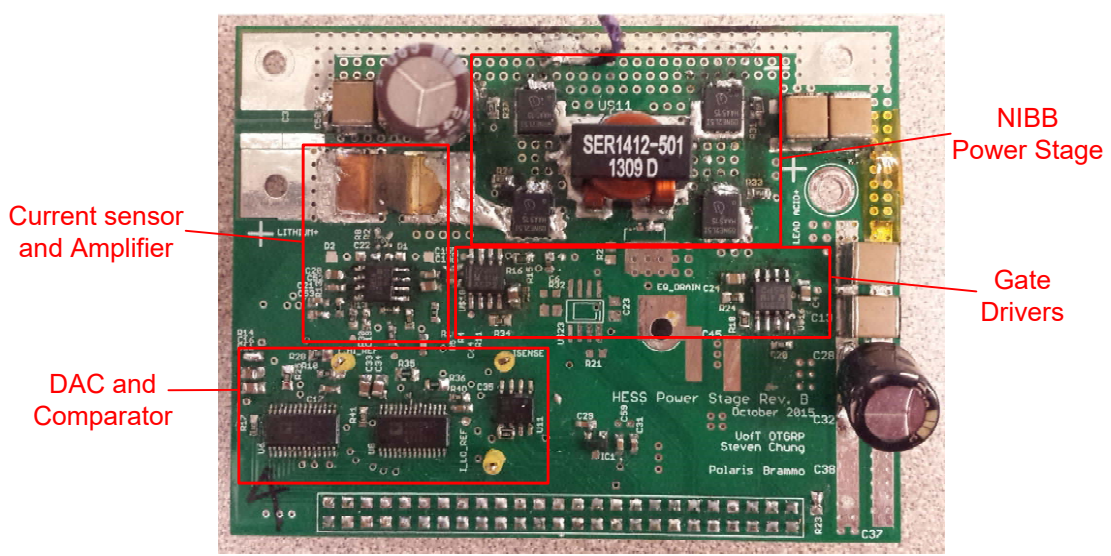

(a)

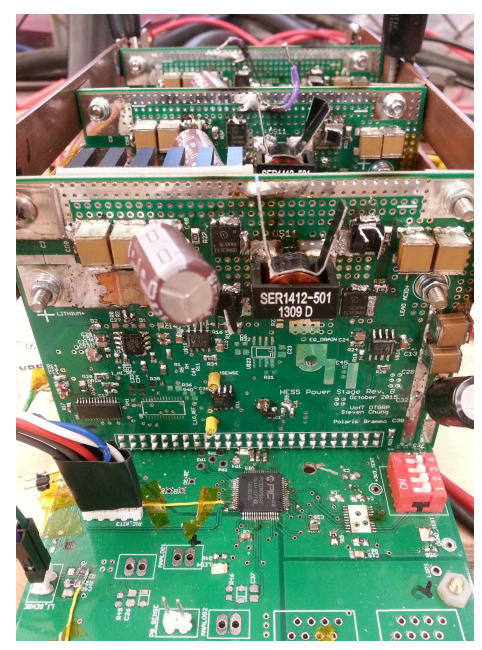

(b)

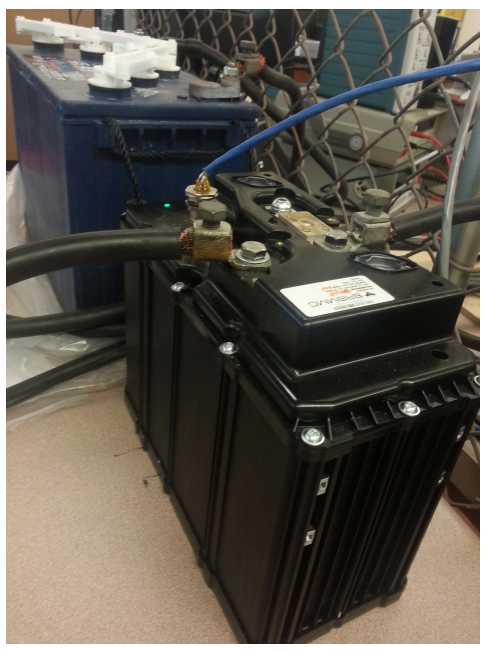

(c)

Figure 6.1: A (a) NIBB power stage PCB, (b) three sub-converters plugged into a common controller board, and (c) the lithium and lead-acid batteries used for experimental verification.

$87 \%$ efficiency at the rated $270 \mathrm{~W}$ power with three sub-converters, as shown in Fig. 6.2(a). The measured efficiency is relatively flat, between $87 \%$ and $88.5 \%$, over a wide range of output power as a result of the multi parallel sub-converter operation. The dc-dc converter is able to maintain the higher efficiencies by enabling the parallel sub-converters depending on the total current reference, $I_{r e f, t o t}$, where

$$
I_{r e f, t o t}=I_{r e f, A}+I_{r e f, B}+I_{r e f, C}
$$

which is known as phase-shedding. To demonstrate the dynamic phase-shedding operation, the converter was run for a thirty minute period, and $I_{r e f, t o t}$ is ramped down from a digital value of 2000, roughly 25 A. As $I_{r e f, t o t}$ falls, the sub-converter reference currents adjust, and the sub-converters turn off accordingly, as shown in Fig. 6.2(b) [1, 2]. All 
three sub-converters are disabled when $I_{\text {ref,tot }}$ falls below 6 A because light-load efficiency is relatively poor.

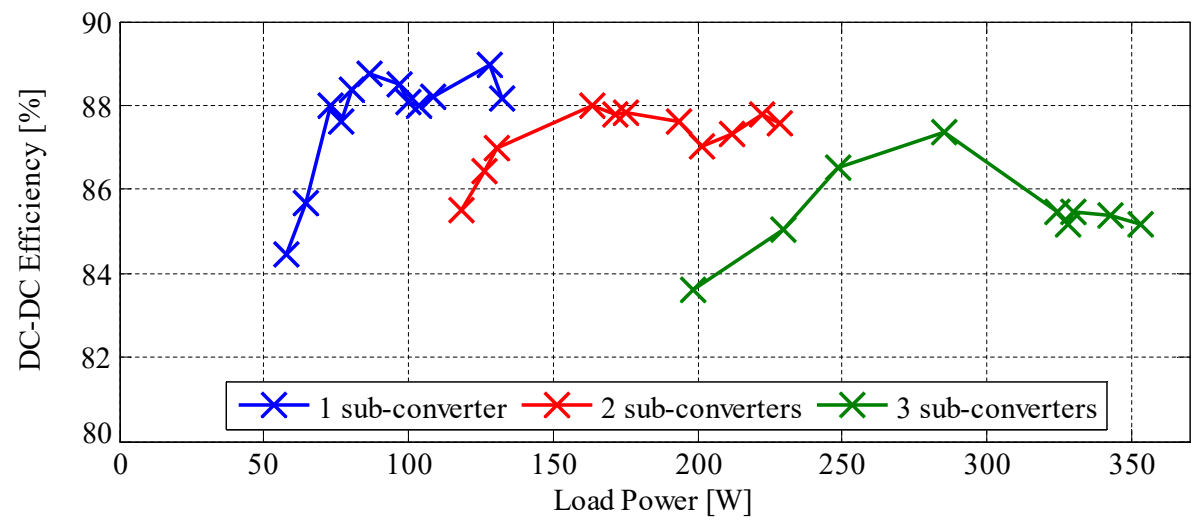

(a)

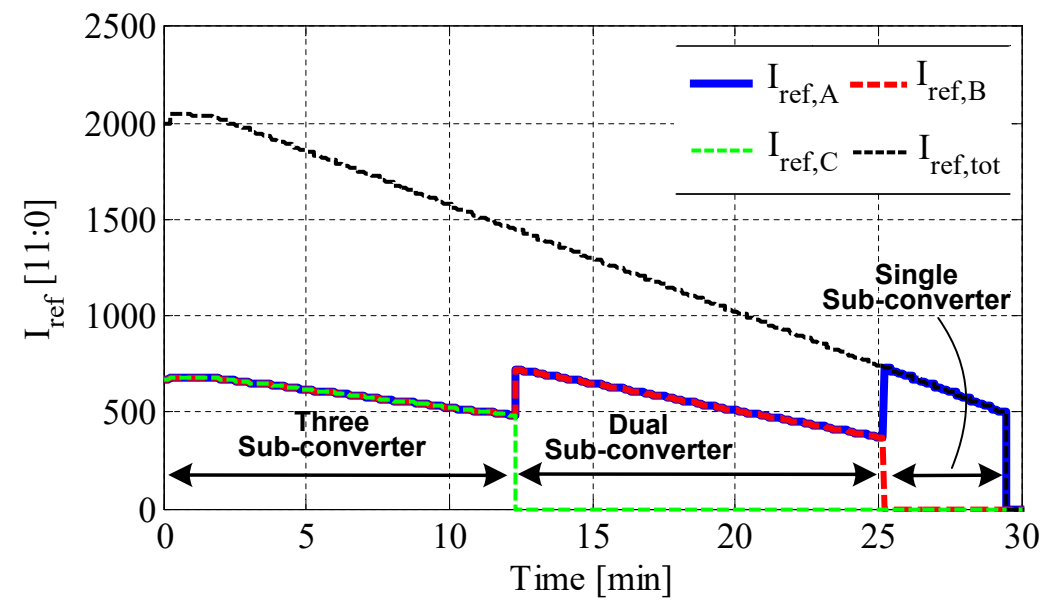

(b)

Figure 6.2: Measured (a) converter efficiency for a single and multi-phase dc-dc operation, and (b) phase shedding of the digital current reference commands.

The measured efficiency numbers miss the calculated efficiency mark of $90.5 \%$ at rated power. The additional loss can be attributed to many factors, such as an underestimate of switching loss, AC core losses, and poor PCB conductivity after numerous reworks or insufficient thermal management. The inductor, in particular, has a high footprint, and the bulk of its windings and core do not make physical contact with the PCB. This results in poor thermal conduction between inductor and heatsink, and the dissipated power contributes to heating the local air around the inductor. A thermal image of the three sub-converters processing $300 \mathrm{~W}$ confirms that the inductors are the hottest components, as shown in Fig. 6.3. While there is still significant loss and heat on the MOSFETs, as calculated in Fig. 4.4, the flat and low thermal resistance package of the 
transistors facilitates efficient flow of heat from the switches through the PCB to the heatsink.

Building a custom inductor that is tailored towards the needs of the converter can improve efficiency. The off-the-shelf component, while inexpensive and small in footprint, uses a single thick copper wire as the winding. This is beneficial for high DC currents, but the high frequency switching required in this converter causes AC-related issues such as skin effect that contribute to winding losses. The use of litz wire will be useful to reduce the $\mathrm{AC}$ resistance and winding loss of the magnetic component. While a dc-dc converter with higher efficiency is preferred, the $87 \%$ multi-phase dc-dc converter is sufficient to prove the DLL and PLL based frequency control loops and the HESS algorithm.

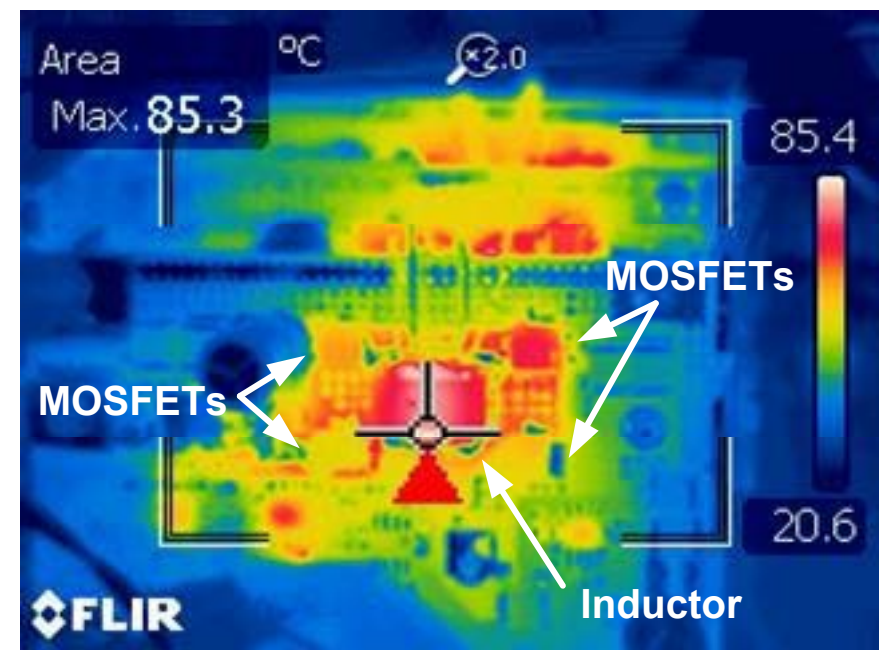

Figure 6.3: A thermal image of the dc-dc converter shows that the inductor windings are the highest source of loss.

\subsubsection{Off-time and Frequency Control}

The single sub-converter operating with PCMC and an off-time generator is shown in Fig. 6.4(a), where the variable dead-times are shown for the $c_{1}$ and $c_{2}$ signals. The startup for multi sub-converter operation is staggered to reduce the step loading on the gate-driver power supply, as shown in Fig. 6.4(b). The three sub-converters begin out of synchronization, and the DLL and PLL frequency loops must work to lock the switching frequency and phases.

Upon a 0 to 20 A startup condition, the DLL-controlled master sub-converter switching period, $T_{s, A}$, reaches a target switching period of $T_{s}^{\prime}=1.82 \mu \mathrm{s}$ within $60 \mu \mathrm{s}$, while the PLL-controlled slave sub-converters converge on $T_{s}^{\prime}$ after $150 \mu \mathrm{s}$, as shown in Fig. 6.5(a). 


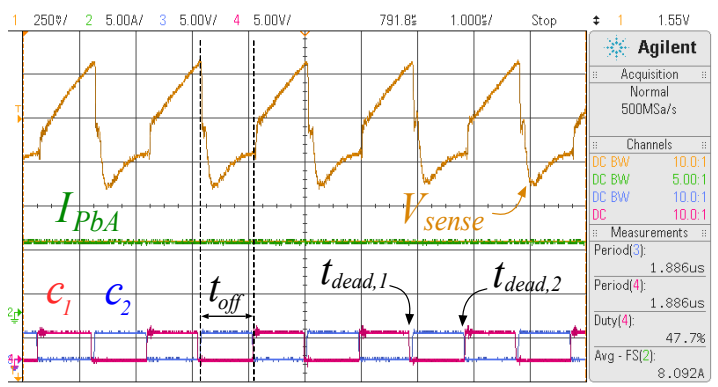

(a)

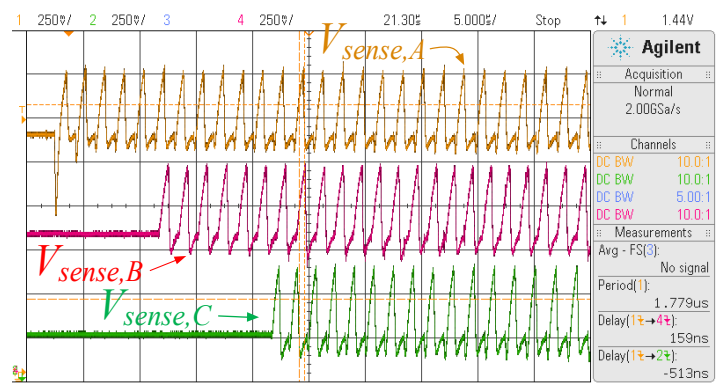

(b)

Figure 6.4: A (a) single sub-converter operating with PCMC off-time control, and (b) the staggered start-up process of the three sub-converters.

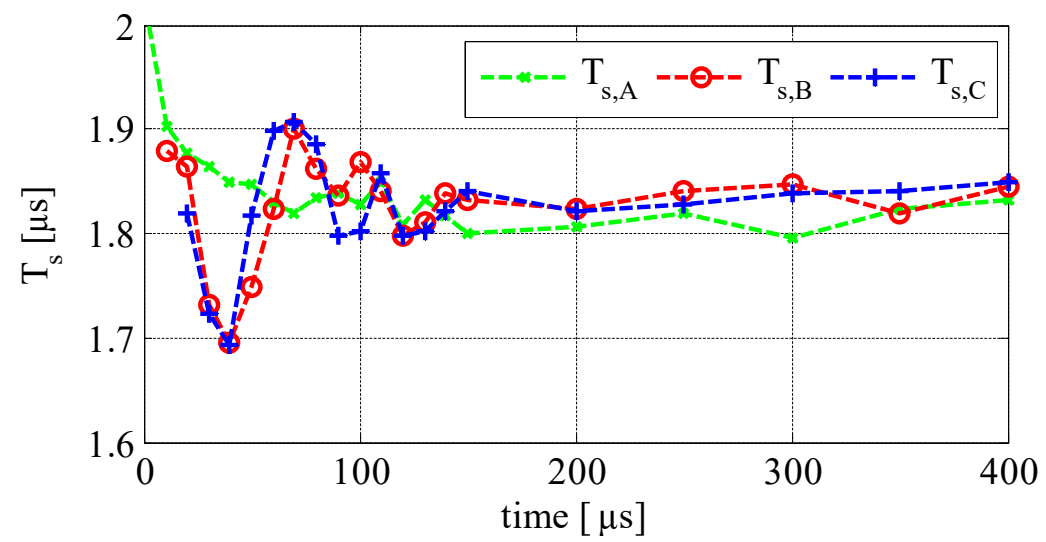

(a)

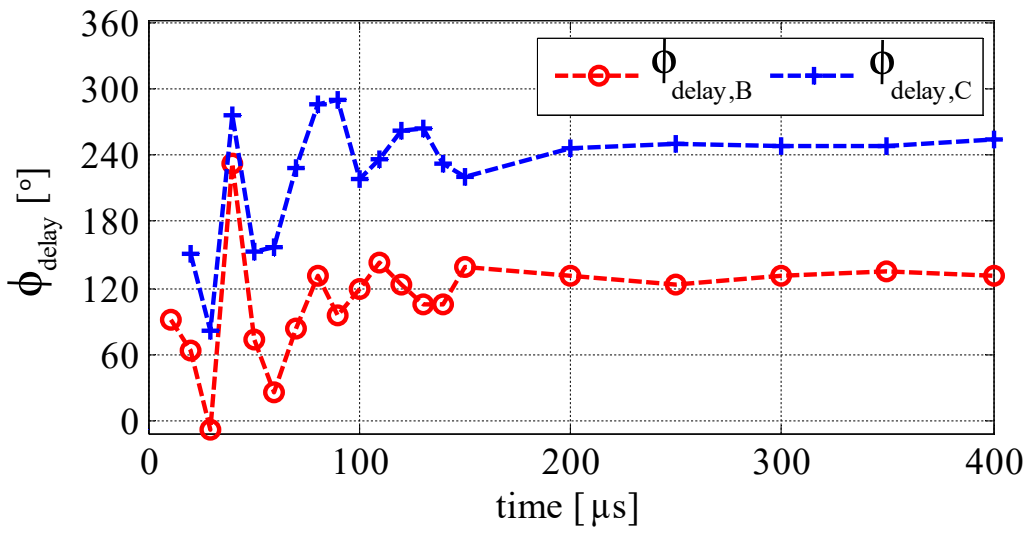

(b)

Figure 6.5: Measured DLL and PLL frequency loop performance showing (a) switching period locking, and (b) interleaved phase locking.

The second order PLL causes the $T_{s, B}$ and $T_{s, C}$ to oscillate around $T_{s}^{\prime}$ before settling, while the first order DLL causes $T_{s, A}$ to settle more quickly and smoothly [3]. The phaselocking of the interleaved sub-converters for the same startup condition is shown in Fig. 6.5(b). After some initial oscillation, the sub-converters lock to a final phase within 150 $\mu \mathrm{s}$. The DLL, PLL stability and off-time generator performance is limited by the 5 ns 
resolution of the FPGA.

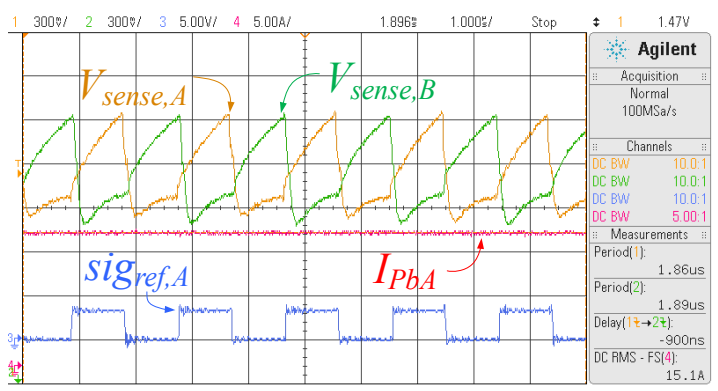

(a)

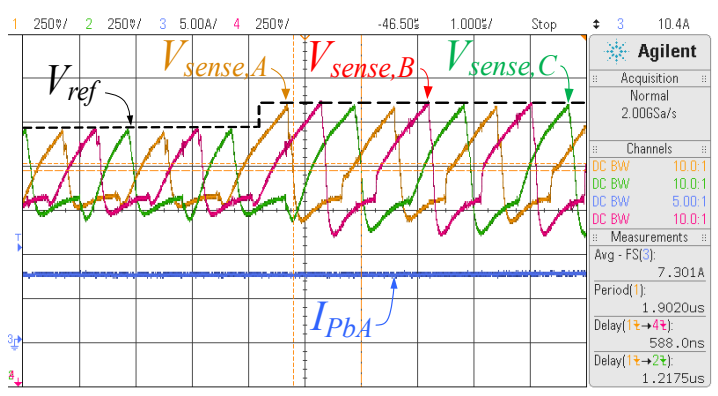

(c)

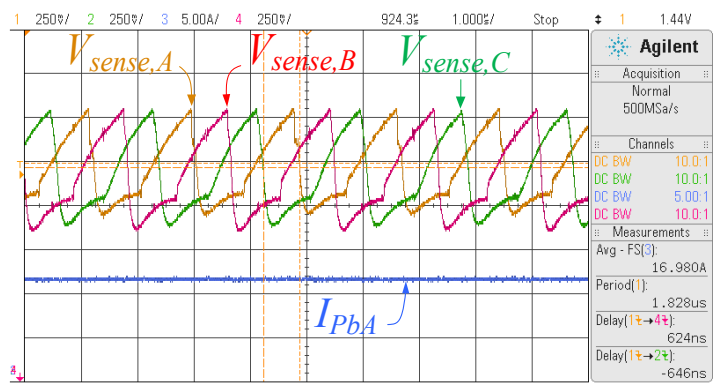

(b)

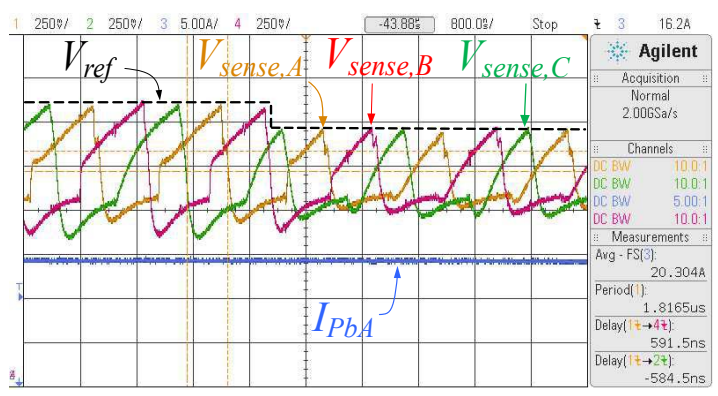

(d)

Figure 6.6: Measured steady state inductor current interleaving with (a) two active subconverters and (b) three active sub-converters, and measured transient (c) 7 to $20 \mathrm{~A}$ step-up response and (d) 20 to 7 A step-down response for three active sub-converters.

The multi-phase converter can adaptively change the interleaving phase shift depending on the number of active sub-converters. The measured interleaved inductor ripple current waveforms of two sub-converters, operating with $180^{\circ}$ phase shift, and three subconverters, operating with $120^{\circ}$ and $240^{\circ}$ phase shift, are shown in Fig. 6.6(a) and Fig. 6.6(b), respectively.

With the adaptive off-time control, the converter does not exhibit oscillations during a step response as seen with the traditional PCMC or the slope compensation methods described in section 4.2.1. During a $7 \mathrm{~A}$ to $20 \mathrm{~A}$ current step, the off-time controlled sub-converters have a single switching period response, and are resilient in maintaining stable QFF operation through the transient, as shown in Fig.6.6(c). Fig. 6.6(d) shows the same fast response and stability for a negative step in the current reference signal.

\subsection{Experimental Drive-cycles}

The programmable electronic load, (e-load), is set to constant-current mode, and the dynamic drive-cycle is programmed into the e-load as a current command, $I_{b u s}^{\prime}$. The bus 
voltage, $V_{b u s}$, is measured and multiplied by four to give, $V_{b u s}^{\prime}$, which emulates the series battery bus in the Ranger EV. The drive-cycle load power, $P_{b u s}^{\prime}$ is divided by $V_{b u s}^{\prime}$, and the quotient yields $I_{b u s}^{\prime}$, as shown in Fig. 6.7. The IHBM controller logs salient HESS data to a host PC over a serial data bus. This measurement data is presented in this section.

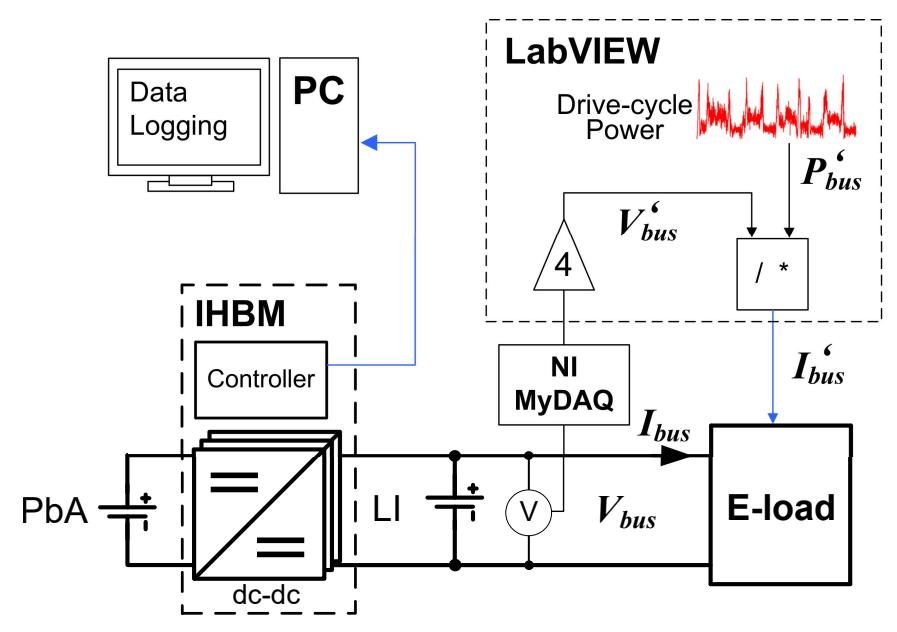

Figure 6.7: Experimental bench setup.

\subsubsection{Measured ESS Comparisons}

For the near continuous $15 \mathrm{MPH}$ drive-cycle, the HESS achieves a $17 \%$ improvement in range over the SESS PbA and performs better than what a linear improvement from SESS PbA to SESS LI would suggest, as shown in Fig. 6.8(a). This improvement can be attributed to the HESS minimizing the Peukert effect in the lead-acid battery module as well as an overall lighter vehicle. With the HESS-2 configuration, the $17 \%$ measured improvement is achieved compared with a $26 \%$ improvement with the SESS-2 configuration. The HESS-2 configuration has a $23 \%$ improvement in efficiency over the SESS PbA configuration, as shown in Fig. 6.8(b).

The similarities between the simulations and measurements suggests that further performance improvements can be achieved with higher overall ESS energy and higher LI energy ratio $E_{L i} / E_{E S S}$. For example, the HESS-1 configuration is expected to yield a $38 \%$ range improvement over the SESS $\mathrm{PbA}$, with a similar $\Gamma$ efficiency improvement of $23 \%$. These factors can be considered when implementing the hybrid battery system in the full vehicle.

During a continuous drive-cycle, the power-mix algorithm adjusts $I_{\text {ref }}$ to oscillate around $I_{\text {ref }}^{*}$ such that $S O C_{P b A}$ and $S O C_{L I}$ traverse the ideal path, as shown in Fig. 6.9(a). 


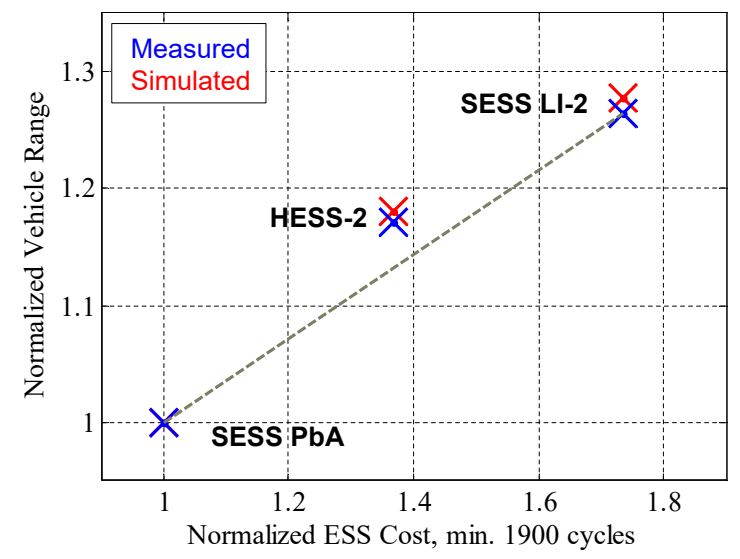

(a)

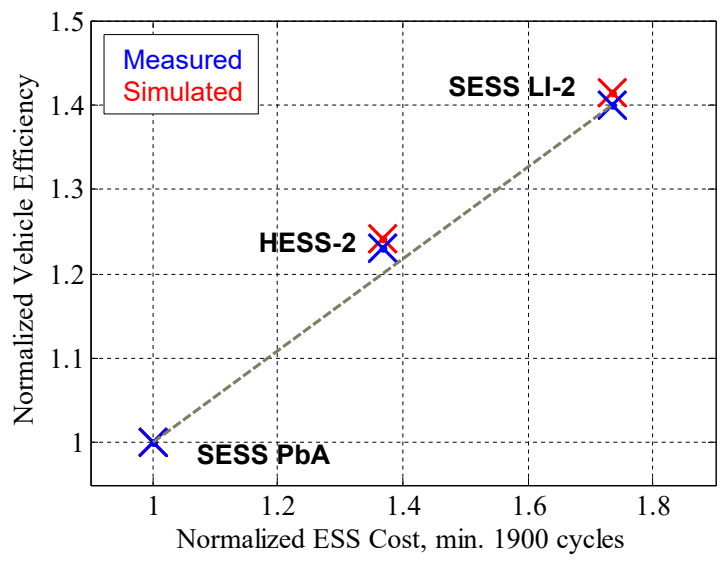

(b)

Figure 6.8: The measured normalized (a) range, and (b) efficiency of a near constant 15 $\mathrm{MPH}$ drive-cycle.

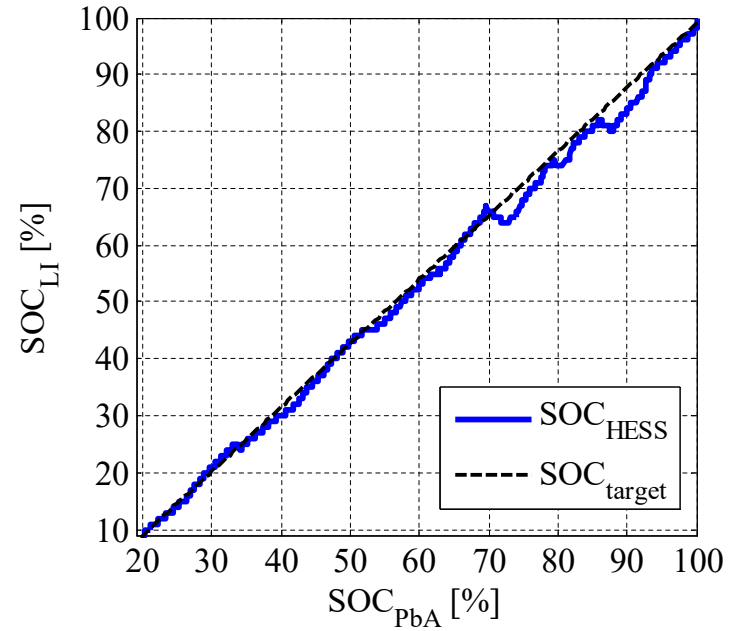

(a)

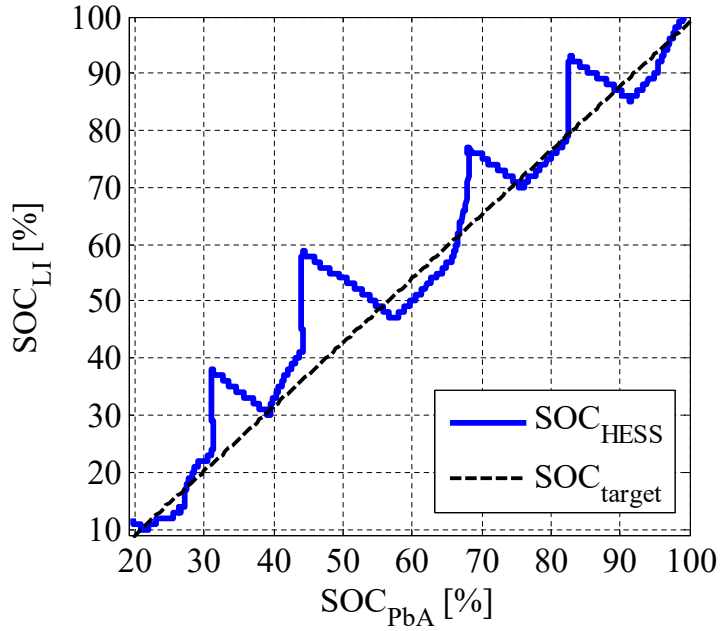

(b)

Figure 6.9: The measured relative SOC path of the batteries for (a) a continuous drivecycle, and (b) start-stop drive-cycle.

The battery SOCs follow the ideal path and reach $S O C_{P b A, \min }=20 \%$ and $S O C_{L I, \min }=$ $10 \%$ at the same instance, minimizing over-utilization losses in the batteries and avoiding under-utilization.

\subsubsection{Start-stop Drive-cycle Measurements}

The start-stop drive-cycle perturb and observe coefficients from Table 5.1 are used for

experimental verification. While the vehicle rests, the LI module is slowly charged, and 
$I_{P b A}$ is minimized to over the length of the drive-cycle. Like in the continuous drive-cycle, the battery SOCs follow the ideal path and reach $S O C_{P b A, \min }=20 \%$ and $S O C_{L I, \min }=$ $10 \%$ at roughly the same instance, as shown in Fig. 6.9(b).

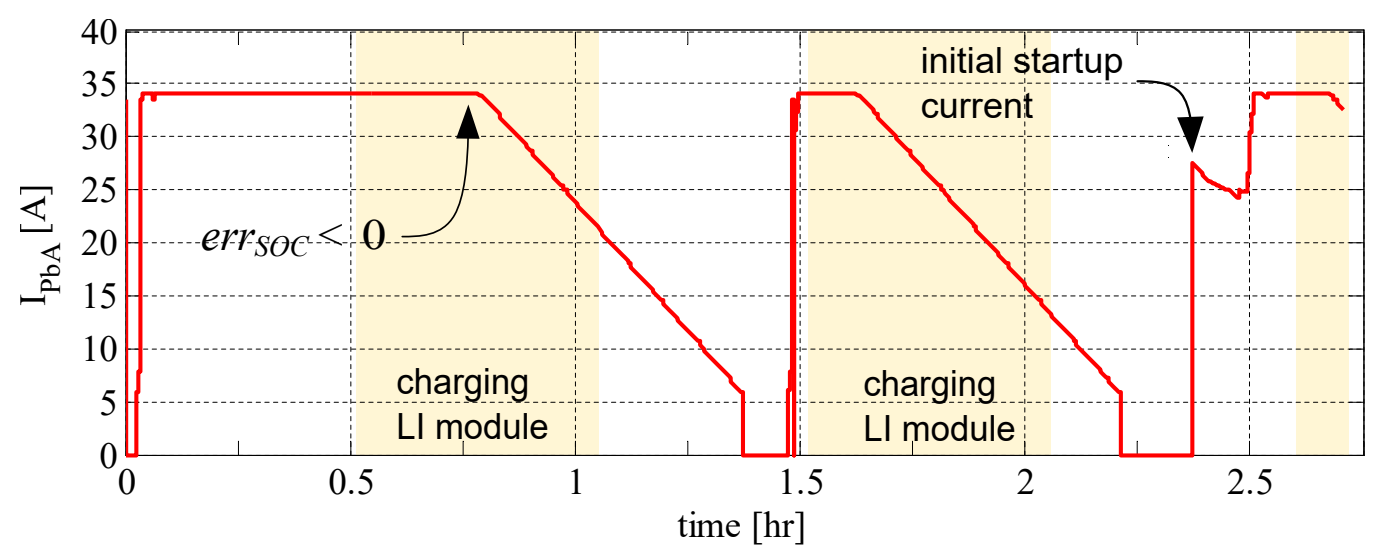

(a)

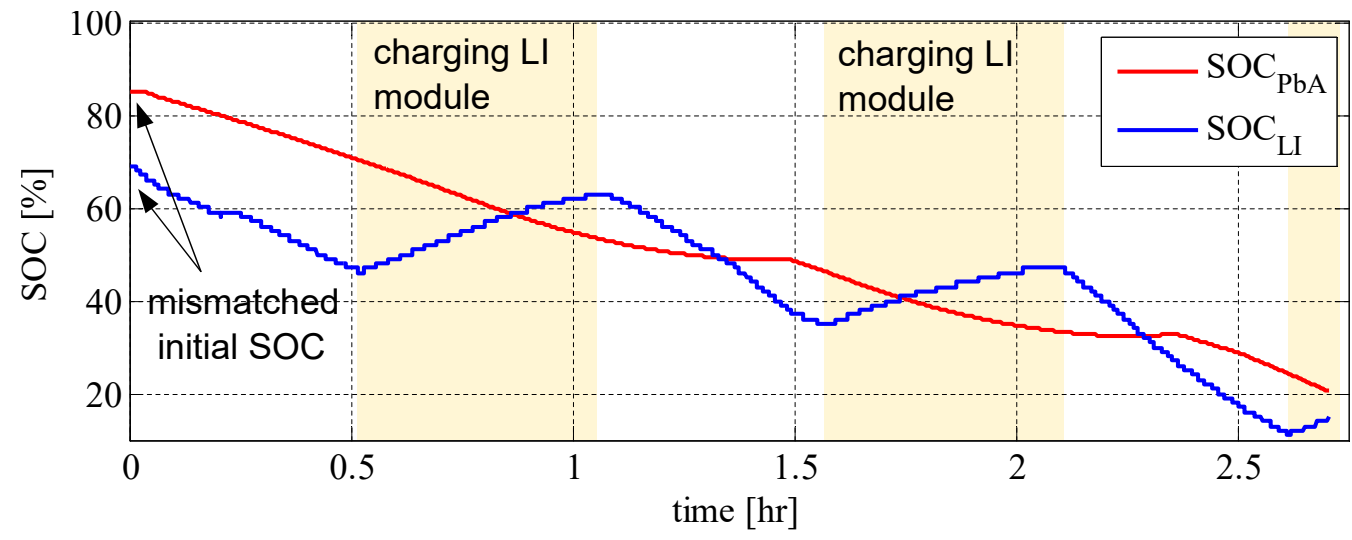

(b)

Figure 6.10: The measured start-stop drive-cycle (a) $I_{P b A}$, and (b) $S O C_{L I}$ and $S O C_{P b A}$, with uneven initial SOCs.

The scenario when the initial battery SOCs are mismatched is also demonstrated. When $S O C_{P b A}(0)=85 \%$, while $S O C_{L I}(0)=68 \%$, the algorithm corrects for the mismatch by maximizing $I_{r e f}$ until $\operatorname{err}_{S O C}$ falls below zero. The $I_{P b A}$ and battery SOC dynamics are shown in Fig. 6.10(a) and Fig. 6.10(b), respectively. With controller coefficient $a_{2}=0.25$ and update rate $T_{k}=15 \mathrm{~s}, I_{P b A}$ decays at a rate of $0.8 \mathrm{~A} /$ minute to charge the LI module during the vehicle rest time. During the half hour resting time, $S O C_{L I}$ recovers between 15 and $22 \%$, and $V_{L I}$ rebounds up to $300 \mathrm{mV}$, as shown in Fig. 6.11 . 


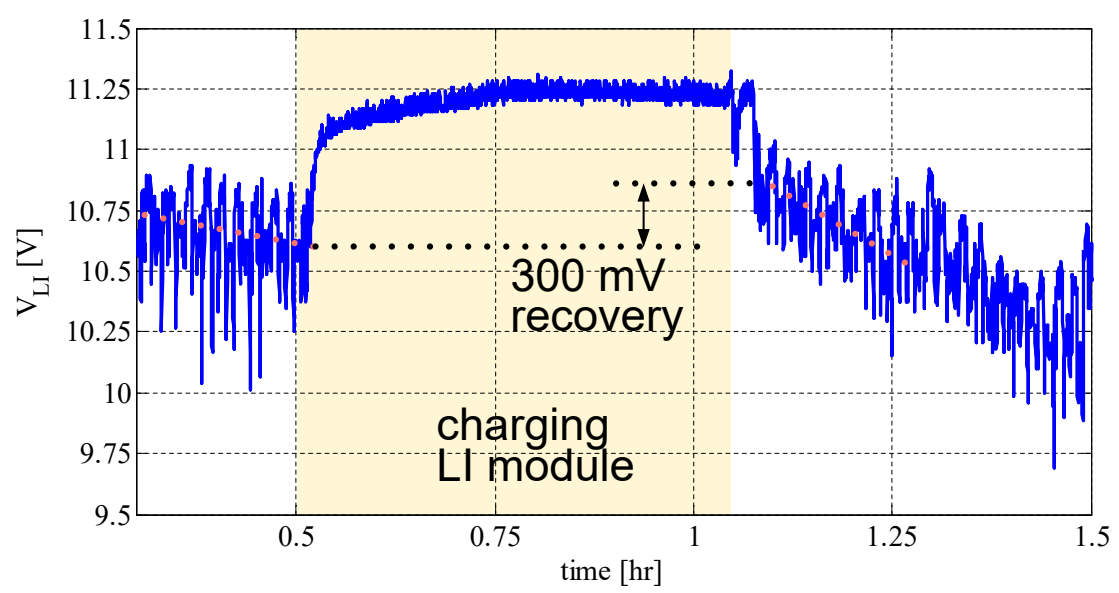

Figure 6.11: The measured $V_{L I}$ for a start-stop drive-cycle.

\subsection{Chapter Summary and Conclusions}

The dc-dc converter hardware is presented and the quasi-fixed frequency (QFF) operation, multi-phase interleaving and phase-shedding are demonstrated. The HESS powermix algorithm is verified for both a continuous and a start-stop drive-cycle. The measured results show close accord of voltage, current and estimated SOC with simulated battery and system models. The HESS achieves a $17 \%$ range improvement and $23 \%$ efficiency improvement for a continuous $15 \mathrm{MPH}$ drive-cycle over the SESS PbA vehicle. These improvements come with a $5 \%$ reduction in total pack energy from the SESS PbA vehicle and a $115 \mathrm{~kg}$ reduction in vehicle mass. The HESS cost is estimated to be midway between the lithium SESS and lead-acid SESS configurations, when assuming a minimum vehicle lifetime of 1900 cycles.

As demonstrated, the algorithm is able to influence the battery SOC trajectory towards a desired path for both the continuous and the start-stop drive-cycles. Unfortunately, optimality is not guaranteed because the controller has no prior knowledge of the drive-cycle. Similar to the rule-based and dynamic programming methods, the effectiveness of this perturb and observe algorithm is bound by how similar the vehicle's actual drive-cycle is to the simulated conditions. For the case of a HESS on a utility LEV, future improvements to the algorithm should involve drive-cycle prediction methods based on more drive-cycle data. 


\section{References}

[1] A. Costabeber, P. Mattavelli, and S. Saggini, "Digital time-optimal phase shedding in multiphase buck converters," Power Electronics, IEEE Transactions on, vol. 25, no. 9, pp. 2242-2247, Sept 2010.

[2] J.-T. Su and C.-W. Liu, "A novel phase-shedding control scheme for improved light load efficiency of multiphase interleaved dc-dc converters," Power Electronics, IEEE Transactions on, vol. 28, no. 10, pp. 4742-4752, Oct 2013.

[3] Y. Wen and O. Trescases, "Analysis and comparison of frequency stabilization loops in self-oscillating current mode dc x2013; dc converters," IEEE Transactions on Power Electronics, vol. 28, no. 10, pp. 4753-4766, Oct 2013. 


\section{Chapter 7}

\section{Conclusions}

\subsection{Thesis Summary and Contributions}

A hybrid battery chemistry HESS using a lead-acid battery, a lithium battery, a multiphase dc-dc converter and controller is designed, simulated, and experimentally tested in this work. The objective to design a HESS configuration that 1) is cost-competitive with a PbA single energy storage system (SESS) and 2) maintains most of the performance benefits of a lithium SESS, is realized for a modular HESS IHBM.

The modular dc-dc converter achieves quasi-fixed frequency (QFF) operation and inductor current interleaving, and measures $88.5 \%$ efficiency at $100 \mathrm{~W}$ output power with single sub-converter operation, and $88 \%$ efficiency at $180 \mathrm{~W}$ with dual sub-converter operation, and $87 \%$ efficiency at the rated $270 \mathrm{~W}$ power with three sub-converters. With the DLL and PLL based adaptive off-time control, the three sub-converters reach steadystate interleaving within $150 \mu$ s of startup, and the converter has a single switching period step response and is resilient in maintaining stable QFF operation through the transient current reference step.

The experimental HESS achieves a 17\% range improvement and $23 \%$ efficiency improvement for a continuous $15 \mathrm{MPH}$ drive-cycle, with a $5 \%$ reduction in total pack energy from the SESS PbA vehicle, and suggests that HESS performance can be further enhanced with improved dc-dc converter efficiency and more overall energy in the battery pack. The proposed Perturb and Observe based power-mix algorithm was also demonstrated on continuous and start-stop drive-cycles, and proven to be robust to various dynamic drive-cycles. The primary contributions of this work are as follows:

- A perturb and observe based power-mix algorithm that maximizes the hybrid battery capacity and range of the LEV for a non-deterministic drive-cycle, 
- A hybrid battery, multi-phase dc-dc architecture that uses a DLL and PLL based off-time control to achieve quasi-fixed-frequency (QFF) operation with inductor current interleaving, with an integrated series battery balancing topology that minimizes additional hardware.

\subsection{Future Work}

Increasing the dc-dc converter efficiency is the most obvious improvement that can be made for this work. Less power loss on the converter stage results in higher battery capacity utilization and improved range. Throughout this work, series HESS modules were assumed to be balanced, which is unrealistic especially with a hybrid battery architecture. The active battery balancing scheme must be demonstrated, and the distributed control of series HESS modules in a $44 \mathrm{~V}$ system must be studied for proper implementation in the vehicle. Additionally, while the perturb and observe method is simple and effective, it does not guarantee optimality. More mathematically intensive algorithms such as dynamic programming can be used to truly optimize the HESS for different drive-cycles and conditions. 